\title{
4 Indirektes und verdecktes Polemisieren bei Melchior Hoffman
}

\subsection{Hoffman in Straßburg, Ostfriesland und den Niederlanden: Die Hintergründe}

Nach einem zweimonatigen Aufenthalt in Ostfriesland kam Melchior Hoffman im Juni I 529 erstmals nach Straßburg. ${ }^{576}$ Hoffman wurde als offener Gegner Luthers von den Straßburger Reformatoren zunächst freundlich empfangen. ${ }^{577}$ Dies beruhte hauptsächlich auf der Tatsache, dass Hoffman in seiner Ablehnung der lutherischen Abendmahlslehre mit den Straßburger Reformatoren übereinstimmte, da jene sich an der zwinglischen Reformation und Abendmahlslehre orientierten. Die Straßburger Theologen lehnten ebenso wie Hoffman die Denkweise ab, dass der Leib Christi im Brot und das Blut Christi im Wein tatsächlich vorhanden wären:

Den Gedanken der ,Impanation Gottes‘, die Vorstellung, das Heilige in die irdischen Elemente zu bannen, konnten die Straßburger Theologen nicht nachvollziehen. Im Unterschied zu Zwingli waren sie nur bereit, die geistige Gegenwart Christi in der Abendmahlsfeier und die Aneignung seines

${ }_{576}$ Am 30. Juni I 529 schrieb Bucer an Zwingli von der Ankunft Melchior Hoffmans. In: Quellen zur Geschichte der Täufer (I959). Bd. XII. Elsaß I, Stadt Straßburg I522-I532 (= TAE I). Bearb. von Manfred Krebs \& Hans Georg Rott. Gütersloh: Mohn, Nr. I 88, S. 240.

577 Hoffman hatte sich am 8. April des Jahres bei einer Disputation in Flensburg gegen u. a. Johannes Bugenhagen verteidigen müssen. Da er seine Lehre, insbesondere seine Abendmahlsauffassung, jedoch nicht widerrief, konfiszierte König Friedrich I. seine Habe und verwies ihn seines Territoriums. Die Disputation kann als Schlüsselereignis gelten, denn sie ließ Hoffman schließlich von einem Lutheranhänger (seit I 523) zu einem erbitterten Gegner der lutherischen Reformationsbewegung werden.

How to cite this book chapter:

Lundström, Kerstin. 2015. Indirektes und verdecktes Polemisieren bei Melchior Hoffman. In: Lundström, Kerstin. Polemik in den Schriften Melchior Hoffmans: Inszenierungen rhetorischer Streitkultur in der Reformationszeit, Pp. 206-277. Stockholm: Stockholm University Press. DOI: http://dx.doi.org/10.16993/bae.d. License: CC-BY 
Verdienstes unter dem Zeichen von Brot und Wein durch die gläubige Seele in stärkerem Maße hervorzuheben. ${ }^{578}$

Zwischen den Straßburger Reformatoren und Luther hatte es in den ungefähr zwei Jahren vor Hoffmans Ankunft schon mehrfach die Abendmahlsfrage betreffende Unstimmigkeiten und schriftliche Auseinandersetzungen gegeben, so dass sie Luthers Gegnern gegenüber freundlich gesinnt waren. ${ }^{579}$ Hoffman profitierte aber bei seiner Ankunft nicht nur von der antilutherischen Einstellung der Reformatoren, sondern auch von der toleranten Führungspolitik des Straßburger Magistrats.

\subsubsection{Religiöse Toleranz und die Einführung der Reformation in Straßburg}

$\mathrm{Zu}$ Beginn der Reformationszeit hatte Straßburg inklusive der 25 umliegenden Dörfer etwa 22.000 Einwohner. ${ }^{58}$ Als freie Reichsstadt war die Stadt Straßburg unmittelbar dem Kaiser unterstellt, was ihr eine gewisse Entscheidungsfreiheit gewährte. Ein gewählter Magistrat besaß die Bevollmächtigung zur Machtausübung, „insbesondere durch zwei Kommissionen: die geheimen Stuben der XIII. und der XV. Die eine befasste sich mit der Außenpolitik und die andere mit den Finanzen und dem Handwerkswesen. " ${ }^{58 I}$ In vielen Fragen konnte der Magistrat mittels dieser zwei Gremien eigene Entscheidungen treffen. So war es ihm möglich, auch in Reformationsfragen eine vom Kaiser weitestgehend unabhängige Stellung einzunehmen.

Die Forderung nach kirchlicher Reformation wurde schon früh durch die evangelischen Prediger Matthäus (Mathis) Zell, Anton Firn,

${ }_{578}$ Deppermann (I979), S. I 54.

579 Vgl. dazu: „When he first appeared in Strasbourg in June I 529, having been exiled from Schleswig-Holstein by the Lutherans, Hoffman was greeted by Bucer as a pioneer in the struggle against the ,magic' of the Lutheran eucharistic teaching." Deppermann, Klaus (1977): „Melchior Hoffman and Strasbourg Anabaptism“. In: Lienhard, Marc (Hg.): The Origins and Characteristics of Anabaptism / Les débuts et les caractéristiques de l'anabaptisme. Den Haag: Nijhoff, S. 216-2 I9, hier S. 2 I 6. Das Marburger Religionsgespräch Anfang Oktober I 529 war der Höhepunkt dieser Streitigkeiten, es besiegelte die Unvereinbarkeit der lutherischen und zwinglischen Abendmahlsauffassungen.

${ }^{580}$ Lienhard, Marc (I99I): Religiöse Toleranz in Straßburg im I6. Jahrhundert (= Abhandlungen der Geistes- und Sozialwissenschaftlichen Klasse / Akademie der Wissenschaften und der Literatur I). Stuttgart: Franz Steiner, S. $5 \mathrm{f}$.

${ }^{581}$ Lienhard (I99I), S. 6. 
Caspar Hedio, Martin Bucer und Wolfgang Capito geäußert. ${ }^{52}$ „[I]n Verbindung mit dem Kleinbürgertum und einigen Intellektuellen“ hatten sie Druck auf den Magistrat ausgeübt, der diesem schließlich nachgab und 1523 ein Mandat erließ, das dazu aufrief, alleinig das christliche Evangelium und die reine Lehre Gottes $\mathrm{zu}$ predigen. ${ }^{583}$ „Bezeichnenderweise fehlte aber die Stelle des Nürnberger Mandats vom 6. März: ,nach Auslegung der von der christlichen Kirche gutgeheißenen und angenommenen Schriften'" "584 Infolgedessen stand den Predigern die Tür zur evangelischen Predigt in der Straßburger Kirche offen. Eine offizielle Einführung der Reformation war jedoch aufgrund des Anteils von Altgläubigen im Magistrat sowie „außenpolitische[n] Rücksichten auf den Kaiser" noch nicht möglich. ${ }^{585}$ Ab I 524 veränderte sich die kirchliche Praxis in Straßburg zunehmend: Die Messe wurde in deutscher Sprache gehalten, das Taufritual sowohl auf Latein als auch auf Deutsch durchgeführt, ${ }^{86}$ das „Abendmahl unter beiden Gestalten gereicht“, Pfarrer heirateten, während Klöster sich aufzulösen begannen, und es wurden evangelische Predigten von Pfarrern gehalten, die von den Pfarreien selbst gewählt worden waren. ${ }^{57}$ Der Magistrat schützte und unterstützte evangelische Prediger, ließ evangelische Schriften unbehelligt erscheinen und nahm eher eine tolerant vermittelnde Position ein, da das Interesse des Magistrats insbesondere darin lag, den inneren Frieden zu bewahren. Dabei wurde den Wünschen der ansässigen Theologen und Bürger oftmals mehr Beachtung geschenkt als in anderen Städten. Allgemein wurde den lauteren Stimmen der

${ }_{582}$ Zur Straßburger Reformation siehe auch: Lienhard, Marc \& Jakob Willer (1982): Straßburg und die Reformation. Kehl: Morstadt Verlag. Chrisman (1982). Kleinschmidt, Erich (1982): Stadt und Literatur in der Frühen Neuzeit. Voraussetzungen und Entfaltung im südwestdeutschen, elsässischen und schweizerischen Städteraum. Köln u. a.: Böhlau. Brady, Thomas A. (I987): Ruling Class, Regime and Reformation at Strasbourg I520-1555. Leiden: Brill. Abray (I985). Rapp, Francis (1995): Réformes et réformation à Strasbourg. Eglise et société dans le diocèse de Strasbourg I450-I 525 . Paris: Ophrys.

${ }_{583}$ Deppermann (I979), S. I49.

${ }_{584}$ Lienhard (I99I), S. 7.

${ }_{585}$ Deppermann (1979), S. I 50.

${ }_{586} \mathrm{Vgl}$. TAE I, Nr. 5, S. 7. Am 31. August I 524, „[i]nfolge einer Eingabe der Prediger und der Klage des altkirchlichen Kapitels von Alt S. Peter, beschließt der Rat $u$. a. ... Allen pfarrherrn sagen, daß meiner herren ernstliche meinung, daß sie eim jeden die sacrament reichen, tauff und andere pfarrliche recht thun, wie es dann ein jeder begert, und es dheim absagen." TAE I, Nr. 9, S. I9 (Hervorhebung im Original, Text der Herausgeber).

${ }_{587}$ Lienhard (I99I), S. 7. 
reformwilligen Mehrheit im Bürgertum sowie im Magistrat Folge geleistet. ${ }^{58}$ Reformationsgegner wurden zum Teil daran gehindert, ihre Schriften zu publizieren, oder mussten hinnehmen, dass ihre fertigen Drucke eingezogen wurden. Der Hauptgegner der Reformation in Straßburg, Thomas Murner, musste I 524 (wie auch andere altgläubige Reformationsgegner) sogar die Stadt verlassen.

Die tolerante Haltung des Magistrats gegenüber Reformatoren führte nicht nur dazu, dass die evangelischen Pfarrer sich einer recht großzügigen Freiheit erfreuten, sondern sie ermöglichte auch anderen Strömungen Einlass und vergleichsweise freie Entfaltung. ${ }^{59}$ So hatten vermehrt Spiritualisten, seit Anfang des Jahres I 526 auch Wiedertäufer in Straßburg Fuß fassen können. Unter den Wiedertäufern sind als die prominentesten Vertreter Wilhelm Reublin, Hans Wolff, Hans Denck, Michael Sattler, Martin Cellarius (Borrhaus) und Ludwig Hätzer zu nennen. ${ }^{59}$ Dass sogar Anhänger des Täufertums, auf dem in anderen Städten die Todesstrafe stand, Asyl in Straßburg fanden, ist zum einen auf die soziale und ökonomische Stabilität der Stadt und den damit verbundenen „durch kaiserliches Privileg garantierten ,freien Zug', der praktisch unbeschränkten Aufnahmebereitschaft von Fremden“, ${ }^{59 I}$ zum anderen auf die Nähe der Straßburger Reformatoren zum Spiritualismus bzw. Täufertum in Fragen des Abendmahls und der Glaubenstaufe zurückzuführen. Besonders Capito hatte Sympathien für die Wiedertäufer gehegt, was ihnen lange Zeit milde Urteile in Rechtsfragen und größe-

${ }_{588} \mathrm{Vgl}$. dazu: „In the I 520 s the magistrates were outpaced by early converts to the new faith [...].“ Abray, Lorna Jane (I988): „The Laity's Religion: Lutheranism in Sixteenth-Century Strasbourg“. In: Hsia, R. Po-Chia (Hg.): The German People and the Reformation. Ithaca \& London: Cornell University Press, S. 216-232, hier S. 226. Vgl. auch: „Individually and as a corporation, the magistrates of Strasbourg proclaimed themselves to be Christian. Very early, perhaps by I 524 and certainly by I 526, the majority of them had become Evangelicals. " Ebd., S. 227.

589 Robert Kreider gibt zudem an, dass die Straßburger Reformatoren sich ebenfalls offen gegenüber neuen theologischen Ideen zeigten. „Strasbourg theology consequently, was assimilative of humanist, Lutheran, spiritualist, and sectarian elements.“ Kreider, Robert (I955): „The Anabaptists and the Civil Authorities of Strasbourg,

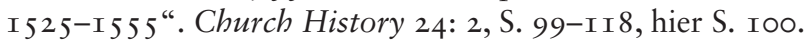

590 Lienhard (I99I), S. I 2. Vgl. dazu: „Im Herbst I 526 tauchten gleichzeitig vier bedeutende Gestalten des protestantischen Radikalismus in Straßburg auf, nämlich Hans Denck, Michael Sattler, Martin Cellarius (Borrhaus) und Ludwig Hätzer. Durch sie - vor allem dank der Mission Hans Dencks - erlebte der Straßburger Nonkonformismus einen großen Aufschwung. Erst jetzt wurde er zum ernsthaften Konkurrenten der offiziellen Straßburger Reformation. “ Deppermann (I979), S. 160 .

591 Depermann (I979), S. I43. 
re Toleranz verschaffte, da er einer der einflussreichsten Reformatoren in Straßburg war. ${ }^{592}$ Trotz aller Toleranz hatten die Täufer und andere radikale Reformatoren jedoch auch in Straßburg kein völlig uneingeschränktes Dasein. Obwohl die Straßburger Reformatoren die Kindertaufe nicht für notwendig hielten, waren sie doch auch nicht dagegen, womit sie sich von den Täufern absetzten. Schon seit I 524 hatten die Reformatoren auch in Straßburg eine negative Einstellung gegenüber den Täufern, ${ }^{593}$ die aber vom Magistrat vorerst nicht grundsätzlich bestätigt wurde:

Im Unterschied zu Luther und Melanchthon haben die Prediger nicht alle Dissidenten in einen Topf geworfen. Sie machten den Unterschied zwischen denen, die energisch zu bekämpfen waren [...], und den anderen, [...] die sie als weniger gefährlich betrachteten. ${ }^{594}$

Es wurden durchaus Stadtverweise und Gefängnisstrafen für diejenigen verhängt, die sich aufrührerisch verhielten: Hans Denck z. B. wurde noch im Jahr seiner Ankunft wieder ausgewiesen, was in Straßburg eine durchaus übliche Verfahrensweise mit Wiedertäufern (und anderen Dissidenten) war, die man als aufrührerisch betrachtete. Anscheinend gab es aber prinzipiell Probleme mit der Gruppe der Wiedertäufer, die sowohl auf einen fehlenden Anpassungswillen an die sozialen Regeln und Pflichten der Stadt als auch auf Missachtung der Obrigkeiten zurückzuführen sind. ${ }^{95}$ Die Folge davon war, dass der Rat am 27. Juli I 527

${ }^{592}$ Vgl. dazu: „Zunächst waren die Prediger, zumindest in den ersten Jahren, durchaus offen für eine gewisse Lehrpluralität. So schien ihnen die Kindertaufe nicht absolut notwendig. Auch später noch kritisierte der Münsterpfarrer Zell das Patenamt. Bis I 532 zeigte Wolfgang Capito, neben Bucer der bedeutendste evangelische Pfarrer, ausgesprochene Sympathie für die Täufer. Er verurteilte zwar die separatistischen und pazifistischen Tendenzen der Täufer, widersetzte sich jedoch ihrer Verfolgung. Man sollte eher den Ehebruch als die Wiedertaufe strafen. [...] Erst ab I 532 ist Capito auf Bucers Kurs eingeschwenkt. "Lienhard (I99I), S. 23.

593 Bucer hatte z. B. I 524 einen Brief an Zwingli geschrieben, in dem er um Schriftbeweise bat, „die die Bekämpfung der Wiedertäufer rechtfertigen. “ TAE I, Nr. ıo, S. I9. Dieser Brief ist nur einer von vielen, in denen Bucer und andere der Straßburger Theologen die Wiedertäufer und deren Bekämpfung diskutieren.

594 Lienhard (I99I), S. 24. Vgl. dazu: „Historians have made much of the Strasburgher's toleration of those whose views where unorthodox in the confessional sense - the relatively lenient treatment of sectarians, the willingness to allow Catholics to live in the city, and the charity shown to Calvinist refugees. This toleration was real but limited, because official policy and public opinion tolerated individuals rather than faiths." Abray (1988), S. 224.

595 Lienhard (I99I), S. 34. 
eine Verordnung aufsetzte, welche die Probleme mit den Wiedertäufern lösen sollte: ${ }^{596}$

[D]emnach so gepieten wir mit hohem ernst allen vnnd jeden vnsern burgernn, hindersossen, angehörigen vnd verwandten, geistlichen vnd weltlichen in stadt vnd lande, das sy sich sollicher jrrigen vnnd der heiligen geschrifft widerwertigen verfüerung verhieten, der widerteüffer oder jrer anhenger sich entschlagen, deren einen noch keinen bey jnen husen, herbergen, etzen oder trencken, noch vnderschleyff geben, sonder die selbigen, als so jrs jrrigen synns nit gestrafft oder vnderwysen wöllen werden, abwysen. Dann welcher das nitt thäte, [...] den oder die wöllen wir mit ernst, der gespür nach, vngestrafft nitt lassen. 597

Der Rat wollte damit die Wiedertäufer selbst bekehren und alle Familienangehörigen und Freunde von Wiedertäufern daran hindern, diese zu beherbergen oder in irgendeiner Form zu unterstützen. Marc Lienhard macht jedoch darauf aufmerksam, dass es

[a]uffallend war [...], daß der Rat sich im Mandat von I 527 nicht über die Lehren der Täufer und anderer Sektierer äußerte. Es fehlte auch die so wichtige Kategorie der Gotteslästerung, anhand derer Melanchthon I 53 I und 1536 die Täufer verwarf und somit auch die Todesstrafe für die Täufer forderte. Davon war in Straßburg weder I 527 noch später die Rede. ${ }^{598}$

Der Magistrat in Straßburg schien demnach eine Politik der Versöhnung zu verfolgen: Der innere Frieden und das Allgemeinwohl standen an oberster Stelle. 599 Die Todesstrafe, die ab I 528 im Kaiserreich auf der

${ }_{596}$ Der Wortlaut der Verordnung macht die sozialpolitischen Beweggründe deutlich: Der Rat sei gezwungen worden einzugreifen und diese Verordnung aufzusetzen, da die Wiedertäufer „so vnder jrem schein, vor andern christen ein fromm leben zu füren, fürgeben, aber dobey zuwider aller göttlicher vnd euangelischer geschrifft die oberkeit [...] allein nit bekennen, sonder auch darneben ettliche vngegründte, böse fürnemen entgegen den artickeln, so zu vnderhaltung gemeins nutzes, lieb, frid vnd einigkeit dienstlich vffgesetzt vnd von gott zu thun nit verbotten sindt, fürhaben vnd als zertrenner vnd beleydiger eins christlichen vnd einhelligen wesens vff jren hartnickigen köpffen beharren vnnd keiner vnderweysung sich settigen wöllen lassen“. TAE I, Nr. 92, S. I 22.

597 TAE I, Nr. 92, S. I $22 \mathrm{f}$.

${ }_{598}$ Lienhard (I99I), S. 34. Vgl. auch Deppermann (I979), S. I6I.

599 Dies betraf nicht nur religiöse Fragen, sondern auch andere Belange der Stadt und ihrer Bürger: „Wenn die Existenz der Stadt auf dem Spiel stand, bemühte sich die neue Oligarchie intensiv darum, eine breite Mehrheit der Bürgerschaft für ihren Vorschlag zu gewinnen, ja, sie überließ sogar formell die Entscheidung dem Großen Schöffenrat der 300. [...] Auch strebte der Rat danach, die sozialen Antagonismen nicht ausufern zu lassen. Im Interesse der kleinen Meister bekämpfte er die Versuche 
Wiedertaufe stand, ${ }^{600}$ wurde in Straßburg allgemein wenig bis gar nicht für die Lehre der Wiedertäufer verhängt. Lediglich Antitrinitarier und andere Gotteslästerer wurden auch in Straßburg durch die Todesstrafe hingerichtet. ${ }^{601}$ Wiedertäufer wurden jedoch nicht als solche betrachtet. ${ }^{602}$ Die Situation der Wiedertäufer in Straßburg war insofern ambivalent: Sie galten zwar nicht als Ketzer, waren aber auch nicht akzeptiert, sie wurden nicht verfolgt, aber dennoch in ihrem Wirken eingeschränkt und verworfen, was die Täuferverordnung von I 527 deutlich macht. Trotz der Verordnung, die eine erste Stellungnahme seitens des Magistrats zu den Wiedertäufern war, und der allgemeinen Ablehnung des Täufertums auf Seiten der Straßburger Reformatoren "gab es in Straßburg zwei missionarisch-aktive Täufergemeinschaften, die Anhänger von Denck und [Jakob] Kautz, sowie jene Gruppe, die den Lehren von Reublin, Sattler und [Pilgram] Marbeck verpflichtet war." ${ }^{603}$ I 528 wurden zudem - obwohl die Todesstrafe bereits über sie verhängt worden war - die aus Augsburg vertriebenen Hutschen Täufer in Straßburg aufgenommen, die konkret apokalyptische Konzepte in die Stadt brachten. ${ }^{604}$ Vor den Hutschen Täufern hatte lediglich der Weber Hans Wolff apokalyptische Ideen geäußert, als er im Juni I 526 die Predigt Zells im Straßburger Münster unterbrach und unter anderem behauptete, dass „[i]n sieben Jahren, am Himmelfahrtstag I 533, Punkt I 2 Uhr, [...] diese entsetzliche Welt untergehen [werde]. "605 Als Melchior Hoffman nach Straßburg kam, hatten demgemäß schon andere Personen und Gruppierungen apokalyptische Endzeitvorstellungen propagiert.

zur Monopolbildung und zur Entwicklung größerer Handwerksbetriebe, die die ärmeren Zunftgenossen um ihre Nahrung gebracht hätten. Bei Auseinandersetzungen zwischen Meistern und Gesellen entschied er wiederholt zugunsten der Schwächeren. “ Deppermann (I979), S. I42.

600 „Ein kaiserliches Mandat hatte am 4.I.I 528 die Todesstrafe über alle Täufer als ,Aufrührer' verhängt. “ Ebd., S. 236.

${ }^{601}$ So wurde z. B. am 20. Dezember I 527 Thomas Saltzmann (Scheidenmacher) geköpft, nachdem er die Trinität Gottes geleugnet und behauptet hatte, Christus wäre ein Mensch gewesen. Siehe TAE I, Nr. I I4, S. I36.

${ }^{602}$ Lienhard (I99I), S. 35. Lediglich der Wiedertäufer Claus Frey (Kutzener) wurde zum Tode verurteilt und am 22.05.I 534 ertränkt. Jedoch nicht aufgrund seiner Anhängerschaft der Wiedertäufer, sondern wegen Ehebruchs. Vgl. Deppermann (I979), S. 306.

${ }^{603}$ Deppermann (I975), S. I 89.

${ }^{604}$ Lienhard (I99I), S. I 2.

605 Deppermann (I979), S. I 59. Vgl. dazu die Protokolle über die Geschehnisse mit Hans Wolff in TAE I, Nr. $47-53$, S. 52-56. 
Die für Flüchtlinge günstigen Verhältnisse in Straßburg hatten zur Folge, dass die Stadt in den Zwanzigern des I6. Jahrhunderts zu einem Sammelplatz der Dissidenten und Andersgläubigen anschwoll: ${ }^{606}$

Im Jahr I 528 hielten sich nahezu fünfhundert Dissidenten in Straßburg auf. Etwa $80 \%$ davon waren Flüchtlinge, die sich der Stadt zugewandt hatten, die unter Handhabung des Privilegs vom freien Zug zumindest bis I 533 ziemlich großzügig mit diesen Menschen umging. ${ }^{607}$

Der freie Zug sowie die soziale und ökonomische Stabilität öffneten die Tore für Flüchtlinge. Den ausschlaggebenden Faktor für die Entwicklung der verschiedenen radikalen Bewegungen sieht Deppermann aber in dem Zögern des Rates: „Dadurch, daß der Rat bis I 529 darum bemüht war, die kirchliche Situation ,offen` zu halten, schuf er ungewollt auch einen Freiraum der Entfaltung für den religiösen Radikalismus “, 608 denn trotz der steigenden Anzahl von Reformationsanhängern in Straßburg musste die endgültige Entscheidung für eine evangelische Kirche noch bis zum Iо. Januar I 529 warten. Ab dem Tag wurde die katholische Messe nach einer Abstimmung des Rats schließlich verboten. ${ }^{609}$ Erst damit war die Reformation in Straßburg von offizieller Seite vollzogen.

\subsubsection{Melchior Hoffmans Weg zum Täufertum}

Melchior Hoffman kam also im Juni I 529 in ein Straßburg, das seitens der Obrigkeit reformiert war, sich aber innerhalb der zweiten Hälfte der zwanziger Jahre des I6. Jahrhunderts zu einem „Treffpunkt der europäischen Nonkonformisten "610 entwickelt hatte. Es ist anzunehmen, dass sich Hoffman bei seiner Ankunft in einer Phase der Umorientierung befand. Der vertriebene Kürschner sah sich vermutlich einerseits als Verstoßener der Lutheraner, hatte aber andererseits höchstwahrscheinlich bereits selbst erkannt, dass sich seine Auffassungen in wichtigen Punkten von denen Luthers unterschieden. Hoffman orientierte sich zum Teil an den frühen Schriften Luthers und hielt an Elementen fest, die dieser mit den Jahren, insbesondere nach I 525 , selbst widerlegt bzw. grundlegend bearbeitet hatte. ${ }^{6 I}$ Viele Elemente von Hoffmans theologischem

\footnotetext{
${ }^{606}$ „They [the refugees] called it the ,City of Hope` and the ,Refuge of Righteousness“." Kreider (I955), S. 99.

607 Lienhard (I99I), S. I I.

${ }^{608}$ Deppermann (I979), S. I 50.

609 Vgl. ebd., S. I 50, Kreider (I955), S. roof. und Lienhard (I99I), S. 9.

610 Deppermann (I978), S. I6I.

${ }^{611}$ Deppermann (I975), S. 203.
} 
Gesamtkonzept waren aber auch von der Mystik, vom Hussitismus und von anderem mittelalterlichen Gedankengut beeinflusst. ${ }^{612}$ Durch die Streitigkeiten um die Apokalypse und das Abendmahl mit den Lutheranern hatten sich die Fronten zunehmend verhärtet, so dass es offenbar wurde, dass eine Einigung nicht mehr möglich war. Die Kontakte zu Karlstadt und der kurze gemeinsame Aufenthalt bei den ostfriesischen Zwinglianern ${ }^{613}$ hatten Hoffman in seiner Abendmahlsauffassung und der Ablehnung der Wittenbergischen Reformationsbewegung zusätzlich bestärkt. Möglicherweise vermutete er, in Straßburg ebenfalls Unterstützung von den zwinglischen Reformatoren zu bekommen. ${ }^{614}$ Letzteren wurde jedoch schon nach kurzer Zeit klar, dass Hoffmans Ideen mit ihren eigenen Vorstellungen unvereinbar waren. Infolgedessen verwiesen sie Hoffman ein weiteres Mal darauf, seinem handwerklichen Gewerbe anstatt theologischen Tätigkeiten nachzugehen. ${ }^{65}$

Von den Straßburger Reformatoren (wie vorher von den Lutheranern) missachtet wandte Hoffman sich dem Kreis der „Straßburger Propheten“ um das Ehepaar Ursula und Lienhard Jost sowie Barbara Rebstock zu. Infolge dieser Umorientierung kam Hoffman erstmals mit wiedertäuferischem Gedankengut in direkten Kontakt. Besonders die Theologie Hans Dencks hatte großen Einfluss auf die weitere Entwicklung der Lehre Hoffmans. Er verwarf die letzten lutherischen Anteile, die Widersprüche in seinem Lehrgebäude darstellten, und übernahm Elemente der Spiritualisten und Wiedertäufer bzw. ergänzte seine eigenen bisher vorhandenen Auffassungen durch jene. ${ }^{616}$ Das Ehepaar

${ }_{612}$ Vgl. Deppermann (I975), S. I77 und Deppermann (I979), S. I4.

613 „Bis I 530 beherrschten die Zwinglianer die religiöse Szene in Ostfriesland, und zwar nicht auf Grund ihrer zahlenmäßigen Überlegenheit, aber wegen ihrer geistigen Aktivität. “ Deppermann (I979), S. I34f.

${ }^{6{ }_{14}}$ „Daß Hoffman sich im Juni I 529 nach Straßburg wandte, geht vielleicht auch auf eine Empfehlung Ulrichs von Dornum zurück. [Dieser hatte bereits Kontakt zu den Straßburger Reformatoren.]. Die Gründe für diesen Schritt kennen wir nicht.“ Ebd., S. I37.

${ }_{615}$ Bucer schrieb 1533 in seinem Bericht Handlung inn dem offentlichen gesprech zu Straßburg iungst im Synodo gehalten: „wolte Gott / er [Melchior Hoffman] gebe der warheyt bey jm raum / vnd wartete seines kürßner handtwercks darfür / dz er die gemeynden Gottes / so schwerlich ergeret / wie wir jn hie zu vor vier jaren gar fleissig ermanet“ (L6r). Zur Linden gibt fälschlicherweise an, dass sich diese Textstelle in der Vorrede der Schrift befände. Zur Linden (I885), S. I89. Schon I 528 hatte Hoffman von Amsdorf den Rat erteilt bekommen, bei seinem Handwerk zu bleiben. Siehe Kapitel 3.I Der Streit mit Nikolaus von Amsdorf I: Die Hintergründe.

${ }^{616}$ Deppermann (I979), S. I63. Auf den Seiten I63-I69 gibt Deppermann eine detaillierte Zusammenfassung der Theologie Dencks, „soweit sie für Hoffman von Bedeutung war." Ebd. 
Jost spielte für Hoffman eine wichtige Rolle, insbesondere die Visionen und Offenbarungen des Paars waren für ihn von großer Bedeutung, so dass er die "Gesichte“ sowohl von Ursula als auch von Lienhard Jost im Druck herausgab. ${ }^{67}$ Hoffman hielt die Prophetien der beiden für ein weiteres Zeichen, das auf das bevorstehende Weltende hinweise, und erweiterte in Bezug auf die Visionen seine apokalyptische Lehre, während er gleichzeitig spiritualistische Einflüsse in seiner Theologie verarbeitete. Deppermann fasst die neuen Entwicklungen von Hoffmans Lehrgebäude innerhalb des ersten Jahres in Straßburg wie folgt zusammen:

Die „zwinglischen“ Theologen der Stadt, auf die er seine Hoffnung gesetzt hatte, stießen ihn von sich, aber die von der Welt verachteten „Straßburger Propheten “ begrüßten ihn als den zweiten Elia. Unter ihrem Einfluß drangen in seine bis dahin attentistische Apokalyptik militant-aktivistische Elemente ein. Schwenckfeld regte ihn zu seiner monophysitischen Christologie an, und mit dem Bekenntnis zu Dencks Lehre von der Universalität der göttlichen Gnade und zum freien Willen brach er vollends mit der eigenen lutherischen Vergangenheit. Schließlich übernahm er noch von den Straßburger Nonkonformisten die Idee der Freiwilligenkirche, in die der einzelne durch die Glaubenstaufe eintrat. ${ }^{618}$

I 530 veröffentliche Hoffman neben den Offenbarungen des Ehepaars Jost auch andere Schriften, unter anderem auch kurz vor dem 23. April die für seine Apokalypse-Vorstellung theologisch zentrale Außlegūg der heimlichē Offenbarung Joannis des beyligen Apostels unnd Euangelisten. ${ }^{619} \mathrm{Da}$ Hoffman in seinem Kommentar den Kaiser sowohl im Text als auch auf dem Holzschnitt des Titelblatts polemisch angreift (s. Abb. 2), ${ }^{620}$ schaltete sich der Magistrat ein, da er diese Majestätsbeleidigung nicht tolerieren konnte.

${ }^{617}$ In seiner Schrift Prophecey oder weissagung (I530) (vollständige Angabe bei Anmerkung 642) zitiert und kommentiert Hoffman eine von den Offenbarungen Ursula Josts. In der kurz darauf, ebenfalls I 530, erschienenen Schrift Prophetische gesicht v̄̄ Offenbarung / der gôtlichē würckung zü diser letstē zeit / die vom xxiiij. jar biß in $d z x x x$. einer gottes liebhaberin durch den heilige geist geoffenbart seind / welcher hie in disem büchlin. lxxvij. verzeichnet seindt. [Balthasar Beck: Straßburg] gibt Hoffman dann 72 Visionen von ihr heraus. Die beiden Ausgaben der hier erwähnten Prophetien Lienhard Josts sind leider verloren.

${ }^{618}$ Deppermann (1979), S. I93. Siehe auch S. I94-235.

${ }_{619}$ TAE I, Nr. 210, S. 259. Der Zeitpunkt der Veröffentlichung ergibt sich aus dem Ratsbeschluss vom 23. April I 530 gegen Hoffman. Siehe TAE I, Nr. 2 I I, S. 26I. Die Offenbarungs-Auslegung wurde I 530 bei Balthasar Beck in Straßburg gedruckt.

${ }^{620}$ Im Text vergleicht Hoffman den Kaiser u. a. mit einem der beiden Heuschreckenflügel (der andere sei der Papst), die die Menschen auf der Erde quälen (Offb 9: 9), aber 


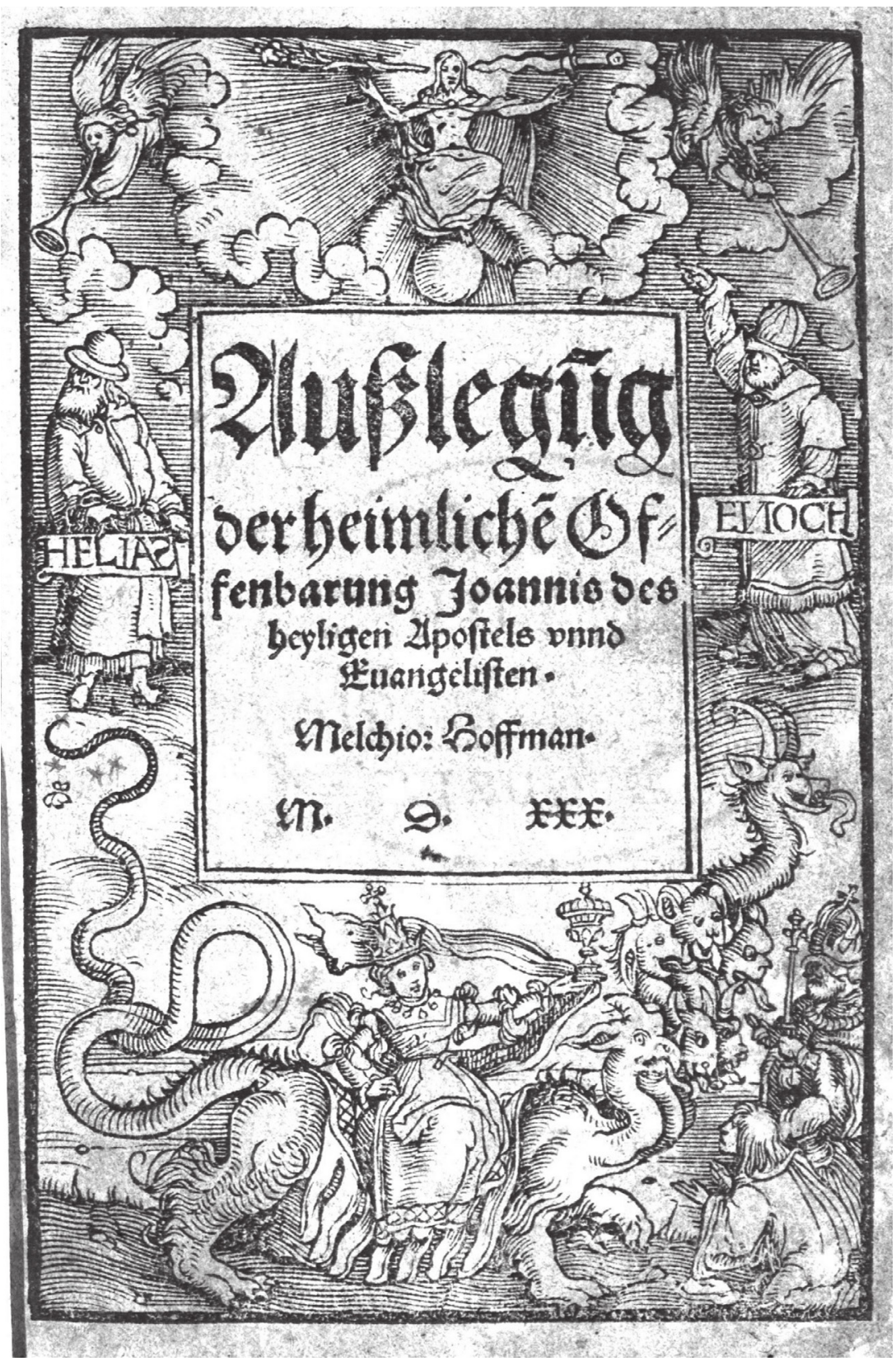

Abbildung 2. Titelblatt mit Holzschnitt der Außlegūg der heimlichēe Offenbarung Joannis des heyligen Apostels unnd Euangelisten (derselbe Holzschnitt ziert auch die aus demselben Jahr stammende Schrift Prophetische gesicht vin Offenbarung). In der rechten unteren Ecke ist der Kaiser bei der Anbetung der auf dem Drachen reitenden Babylonischen Hure abgebildet. 
Die ungefähr zur selben Zeit gestellte Forderung Hoffmans, eine eigene Kirche für sich und seine Anhänger zu bekommen, trug ebenfalls dazu bei, dass der Magistrat aktiv gegen Hoffman vorging: ${ }^{62 \mathrm{I}}$ Balthasar Beck, der Drucker der Außlegūg der heimlichē Offenbarung, und Christian Egenolff, der den Holzschnitt des Titelblattes gefertigt hatte, wurden festgenommen und verhört. ${ }^{622}$ Für Hoffman wurde ein Haftbefehl ausgestellt, dem er jedoch durch seine Flucht nach Ostfriesland am 23. April I 530 entkommen konnte. ${ }^{623}$

In Ostfriesland führte Hoffman das erste Mal selbst die Erwachsenentaufe durch. Mit der Erwachsenentaufe unterschied er sich jedoch von den Sakramentariern dort, musste infolgedessen „[i]m Spätherbst I 530 [...] Ostfriesland tatsächlich verlassen“"624 und zog weiter in die Niederlande, ${ }^{625}$ wo Hoffmans apokalyptische Lehre auf nahrhaften Boden fiel. Hoffman gewann vermutlich aufgrund der „schweren ökonomischen Depressionen“ viele Anhänger aus den notleidenden Bevölkerungsgruppen. ${ }^{626}$ Auch in den Niederlanden taufte Hoffman weitere 50 seiner Anhänger, bis einer der Getauften, Jan Volkerts, die Namen anderer Glaubensgenossen an die Behörden weitergab. Die Folge davon war, dass er und einige derjenigen, die als Getaufte genannt wurden, hingerichtet wurden.627 Als Reaktion darauf „befahl [Hoffman], die Taufpraxis für zwei Jahre (bis Ende I 533) einzustellen“". ${ }^{628}$ Trotz des Taufverbots wird Hoffman angerechnet, die Erwachsenentaufe in die Niederlande gebracht und im Allgemeinen

auch - wesentlich schlimmer - mit dem Drachen: „diser grosse Trach sey erschinen / welcher Trach ist der Sathan / mit seinen glidern [...] vnd wie der Künig Pharao in Egipten auch ein Trach genāt in Ezecchiel .xxix. also wirt der oberst des Ro̊mischen reichs gestelt vnnd abgemalet [...] Vnnd wirt der selbige das oberst haubt mitt seinen haren / vnnd allen Fürsten herren vnnd sein pracht volck ihn einen Thrachen vergleichet durch welche der Sathan alle welt vnd sein reich regieret [...]“. Hoffman ( I 530): Außlegūg der heimlichē Offenbarung, M3v, Zitat auf O8r-v.

${ }^{621}$ „Melchior Hofmans supplication den widertäuffern ein eigene kirche zu ordnen, dergleichen sin ußlegung der I 2 cappittel in Apocalipsi, wie er die figur uf den kaiser ziht. “ TAE I, Nr. 2I I, S. 26If.

${ }_{622}$ TAE I, Nr. 2I 2, S. 262.

${ }_{623}$ Vgl. Neff (I956), S. 78 I und Deppermann (I979), S. I93.

${ }^{624}$ Deppermann (I979), S. 276.

${ }^{625}$ Hoffman hielt sich z. B. im Sommer I 53 I in Amsterdam auf. Ebd., S. 284.

${ }^{626}$ Ebd., S. 28I.

${ }_{627}$ Deppermann (I979) schildert den Fall detailreich, siehe S. $285 \mathrm{f}$.

${ }^{628}$ Ebd., S. 286. 
das niederländische Täufertum maßgeblich beeinflusst zu haben. ${ }^{629}$ Die Quellen zu Hoffmans Wirken in den zwei Jahren seines Aufenthalts in Ostfriesland und den Niederlanden sind jedoch spärlich. Die vorhandenen niederländischen Schriften Hoffmans und die Bekenntnisse von Obbe Philips geben dennoch vereinzelte Hinweise auf Hoffmans Tätigkeiten und deren Wirkung.

Noch bevor in den Niederlanden das Münstersche Täuferreich durch Jan Matthijs und Bernd Rothmann vorbereitet wurde, kehrte Hoffman im März I 533 nach Straßburg zurück. ${ }^{630}$ Hoffman erwartete dort das Jüngste Gericht und das himmlische Jerusalem, deren Verwirklichung er selbst in seiner Daniel-Auslegung auf diese Zeit datiert hatte. Nachdem ihm ein alter Friese die Prophezeiung gemacht hatte, dass er ein halbes Jahr im Gefängnis großes Leiden hinnehmen müsse, bevor er zum geistigen Anführer der Welt würde, ${ }^{63 \mathrm{I}}$ empfand Hoffman seine Verhaftung nach einem nur kurzen Aufenthalt in Straßburg sowohl als Erfüllung dieser Weissagung als auch als Bestätigung seiner eigenen Prophetie der nahenden Apokalypse und ging "gutwillig, fröhlich und wohl getröstet ins Gefängnis“. ${ }^{632}$ Seine Erwartung, bald wieder auf freiem Fuße zu sein, löste sich jedoch bis an sein Lebensende nicht ein, denn Hoffman blieb bis zu seinem Tod Ende des Jahres $1543^{633}$ im Straßburger Gefängnis. In seinen ersten Jahren als Gefangener war Hoffman zunächst sehr produktiv und brachte mit Hilfe seiner Anhänger mehrere Schriften heraus. Ein offizielles Schreibverbot, das ihm Ende Juni I 533 erteilt wurde, konnte ihn nicht am Schreiben hindern, denn er schrieb sogar auf Tüchern weiter. Es schränkte dennoch seine publizistische

629 Mellink, Albert F. (I975): „Das niederländisch-westfälische Täufertum im I6. Jahrhundert“. In: Goertz, Hans-Jürgen (Hg.): Umstrittenes Täufertum: I $525-1975$. Neue Forschungen. Göttingen: Vandenhoeck \& Ruprecht, S. 206-222, hier S. $206 \mathrm{f}$. 630 „Drei Aufenthalte in Straßburg können als gesichert gelten: der erste von Ende April I 529 bis Juni I 530 (TAE I Nr. I 88 \& Nr. 2I I); der zweite im Dezember I 53 I (TAE I Nr. 279, 280, 298); der dritte vom März I 533 bis zu seinem Tode Ende I 543 (TAE II, Nr. 346; Str. St A Rät und XXI I 543, fol. 502; Schwenckfeld: Epistolar I, S. 594).“ Deppermann (I979), S. 253, Anmerkung 88.

${ }_{631}$ Neff (I956), S. 782. Deppermann (I979), S. 253.

${ }_{32}$ Philips (1962), S. 323.

${ }_{63}$ Hoffmans Tod muss zwischen dem I9.I I. und dem I 4. I 2. I 543 liegen: Am I9. I I. ist ein Eintrag in den Akten über Hoffmans schlechten gesundheitlichen Zustand verzeichnet, am I4.I 2. muss Hoffman schon tot gewesen sein, da in einem Akteneintrag (Brief) von der „Historia[] Hoffmani“ die Rede ist. Quellen zur Geschichte der Täufer (I 988). Bd. XVI. Elsaß IV, Stadt Straßburg I 543-I 552 samt Nachträgen und Verbesserungen zu Teil I, II und III (= TAE IV). Bearb. von Marc Lienhard, Stephen F. Nelson \& Hans Georg Rott. Gütersloh: Mohn, Nr. I 526, S. 55 \& Nr. I 532, S. 60. 
Tätigkeit ein und ist maßgeblich für das verdeckte Polemisieren in der Zeit verantwortlich.

Im Allgemeinen kann Hoffmans Zeit in Straßburg, Ostfriesland und den Niederlanden als seine produktivste Phase bezeichnet werden: Hoffman schrieb seine zwei großen Bibelkommentare (zu der Offenbarung und dem Römerbrief), eine Vielzahl unterschiedlicher Traktate, einen Reformationsdialog (zusammen mit Karlstadt) und Sendbriefe. Eine weitere persönliche Kontroverse (nach der ApokalypseKontroverse mit Amsdorf I 527/28) führte er zwar nicht, aber nur in seltenen Fällen verzichtete er in den Schriften aus diesen Jahren auf Polemik gegen die Lutheraner und Zwinglianer. In den Schriften zwischen I 529 und I 534 (danach sind keine weiteren bekannt) lässt sich beobachten, dass Hoffman sich mehr des indirekten und verdeckten Polemisierens bedient. In den folgenden Kapiteln werden mögliche Gründe dafür erörtert und die Umsetzung dieser Formen des Polemisierens in Hoffmans späteren Schriften analysiert.

\subsection{Die Vorrede als Ort indirekten Polemisierens}

Hoffmans Schrifttum in seinen späteren Lebensjahren besteht zum Großteil aus Bibelkommentaren und Traktaten, die als Textsorten grundsätzlich nicht als polemisch bezeichnet werden würden. Es wurde bereits festgehalten, dass es auch in solchen Texten, deren Hauptfunktion nicht das Streiten ist, Möglichkeiten gibt, einen Streit zu inszenieren und durch Fremd- und Selbstzuschreibungen einen polemischen Antagonismus zu entwerfen, umzudefinieren oder zu festigen.

Dem Anbringen von Polemik sind somit a priori keine Grenzen durch literarische Formen gesetzt. Unterschiede lassen sich dennoch dahingehend ausmachen, dass Polemik in verschiedenen Textformen jeweils auch andere kommunikative Formen annimmt; d. h. die Art des Polemisierens steht in einem gegenseitigen Abhängigkeitsverhältnis mit der jeweils verwendeten Form. Im Hinblick auf die Beobachtung, dass Gesamttexte selten durchgehend einheitlich konstruiert sind, sondern dass sich einzelne Textteile voneinander abgrenzen lassen, erscheint es sinnvoll, einen Gesamttext in seine verschiedenen Textteile (soweit vorhanden) zu unterteilen. Nicht zuletzt aufgrund der klassischen Rhetoriklehre, die eine Gliederung der Rede, eines Briefs etc. in einzelne Abschnitte (dispositio) vorgibt, zeigt sich die analytische Zerlegung eines Textes in seine abgrenzbaren Einzelabschnitte als produktives Vorgehen. 
Bei der Untersuchung der Schriften Hoffmans lassen sich zwei übliche, rhetorische Strukturmuster identifizieren. Zunächst spielt die Briefstruktur eine wichtige Rolle, denn sowohl in den als Sendbriefen konstruierten Texten als auch in den persönlichen Fehde-Schriften gegen Nikolaus von Amsdorf sind typische Strukturelemente der in der Rhetorik gelehrten dispositio des Briefs anzutreffen. Obgleich Hoffman seine Schriften gegen Amsdorf nicht vollständig und durchgängig nach einer klassischen Strukturvorgabe konstruiert, tauchen in Abschnitten seiner Schriften Elemente auf, die mit den Vorgaben der Rhetoriklehre korrespondieren. Dies deutet auch daraufhin, dass Hoffman bei der Konstruktion seiner Schirften autodidakt vorging und sich nicht streng an Ratgebern der Rhetorik orientierte. Insbesondere die formelhaften Anfangs- und Schlussworte, salutatio und peroratio, aber auch captatio benevolentiae und/oder petitio kommen als Rahmung der narratio in Hoffmans Schriften zur Anwendung. Wie bereits anhand des polemischen Schriftwechsels erörtert wurde, eignet sich die briefähnliche Struktur nicht nur für direktes, sondern auch für indirektes Polemisieren. Die dialogische Grundhaltung dieser Ausformung kann als Gesprächsangebot entweder an das polemische Objekt oder an die polemische Instanz inszeniert werden, wobei ein tatsächliches Gesprächsangebot nicht zwingend daraus hervorgehen muss. Ein Wechsel der Kommunikationssituation vom direkten zum indirekten Polemisieren und vice versa innerhalb des Textverlaufs ist nicht zuletzt durch die Textaufteilung leicht realisierbar und wird daher oft eingesetzt.

Als zweiten größeren Komplex aus Texten kann man bei Hoffman die exegetischen und religionstheoretischen Texte nennen. In ihren erörternden, erklärenden, interpretierenden, informierenden und belehrenden Funktionen machen sie dem Leser prinzipiell kein Gesprächsangebot, sondern sind vielmehr monologisch konstruiert. Es wird in der Regel nicht offenkundig, sondern nur implizit zu jemandem gesprochen, $d . h$. ein Rezipient wird auf der Textebene nicht als Kommunikationspartner angelegt.

Da im I6. Jahrhundert das Dialogische in Texterzeugnissen eine zentrale Bedeutung hatte, ${ }^{634}$ wurden die religiösen Abhandlungstexte sehr häufig in ihrer (auf Textebene) monologischen Form mit sich an den

${ }^{634}$ Vgl. Keller, Andreas (2008): Frühe Neuzeit. Das rhetorische Zeitalter. Berlin: Akademie Verlag, S. I7. 
Leser richtenden Paratexten publiziert. Bei exegetischen Texten und religiösen Traktaten nimmt die Vorrede eine prägnante Stellung ein: Sie gehört zwar unmittelbar zum Haupttext und ist an diesen gebunden, hat aber in der Regel eine von diesem abgegrenzte, eigenständige Funktion, denn

[c]harakteristisch für Prolog und Vorrede ist die Vermittlung zwischen Autor, Werk und Leser [...]. Während Prolog und Vorrede typischerweise durch die Erzählperspektive und poetologische Thematik vom Werk unterschieden sind, ist dennoch die Verbindung mit einem spezifischen Werk und die Ausrichtung auf eine bestimmte Rezipientengruppe kennzeichnend. ${ }^{635}$

Was hier für fiktionale Texte formuliert wird, trifft ebenso auf die nicht-fiktionalen Bibelkommentare oder Traktate der Reformation im Allgemeinen und Hoffmans theologische Schriften im Besonderen zu: Die Gliederung der Texte einerseits in einen Hauptteil, der religiöse Fragen oder Bibelstellen diskutiert, und andererseits in Rahmentexte (z. B. die Vorrede und eventuell auch eine „Nachrede“6636), die sowohl Platz für (Meta-)Kommentare zum Text und/oder seinem Entstehungskontext ${ }^{637}$ als auch für die Leserlenkung und -gewinnung bieten, ist auch in Hoffmans Schrifttum zu beobachten. Im Gegensatz zu dem Haupttext, der religiösen Abhandlung, zeichnet sich die Vorrede im Allgemeinen durch einen höheren Grad der Ausrichtung auf die Rezipienten aus, d. h. sie richtet sich auf der Textebene häufig dialogisch entweder an einen definierten Leser(-kreis) oder an ein undefiniertes Publikum. ${ }^{638}$ Selbst in Fällen, in denen auf die explizite Anrede der Leserschaft verzichtet wird, kann die Vorrede als eine Textform betrachtet werden,

${ }^{635}$ Kohl, Katrin (2007): Poetologische Metaphern. Formen und Funktionen in der deutschen Literatur. Berlin \& New York: De Gruyter, S. 2 I 3.

${ }_{636}$ Schramm, Gabriele (2010): Widmung, Leser und Drama. Untersuchungen zu Formund Funktionswandel der Buchwidmung im I7. und I8. Jahrhundert. Hamburg: Verlag Dr. Kovač, S. 93.

637 Vgl.: „Im Unterschied zum Kolophon und zum Titelblatt, die als Paratexte sehr geringen Umfangs es meist nur erlauben, knappe und formelhafte Informationen über den Text zu vermitteln, transportiert schon die erste gedruckte Widmungsvorrede sehr differenzierte Reflexionen über die Produktion und Distribution des Buchs an den Leser.“ Wagner, Bettina (2008): „An der Wiege des Paratexts. Formen der Kommunikation zwischen Druckern, Herausgebern und Lesern im I 5 . Jahrhundert “. In: Ammon, Frieder von \& Herfried Vögel (Hg.): Die Pluralisierung des Paratextes in der frühen Neuzeit. Berlin: LIT Verlag, S. I33-I 55, hier S. I 50.

${ }_{63} 8 \mathrm{Vgl}$. Schramm (2010), S. 93. 
die funktional der Kontaktaufnahme mit dem Rezipienten sowie der Gewinnung von dessen Gunst dient. ${ }^{639}$

Die Ausrichtung der Vorrede auf die Leserschaft und die damit verbundenen Funktionen der Texterklärung und Leserlenkung bieten den idealen Nährboden für Polemik. ${ }^{60}$ Wie sich die Polemik in der Vorrede bei Hoffman manifestiert und welche konkreten Formen sie annimmt, wird nachfolgend anhand einiger prägnanter Beispiele von Vorreden, sowohl mit als auch ohne Widmung, erörtert.

\subsubsection{Indeterminierte Polemik in der Widmungsvorrede}

Bei der Analyse der Vorreden in Melchior Hoffmans Schriften ist durchgängig erkennbar, dass die Vorrede für ihn einen Ort der Legitimierung und Autorisierung darstellt. Eine oft vorangestellte und typographisch abgehobene Widmung dient in diesem Zusammenhang nicht nur als Zueignung, die auf mögliche Gegenleistungen des Widmungsempfängers abzielt, sondern kann auch als Instrumentalisierung der Autoritätsperson betrachtet werden, mittels derer Hoffman sein Schreiben, wie durch eine höhergestellte Autorität beglaubigt, konstruiert. Auffällig ist nämlich, dass die Zueignungen immer ranghöheren, zumeist mächtigen oder adligen Persönlichkeiten gelten: Hoffman widmet z. B. seine Auslegung des Hohelieds Salomos, Dat Boeck Cantica Canticorum, ${ }^{64 \mathrm{I}}$ der Königin Sophia von Pommern, die Schriften Prophecey oder weissagung $v \beta$ heiliger gotlicher schrifft ${ }^{642}$ und WEissagung $v \beta$ heiliger

${ }_{339}$ „Sie [die Vorrede] ist zwar formal vom Werk selbst getrennt, aber physisch in das Buch integriert. Aus der Perspektive des Autors oder Herausgebers stellt sie den ersten Bezug zum Leser her und sucht ihn mit überzeugenden und unmittelbar eingängigen Argumenten für das Werk einzunehmen. “ Kohl (2007), S. 2 I I.

${ }^{64}$ Vgl. dazu: „Der Rezeptionssteuerung dienen vor allem paratextuelle Elemente wie Titelblätter, Marginalien und Vorreden; letztere werden zugleich als Raum für metapolemische Diskussionen genutzt, hier reflektieren die Verfasser ihr eigenes Tun und rechtfertigen den umstrittenen Gebrauch v. a. persönlicher Argumente. “ Paintner 201 I, S. 459.

${ }^{64}$ Hoffman, Melchior (I529): Dat Boeck Cantica Canticorum: edder dat hoge leedt Salomonis: vthgelecht dorch Melchior Hoffman Köninckliker maiestat tho Dennemarcken gesetter Prediger thom Kyll: ym lande tho Holsten. Kiel: [Melchior Hoffman].

${ }^{642}$ Hoffman, Melchior (I 530): Prophecey oder weissagung uß warer heiliger gótlicher schrifft. Von allen wundern vnd zeichē / biß zu der zükunfft Christi Jesu vnsers heillands / an dem Jüngsten tag / vnd der welt end. Dise Prophecey wirt sich anfahen am end der weissagung (kürtzlich vō mir außgangen / in eim anderen büchlin) Von der schweren straff gotes / über alles gotloß wesen / durch den Türckische tirannen / 
gótlicher geschrifft ${ }^{643}$ dem an der ostfriesischen Reformation beteiligten Ulrich von Dornum, Häuptling von Oldersum. Die Außlegūg der heimlichē Offenbarung ${ }^{644}$ dedizierte er I 530 sogar dem dänischen König Friedrich I., obwohl dieser Hoffman noch ein Jahr zuvor einen Landesverweis erteilt hatte. Trotz dieses Urteils sah Hoffman in dem dänischen König den Wegbereiter für die Erfüllung seiner Prophetie, ${ }^{645}$ so dass die Widmung hier mehrere performative Funktionen hat, die über das Darbieten des Textes hinausgehen: Erstens dient sie der Lobpreisung und Würdigung des Königs, zweitens der Unterstreichung von Hoffmans apokalyptischer Theorie (indem er den König zu einem Teilhaber daran macht). Als dritte Funktion ist zudem die Fürbitte an den König um Unterstützung zu nennen, die auf eine Rückwirkung der Schrift beim Widmungsempfänger zielt. ${ }^{646}$ Viertens fungiert die Widmung als Autorisierung der Publikation durch die Majestät selbst. ${ }^{647}$ Letzteres ist auf eine Reaktion beim Publikum ausgerichtet und kann

auch wie er regieren $v \bar{n}$ ein end nemmen wirt. [et]c. [Straßburg: Balthasar Beck]. Kurztitel: Prophecey oder weissagung.

${ }_{443}$ Hoffman, Melchior (I 529/30?): WEissagung vsz heiliger gótlicher geschrifft. Von den trübsalen diser letsten zeit. Von der schweren hand vnd straff gottes über alles gottloß wesen. Von der zükunfft des Türckischen Thirannen / und seines gantzē anhangs. Wie er sein reiß thion / vnnd volbringen wirt / vns zü einer straff vnnd rutten. Wie er durch Gottes gwalt sein niderlegung vnnd straff entpfahē wirt. [et]c. [Straßburg: Balthasar Beck]. Kurztitel: WEissagung vsz heiliger gôtlicher geschrifft.

${ }^{644}$ Vollständige Angabe bei Anmerkung 39. In diesem Teilkapitel werden Zitate aus der Offenbarungs-Auslegung nur mit der Folienangabe (in Fußnoten auch mit den Inititalen $\mathrm{OA}=$ Offenbarungs-Auslegung) in nachgestellten Klammern gekennzeichnet.

${ }^{645}$ Hoffman wendet sich innerhalb der Vorrede direkt an den König: „Dieweil ich aber an E. Kü. Ma. [Eurer königlichen Majestät] ein solchen geist vnd můt erkennet vnnd gespưret hab / der da ein waren eyfer hat / nach der gôttlichen gerechtigkeit vnd der warheit / ist mein hertz vnnd můt alle zeit in grossem hoffen / gegen Gott vnnd vnserem heylandt Christo Jesu / dz er werd sein werck durch ein solches ein fürgang lassen haben “ $\left(\mathrm{OA}, \mathrm{A}_{4} \mathrm{r}\right)$. Darauf folgend wird erklärt, dass Hoffman im König einen der zwei Beschützer der Zeugen der Apokalypse sieht.

${ }^{646}$ Vgl. dazu Karl Schottenloher, der als Beweggründe für die Widmung einen „gesteigerten humanistischen Geltungswillen“, „das vermehrte Mitteilungsbedürfnis“ und den „Wunsch der Verfasser oder Herausgeber [...], einen Gönner oder Beschützer zu gewinnen“ sieht. Er fasst zusammen: „Hier verflochten sich also Werbung und Vergütung mit der Widmungsvorrede." Schottenloher, Karl (I953): Die Widmungsvorrede im Buch des I6. Jahrhunderts. Münster: Aschendorffsche Verlagsbuchhandlung, S. I75.

${ }_{447}$ Vgl. dazu: „Autoritätsbeleg - diese Funktion kommt ebenso den Dedikationen zu. “ Bremer (2005a), S. 516. Bremers Aussage gilt einer Widmungsvorrede Georg Scherers, der „in aller Regel fürstliche Dedikationsadressaten“ (ebd.) wählt, hat aber seine Gültigkeit für viele Widmungen. 
dazu beitragen, die Glaubwürdigkeit des Verfassers und seiner Schrift zu stärken, ${ }^{648}$ die ihrerseits eine unverzichtbare Voraussetzung für die Wirkung und Durchschlagskraft der angewendeten Polemik darstellt. ${ }^{649}$

Im Zusammenhang mit einer persönlichen Widmung wird zumeist auch ein größeres Publikum genannt, manchmal sogar direkt angesprochen. Hoffman wünscht z. B. in der Außlegūg der heimlichē Offenbarung nicht nur dem König „gnad / vnd den ewigen fride / vn das ewige heil“, sondern „auch allē vsserwòltē glåubigē / von Gott dem barmhertzigen hī̄lischen Vatter" (A2r). Auch dieser Gnadenausspruch hat einen performativen Charakter, denn er lässt die Leser automatisch zu solch auserwählten Gläubigen werden, denen Hoffman diese Schrift mittels des Grußes zudenkt. Da nur diese als Leser intendiert und sämtliche anderen als solche exkludiert werden, schließt der Akt des Lesens (oder auch Hörens) gleichzeitig eine positive Charakterisierung des Rezipierenden mit ein. Dieses immanente Rezipientenlob schafft eine Verbindung zwischen Hoffman und dem Publikum, was ebenfalls eine Grundlage für die wohlwollende Aufnahme des Inhalts, der Argumente und der Polemik schafft.

Im Gegensatz zu den personengerichteten polemischen Schriften (wie z. B. den Schriften gegen Amsdorf) ist bei den theologischen Abhandlungen zu erkennen, dass eine gegnerische Partei nicht angesprochen wird, sondern lediglich die zwei Rezipienten(-gruppen) unterschiedlicher Qualität genannt werden, denen Hoffman jeweils wohlgesinnt ist. Von ihrer Hauptfunktion - der Auslegung, Erklärung oder Bewertung einer Bibelstelle bzw. der Diskussion eines religiösen Sachverhalts - bestimmt, richten sich Bibelkommentare, z. T. auch Traktate, selten direkt an Widersacher oder Kontrahenten. Infolgedessen ist die Kommunikationssituation verwendeter Polemik in der Regel die

${ }^{648}$ Vgl.: „Die Einrichtung der Widmungsvorreden hat also den Verfassern nicht nur manche Gegengaben [...] eingebracht, sondern sie auch mit dem gesellschaftlichen Leben stark verankert und ihnen ein gesteigertes öffentliches Ansehen verliehen.“ Schottenloher (1953), S. I96.

${ }_{449}$ Vgl.: „[Der Begriff der Glaubwürdigkeit] betrifft generell die Überzeugungskraft der Rede und wird für die Wahrheit von Sachverhaltsdarstellungen, aber auch für die Aufrichtigkeit von Emotionen und Intentionen des Redners, die Vertrauenswürdigkeit von Meinungen und Ratschlägen, die Richtigkeit von Bewertungen, die Ehrenhaftigkeit von Handlungen und schließlich zur Charakterisierung des Ethos des Redners gebraucht. “ Deppermann, Arnulf (2005): Glaubwürdigkeit im Konflikt. Rhetorische Techniken in Streitgesprächen. Prozessanalysen von Schlichtungsgesprächen. Radolfzell: Verlag für Gesprächsforschung, S. 33 . 
des indirekten Polemisierens, denn während Widmungsempfänger und Publikum explizit oder implizit angesprochen werden, kann mittels der Rede über das polemische Objekt gegen dieses polemisiert werden. Wie die Kommunikationssituation des indirekten Polemisierens im konkreten Fall in der Widmungsvorrede bei Hoffman aussieht, welche besonderen Strategien für den polemischen Zweck eingesetzt werden und welche Implikationen die Zueignung an Autoritätspersonen dabei haben kann, soll im Folgenden anhand der Widmungsvorrede der Außlegūg der heimlichē Offenbarung erörtert werden.

\section{Die Widmungsvorrede der Außlegūg der heimlichē Offenbarung}

Die Widmungsvorrede in der 367-seitigen Auslegung des biblischen Buches der Offenbarung des Johannes ist relativ lang für eine Vorrede; sie zählt I4 Seiten. Nach der bereits genannten typographisch abgetrennten Dedikation an den König und der Begrüßung der übrigen Rezipienten adressiert Hoffman zunächst weder den König noch die Leserschaft, sondern berichtet in allgemeiner, monologischer Form, dass sich die Welt „yetzt zů diser zeyt" (A2v $)^{650}$ kurz vor dem Jüngsten Gericht befinde (A2r-A3v). Hoffman zeigt damit deutlich an, dass er das Buch der Offenbarung des Johannes unmittelbar auf seine Zeit bezieht und begründet so, dass seine Auslegung von höchstaktueller Relevanz für jeden Christen sei. Diese narratio ohne konkreten Adressaten nimmt den größten Teil der Vorrede ein; im Zusammenhang mit der Kontextualisierung wird der König jedoch an mehreren Stellen direkt angesprochen ${ }^{65}$ und erscheint dadurch auch nach dem Widmungsteil noch als Hauptadressat der Vorrede.

Polemische Töne sind erst auf der siebten Seite der Vorrede (A5r) zu verzeichnen. Es lässt sich dokumentieren, dass Hoffmans Polemik innerhalb der Vorrede durchgehend indeterminiert bleibt, so dass eine Entschlüsselung des polemischen Objekts allein durch die textinterne Informationsvergabe nicht möglich ist, sondern textexterner Hinweise bedarf. Die Fingerzeige, die Hoffman auf der Textebene gibt, erfordern in der Vorrede zunächst eine Deutungsleistung auf Seiten des

${ }^{650}$ In fast jedem Abschnitt auf den ersten vier Seiten kommen ähnliche zeitliche Indexikalisierungen vor: „zů diser letstē zeyt am end der vergencklichen welt“ $(\mathrm{A} 2 \mathrm{r})$, ,vff diese yetzige zeyt" ( $\left.\mathrm{A}_{3} \mathrm{r}\right)$, „auch yetzt die zeit“ $\left(\mathrm{A}_{3} \mathrm{v}\right)$ etc.

${ }_{651}$ Zuerst auf A4r (Wortlaut siehe Anmerkung 645), weitere Male auf A4v, A6r, A6v, A8v. Anredeform: „E. Kü. M. [Eure königliche Majestät]“, „Eü. Künigliche M.“ oder „K. W. [Königlicher Würden]“. 
Rezipierenden. Lediglich im Folgetext, der Auslegung, die Hoffman vornimmt, wird die Polemik in der Vorrede im Nachhinein präzisiert. Bei einer chronologischen Rezeption fällt das Deutungspotential hingegen einstweilen in den Bereich des Publikums.

Nachdem Hoffman erklärt hat, dass sein Hier und Jetzt die „letzt[e] zeyt am end der vergencklichen welt“ (A2r) und eine Zeit, „als da war zů der zeit der Apostel / da gott vß goß sein heiligē geist über alles fleisch“ (A3v), sei, konstatiert er, dass es in der Geschichte immer wieder Zweifler gegeben habe, da es „von anfang an geschehen [ist] / das der hohe gottes geist nit hat mo̊gen von fleisch vnd blůt erkandt werden / sundern im ein thorheit geweßt. j. Corint. ij. also auch noch " (A 5 r). Mit dem Zusatz „also auch noch“ antizipiert Hoffman auch in Bezug auf seine Schrift und den darin verkündeten Inhalt mögliche Zweifel bereits vor der Veröffentlichung und deklariert solche Skepsis als menschliche, ja fleischliche Unzulänglichkeit, den hohen Geist Gottes zu fassen. Daran anknüpfend verurteilt er die Kritik, die er zum einen bereits erfahren hat und die er zum anderen für die Zukunft vermutet:

aber es wer ja gůt wan̄ die phariseyerische art ein ding nicht verstünd / das sye solches auch liessen vnuerlestert bleiben. Aber es ist ein solche art die un (sic!) nit anderst thůt / dann das sye nit verstan mo̊gen vnd erkennen / das sye das selbig schenden / lestern / vnnd verwerffen / verspotten vnd verspeien / vnd vnder die füß drette [...] aber an solche blinde geister / můß sich ein frummer liebhaber der warheit nit keren[.] ( $\mathrm{A}_{5} \mathrm{r}$ )

Durch die Stilisierung seiner eigenen Auslegung als Zugang zu dem hohen Geist Gottes vergleicht Hoffman die scharfen Kritiker mit Gotteslästerern. Der Gebrauch des Stigmawortes ,pharisäische $\mathrm{Art}^{\star}$ an dieser Stelle verweist der allgemeinen Verwendung in der Reformationspolemik entsprechend zum einen auf das „heuchlerische[] und scheinheilige[] Wesen[]“652 der Zweifler. Zum anderen spielt das Stigmawort - die Kenntnis des Bedeutungsrahmens in Hoffmans Polemik um I 530 bzw. in radikalreformatorischer Polemik vorausgesetzt - aber auch auf sämtliche geweihte Prediger an, denn unter den radikalen

${ }_{552}$ „Mit der Bezeichnung ,Pharisäer` als Inbegriff alles heuchlerischen und scheinheiligen Wesens folgt die Reformationszeit den Aussprüchen Christi in seinem steten Kampf mit den Schriftgelehrten und Pharisäern. Wie Christus die Frömmelei dieser Leute aufs Schärfste angriff und die Scheinreligiosität tadelte, die sich nur im Tragen langer Kleider, im Sprechen grosser Gebete und in strenger Beobachtung von Ceremonien und Fasten kundgab, so verurteilte die Reformation die Veräusserlichung der Frömmigkeit aufs Entschiedenste und nahm dabei das Neue Testament ausdrücklich zur Norm ihrer Polemik." Lepp (I908), S. 62 f. 
Reformatoren hatte sich der Gebrauch des Stigmawortes „Pharisäer oder ,pharisäisch' bereits sowohl für altgläubige als auch für evangelische Kleriker verbreitet. ${ }^{65}$

Was an dieser Stelle nur angedeutet wird, erfährt etwas später weitere Konkretisierung. Zuvor äußert Hoffman jedoch eine Reihe von aufeinanderfolgenden Bescheidenheitstopoi, ${ }^{6}{ }_{54}$ die wie die Widmung und das Rezipientenlob zu den rhetorischen Mitteln gehören, die eingesetzt werden, um „die Hörer wohlwollend, aufmerksam und gefügig zu stimmen." ${ }^{655}$ Mit der Nutzung dieser Topoi zeigt Hoffman abermals seine prozedurale Kenntnis der rhetorischen Konventionen, die er offensichtlich trotz fehlender rhetorischer Schulung zu verwenden weiß. Trotz seiner autodidaktischen Gelehrsamkeit betont Hoffman auch hier, wie so oft, bewusst seinen Laienstatus: „Vnd hab ich armer vnwirdiger Ley / vñ elender wurm auß Gotes gnaden hie zum ersten ein kleine anweisung gethon / vnd ein kurtzen durchgang / in schneller eil / so vil der gôttlich will vergünnet hat" (A6r). Zum einen hält sich Hoffman damit an die Rhetoriktradition der Bescheidenheitsbekundung, ${ }^{656}$ zum anderen deklariert er sich damit zu einem der „armen des geistes“ (A4r), die er als die Auserwählten Gottes aufzählt. „[F]rom / heilig / vnd in reichem hoffertigen geist hereiner [zu treten] “ (ebd.), ist insofern für ihn nicht möglich, ohne sich selbst theoretisch „in ewige[] verdammung / vnnd

${ }_{653}$ „Die Gegner eignen sich das Schlagwort bald an, und die Lutherischen werden als ,neue Pharisäer' gebrandmarkt.“ Lepp (I908), S. 63.

${ }^{654}$ Auf etwa einer ganzen Textseite beteuert Hoffman, dass er dem heiligen Anliegen nicht gerecht werden könne: „Vnd ich mich nicht wirdig bekē̄ / noch schetz / dz ich den ringsten silben solches schatz / vnd des hohē gòtlichen willens / rats vnd wolgefallens / von got in ero̊ffnung sol haben [...]“ (A $5 \mathrm{v})$. Das Erklären der eigenen Mangelhaftigkeit bzw. die „affektierte Bescheidenheit“ bei gleichzeitiger Huldigung an die Obrigkeit (oder z. B. das Gericht) ist schon seit der Antike eine übliche Strategie, die rednerische Demut zu beweisen. Curtius, Ernst Robert (I993): Europäische Literatur und lateinisches Mittelalter. Tübingen: Francke, S. 93

${ }_{655}$ Curtius (I993), S. 93. Aus der vorchristlichen Rhetorik übernommen, gewinnen die Bescheidenheitsformeln auch „in der lateinischen und volkssprachlichen Literatur des Mittelalters eine ungeheure Verbreitung. Bald beteuert der Autor im allgemeinen seine Unzulänglichkeit, bald seine ungebildete, rohe Sprache (rusticitas). [...] Die Autorität der Bibel bewirkte, daß der antike topos oft mit Selbstverkleinerungsformeln kombiniert wurde, die dem Alten Testament entstammen." Ebd., S. $93 \mathrm{f}$.

${ }^{656}$ Hoffman verwendet an dieser Stelle „[d]ie Devotionsformel, ,die dem Gedanken Ausdruck verleiht, daß der Aussteller seine irdische Sendung der Gnade Gottes verdanke““, „[d]ie Demutsformel“, mit der er seine „soziale Niedrigkeit“ betont, und den Topos der brevitas, der zum „Topos, dem Leser Überdruß ersparen zu wollen“ gehört. Hagenbichler, Elfriede (I992): „Bescheidenheitstopos“. In: HWRh I. ABib, Sp. I49I-I495, hier Sp. I49I \& I494. 
maledeyung / vnnd in [das] ewige[] wee“ (ebd.) zu bringen. Diese droht er nämlich den im Geiste Reichen als Strafe an, denn im Sinne eines Tertium non datur gibt es für Hoffman nur das ewige Heil oder die ewige Finsternis, die Erlösten oder die Verdammten.

Mit der dichotomischen Ausklammerung einer möglichen Grauzone setzt Hoffman die Konstruktion seines polemischen Antagonismus fort. Die Bildung einer Analogie der eigenen Welt zur biblischen Geschichte, wie z. B. zu der Apostelzeit oder der Passion Christi, bildet, wie so oft bei Hoffman, die Grundlage der Polemik gegen die ,falschen Lehrer ${ }^{\star}$ seiner Zeit:

Dan̄ ein solche zeit ist vorhanden als die gschrifft meldet / das die bůchstabische art / vñ die gschrifftgelerten yetz wiederumb Christum verspotten werden vnd verlestern / verfolgen / vnd zů kreützigen lassen überantworten / ihn den gewalt der o̊bersten / auff das jn hernach wirt bekant werden / welchen sy gestochen haben / so der sonnen glantz Christus Jesus recht auß den himmelfesten erglasten wirt. (A6v)

Wie viele Autoren von Reformationsschriften verwendet Hoffman Schlagwörter, wie ,buchstäbisch“ und ,Schriftgelehrte', die komplexe programmatische Inhalte „kondensiert“ wiederzugeben vermögen: ${ }^{657}$ Die Bedeutung des Stigmawortes bzw. Slogans der „bůchstabische[n] art" kann als eine Integration aus biblischem Sinngehalt und dem reformatorischen Kontext betrachtet werden. ${ }^{658}$ In der Bibel steht der Buchstabe häufig für das (jüdische) Gesetz (z. B. Röm 2: 27-29) aber auch für das Neue Testament. In beiden Fällen ist das Wort in einem materiellen, wörtlichen Sinn gemeint. Als Gesetz, das den Menschen von außen auferlegt wird, hat es aus paulinischer Sicht jedoch keinen Wert ohne die Verinnerlichung durch den einzelnen Menschen, „[d]enn der Buchstabe tötet, aber der Geist macht lebendig “ (2 Kor 3: 6). ${ }^{659}$ Die Dichotomie von Buchstabe und Geist ist insbesondere in dem spiritualistischen Gedankengut Hoffmans und vieler radikaler Reformatoren

${ }_{657}$ Dieckmann (I975), S. I03.

${ }_{55} 8$ Vgl. dazu Zur Linden, der von dem „bedeutungsvollen Gegensatz zwischen Buchstabe und Geist, der bisher zwischen der reformatorischen Theologiepartei und den radikalen Separatisten so vielfach erörtert worden war", spricht. Zur Linden (I885), S. 391. Insbesondere Luthers Ein Sendbrieff / von Dolmetschen / vnd Fürbitte der Heiligen von I 530 (Wittenberg) ist ein prominentes Beispiel dafür.

${ }_{559}$,[W]elcher [Gott] auch uns tüchtig gemacht hat, das Amt zu führen des Neuen Testaments, nicht des Buchstaben, sondern des Geistes. Denn der Buchstabe tötet, aber der Geist macht lebendig. “ www.bibel-online.net, nach Luther I9I2. 
zu finden. ${ }^{660}$ In Kombination mit der Stellung des einfachen Schriftsinns und der wörtlichen Auslegungspraktik der lutherischen Reformatoren, funktioniert das Schlagwort als Kritik der auf den Literalsinn begrenzten Exegese und deren Befürworter, ${ }^{66}$ die in Hoffmans spiritualistischer Sichtweise eine ungeistige, äußerliche und von daher zu verwerfende Praxis bedeutete.

Das Schlagwort ,Schriftgelehrte' ist in engem Zusammenhang mit dem Gebrauch von ,Pharisäer ${ }^{6}$ zu betrachten. ${ }^{662}$ Als Hinweis auf die Verfolger und Kreuziger Jesu Christi besitzt das Schlagwort eine negative Konnotation, ${ }^{663}$ die sich in Hoffmans Polemik auf sämtliche theologische Gelehrte seiner Zeit bezieht, und wird insofern als Stigmawort eingesetzt. Für Hoffman-Kenner war diese Deutung voraussichtlich die naheliegende, aber auch für andere Rezipienten war es mit Kenntnis der Reformationspolemik generell erschließbar, dass es sich um Theologen handelt, denen Hoffmans Polemik gilt: ${ }^{64}$ Insbesondere durch die per-

${ }^{660}$ Vgl. dazu: „Die Spiritualisten standen in der Tradition eines Denkens, das die äußeren Dinge, den Buchstaben der Heiligen Schrift, die Elemente des Abendmahls, die Rituale und Ordnungen der Kirche, vergeistigte. [...] Der Verkehr des Menschen mit Gott, darauf kam es letztlich an, vollzog sich ausschließlich im Inneren des Menschen“. Goertz (I993), S. 36. Vgl. z. B. auch Sebastian Francks Auffassung der Bibelauslegung, siehe Dellsperger, Yvonne (2008): Lebendige Historien und Erfahrungen: Studien zu Sebastian Francks „Chronica Zeitbuoch vnnd Geschichtsbibell“. Berlin: Erich Schmidt, S. 58-63.

${ }^{66}$ Lepp und Diekmannshenke erwähnen das Wort ,buchstäbisch“ nicht in ihren Arbeiten. Es ist jedoch berechtigt, es zu den Schlagworten zu zählen, da es in den Schriften radikaler Reformatoren, z. B. bei Hans Denck, immer wieder in gleicher Bedeutung anzutreffen ist und es einen programmatischen Sinngehalt besitzt.

${ }^{662}$ Nicht selten tauchen sie gleichzeitig auf - auch im Neuen Testament werden sie meist zusammen genannt (z. B. Mt 23) - und liegen in ihrer Bedeutung sehr nahe. ,Pharisäer' kann sowohl als Stigmawort als auch als Schimpfwort betrachtet werden. In der Reformation hat es oft Stigmawortcharakter, da es häufig eine programmatische Bedeutung trägt, die über den Schimpfwortcharakter hinausgeht.

${ }^{663}$ Die Kritik speist sich aus den Vorwürfen, die Jesus den Schriftgelehrten seiner Zeit machte: „[S]o wirft ihnen Jesus vor allem fehlende Demut (Mt 23,5ff uö), fehlende Selbstlosigkeit (Mk I2,4Oa) und fehlende Wahrhaftigkeit (Mk I2,4ob uö) vor. Sein härtester Vorwurf aber ist der, daß sie selbst nicht tun, was sie in Lehre und Predigt fordern (Lk I I,46 uö). “ Diekmannshenke (I994), S. I42 (Diekmannshenke zitiert hier aus: Theologisches Wörterbuch zum Neuen Testament. Hg. von Gerhard Kittel, Bd. I, S. 742).

${ }^{664}$ „Grundvoraussetzung ist nur, daß in der aktuellen Kommunikationssituation sowohl bei Sender als auch Empfänger das Verständnis für eine bestimmte Anreicherung des Begriffs vorhanden ist." Honecker, Patrick (2003): Vorreformatorische Schlagwörter. Spiegel politischer, religiöser und sozialer Konflikte in der frühen Neuzeit. Diss. Univ. Trier. URL: http://ubt.opus.hbz-nrw.de/volltexte/2004/I49/ pdf/2002I2I2.pdf (I8.I0.20I 5), S. 2 I. 
formativ umdeutende Zitation Müntzers wurde die Verwendung „gegen die Reformatoren als die ideologischen Rechtfertiger der bestehenden Gesellschaftsordnung " dominant. ${ }^{665}$

Die bipolare Einteilung in gute und schlechte, auserwählte und verdammte Menschen kulminiert bei Hoffman schließlich in einer antithetischen Gegenüberstellung. Zunächst beschreibt er die ,falschen Lehrer', von denen

etliche seindt schon vffgeplasen / vnd ein reichen hoffertigen vollē geist hand ererbet vnd erlanget / in welchem geist gar kein ware Gottes lieb / noch forcht herrschet noch wont / vn̄ von jn auch nicht der preiß Gotes gesůcht wirt / sonder solche sůchen jhren preiß / pracht / eer / statt / gelt / gůt / vnd der gleichen[.] (A7r)

Direkt anknüpfend an die abwertende Beschreibung derjenigen christlichen Lehrer, die nach weltlichem Ruhm und Reichtum streben, nennt er die

treüwen Apostolischen hirten vnd lerer[] [...] Gottes knecht[] / vnd diener Christi Jesu / die yetz in hohen gottes forchtē vnd in ernsthaffter lieb die herd Christi weyden / vn̄mit aller glassener geistligkeit mit d[er] herd vffwachsen in festem eifer nach der warheit vnd gerechtigkeit[.] (Ebd.)

Diese gottergebenen Lehrer stehen den erstgenannten diametral gegenüber: Erstere haben „ein reichen hoffertigen vollē geist“, Letztere „glassene[] geistligkeit“. Wo bei den an weltlichen Gütern orientierten Lehrern „gar kein ware Gott lieb / noch forcht herrschet noch wont“, weiden die „Apostolischen hirten“ ihre zu bewachenden Schäflein „in hohen gottes forchtē vnd ernsthaffter lieb “, und während die einen lediglich ,jhren preiß / pracht / eer / statt / gelt / gůt / vnd der gleichen “ suchen, streben die anderen „in festem eifer nach der warheit vnd gerechtigkeit" (ebd.). Durch die antithetische Gegenüberstellung entsteht die Polemik - zunächst gegen eine nicht definierte Gruppe theologischer Leitfiguren, die erst im Haupttext einerseits als Altgläubige und andererseits als Lutheraner konkretisiert werden. ${ }^{666}$

${ }_{665}$ Diekmannshenke (I994), S. I43.

${ }^{666}$ Beispielsweise legt Hoffman Kapitel 22: I 5 („Dann heraussen seind die hundt / vnd die zauberer / vnnd die hůrer / vnnd die todtschlager / vnnd die gôtzen eerer / vnnd alle die lieb haben vnnd thůnd die lugen“ $\left[Z_{3} v\right]$ ) wie folgt aus: ,[...] vnnd seind die hundt geistliche hundt / die da Gottes warheit verfolgen / vnd dar wider schreyen vnd bellen / vnnd ist nitt solches allein vß des Bapsts hauffen / sundern vß solchen / die sich yetz für die ersten lerer der Christen vß geben $[\ldots]$ “. $\left(\mathrm{Z}_{3} \mathrm{v}-\mathrm{Z}_{4} \mathrm{r}\right)$. 
Hoffman polemisiert demnach hier nicht nur indirekt in Hinsicht auf die polemische Situation, die in der Vorrede konstruiert wird, sondern er lässt auch das polemische Objekt vorerst indeterminiert und simuliert einen großen Definitionsspielraum. Die Gründe für die undefinierte Polemik in der Vorrede liegen höchstwahrscheinlich in der direkten Anrede einer Person hohen Ansehens. Der Widmungsempfänger und textinterne Adressat, König Friedrich I. von Dänemark, nimmt in der Kommunikationssituation der Polemik die Rolle der polemischen Instanz ein bzw. bildet eine von zwei relevanten polemischen (Teil-) Instanzen. Die Anrede der königlichen Hoheit vermag die sonst so scharfe und personalisierte Polemik Melchior Hoffmans in diesem Fall zu mäßigen. Es geht weniger um konkrete Imagezerstörung der gegnerischen Partei als um seine „fleissige hòchste bitt an [die] Künigliche M[ajestät]“ (A6r),

das solchen nit statt werd gegeben / ihn disen ferlichen geschwinden leuffen / die da rat oder that geben / das man yetz vmb des glaubens willen yemandts soll verfolgen / dañ es in der warheit nit ist der ware gôtlich weg der gerechtigkeit / dieweil der glaub ein gab Gotes ist / vnd nicht des menschen / noch auß dem willen des selben / sonder allein auß gootlicher erbarmung / aber wa übelthat ist / da ist ein yeder diener des schwerts treüw in seinem ampt / Gott den allmechtigen / vnd seinē herren / der jn zů solchem verordnet hat. (A6r)

Hoffmans Gesuch, niemanden für seinen Glauben zu verfolgen, entspringt zum einen aus seiner Zeit, in der die Todesstrafe für Andersdenkende, wie z. B. für Wiedertäufer oder Antitrinitarier schnell als Urteil gefällt wurde, zum anderen aus seinen eigenen Erfahrungen als mehrfach Vertriebener. Die Aussage Hoffmans, wann ein „diener des schwerts" zu agieren habe und wann nicht, hat auch hier performative Funktion: Sie ist weniger Feststellung einer Gegebenheit als ein Versuch, diese Realität erst ins Leben zu rufen.

Die bezüglich des polemischen Objekts undefinierte Polemik übernimmt in diesem Zusammenhang die Aufgabe, die führenden Theologen in ein schlechtes Licht zu rücken, ohne die Polemik augenfällig erkenntlich zu machen. Der polemische Zweck wird als Anliegen, eine „fleissige treüwe ermanung / v̄ auch warnung “ (A6r) auszusprechen, inszeniert. In Kombination mit der sich daran anschließenden polemischen Auslegung des biblischen Buchs der Offenbarung des Johannes lässt sich die in der Widmungsvorrede nur indeterminierte Polemik gleichwohl entschlüsseln. 


\subsubsection{Polemische Legitimationsstrategien in der Vorrede ohne Widmung}

Im Gegensatz zu der Widmungsvorrede der Außlegūg der heimlichē Offenbarung, in der Polemik indeterminiert und in gemäßigtem Ton geäußert wird, scheint die Vorrede ohne Widmung bei Hoffman zum Teil ein Ort scharfer und personalisierter polemischer Attacken zu sein. Diese auf ersten Beobachtungen basierende These wird im Folgenden detaillierter erörtert. Es wird dabei untersucht, ob und inwiefern Zusammenhänge zwischen Widmung, salutatio und Polemik erkennbar sind. Welche Form die Polemik in der Vorrede ohne Widmung bei Hoffman annimmt und welche Funktion sie erfüllt, sind weitere Gesichtspunkte der Analyse.

Auf Basis der Fragestellungen sind insbesondere drei Schriften Hoffmans hervorzuheben, da ihre Vorreden einen sehr hohen Anteil polemischer Züge aufweisen: Zum ersten Das freudenreiche zeucknus vam worren friderichen ewigen evangelion, ${ }^{667}$ zum zweiten Een waraftighe tuchenisse vnde gruntlyke verclarynge ${ }^{668}$ und zum dritten Vā der

667 Hoffman, Melchior (I532): Das freudenreiche zeucknus vam worren friderichen ewigen evangelion, Apoc. I4, welchs da ist ein kraft gottes, die da sallig macht alle die daran glauben, Rom. I, welchem worren und ewigen evangelion itzt zu disser ketzten zeit so vil dausend sathanischer geister mit falscher ketzerischer irriger lugenhaftiger zeucknus gegenstandt. [Straßburg?: o. Dr.]. Kurztitel: Das freudenreiche zeucknus. Das Original verbrannte laut Röhrich I870 in der Straßburger Stadtbibliothek. Siehe dazu TAE I, Nr. 298, S. 4I If. Auszüge in Zur Linden (I 885 ), S. 429-432. Zur Linden fügt hinzu: „Das Schriftchen umfasste in der auf der Bibliothek zu Strassburg verbrannten Originalausgabe 7 Blätter in $4^{\circ}$. Auf dem Titelblatte befand sich von alter Hand die Notiz: Durch Melchior Hofman im sinodo überantwortet.“ Ebd., S. 429, Anmerkung I. Die Quellenangaben bei Zitaten werden mit den Initialen FZ und der Seitenangabe aus Zur Linden (I 885 ) der Übersichtlichkeit halber in Klammern gestellt.

${ }^{668}$ M. H. [i. e. Melchior Hoffman] (1532): Een waraftyghe tuchenisse vnde gruntlyke verclarynge wo die worden tho den Ro. ix. Ca. van dē Esau vī Jacob soldeē verstaen worden / teghen den falschen / kettersschen / dwalenden / lugenhaftygen / sathanysschē / ingevorden verstant / des Luterschen vnde zuyngelshen hupen. [Deventer: Albert Paffraet]. Eine Paginierung ist auf Blatt A5r vorhanden, so dass folgende Folienzählung angenommen wird: AIr-B2v (AIr = Titelblatt, A2v \& B2r-v leer, I6 Textseiten). Kurztitel: Een waraftyghe tuchenisse. Die Quellenangaben bei Zitaten werden mit den Initialen EWT und der Folienangabe der Übersichtlichkeit halber in Klammern gestellt. Diese Schrift ist höchstwahrscheinlich dem ostniederländischen Sprachraum zuzurechnen. Gronisch-friesische und westfälische Spracheinflüsse scheinen ebenfalls vorhanden. Eine exakte sprachliche Einordnung kann hier nicht geleistet werden. Es ist zu vermuten, dass die vorliegende Schrift die Übersetzung einer (nicht erhaltenen) hochdeutschen Vorlage ist, da die zitierten Anfangsworte des „andern büchlin“, das im „Gutachten einer 
ware hochprachtlichen eynigen magestadt. ${ }^{669}$ Sämtliche drei Schriften sind entweder mit der Jahresangabe I 532 versehen oder werden auf dasselbe Jahr datiert. ${ }^{670}$ Sie können zudem allesamt als Traktate bezeichnet werden, da sie jeweils hauptsächlich eine einigermaßen eingrenzbare religiöse Fragestellung behandeln.

Die beiden erstgenannten Schriften argumentieren gegen die Prädestinationslehre. Hoffman lehnt den Gedanken ab, dass die

eigens dazu ernannten Synodal-Kommission über die in der Juni-Synode eingereichten Schriften von Hofmann und Schwenckfeld“ (I 533) genannt wird, fast exakt mit den Worten aus Een waraftyghe tuchenisse übereinstimmen: „,Es vermeint der blind, bestrickt, verstockt, jrrig, falsch, ketzerisch, lugenhafftig, luterisch, zwinglisch, schrifftgeleert hauff', etc.“. TAE II, Nr. 444, S. I 82-I93, hier S. I 82-I 84. Bis auf das Wort „schrifftgeleert“ sind die Anfangsworte der niederländischen Schrift semantisch identisch mit dem im Gutachten zitierten Wortlaut (anstatt „jrrig“ steht dort allerdings, wie im Titel, „dwalende“). Diese hohe Übereinstimmung könnte entweder ein Hinweis auf eine hochdeutsche Vorlage sein oder stellt eine ungenaue Übersetzung dieser Schrift dar (Letzteres ist Deppermanns Vermutung, siehe TAE IV, Nachträge, S. 505). Dessen ungeachtet widerlegt die große Ähnlichkeit des obigen Zitats der Täuferakten mit dem Wortlaut der Schrift Een waraftyghe tuchenisse die Annahme, dass es sich um die nicht erhaltenen Anfangsworte der Schrift Das freudenreiche zeucknus handelt. Siehe dazu TAE II, Nr. 444, S. I 83 , Anmerkung 3. Dass die niederländischen Schriften Übersetzungen seien, begründet Deppermann mit dem durchweg „sprachlich viel höheren Niveau“ im Vergleich zu den deutschen Schriften Hoffmans sowie anhand von „ständig wiederkehrende[n] grammtische[n] Fehler[n] in Hoffmans niederländischen Schriften “. Deppermann (I979), S. 287, Anmerkung 32. Siehe auch Cramer, Samuel (I909): Nederlandsche Anabaptistica (geschriften van Henrick Rol, Melchior Hoffman, Adam Pastor, De Broederlicke vereeninge) (= Bibliotheca Reformatoria Neerlandica 5). 's-Gravenhage: Nijhoff, S. I74.

${ }^{669}$ Hoffman, Melchior [1532?]: Vā der warē hochprachtlichen eynigen magestadt [= Majestät] gottes / vnnd vann der worhaftigen menschwerdung des ewigen worttzs vnd Suns des allerhochstē / eyn kurtze zeucknus vī anweissung allen liebhabern der ewigen worheit. [Deventer: Albert Paffraet]. Eine Paginierung ist auf Blatt BIr und B2r vorhanden, so dass sich folgende Folienzählung ergibt: Aır-B8r (A Ir = Titelblatt, B8v leer). Kurztitel: Magestadt gottes. Die Quellenangaben bei Zitaten werden mit den Initialen $M G$ und der Folienangabe der Übersichtlichkeit halber in Klammern gestellt.

${ }_{670}$ Magestadt gottes besitzt keine Jahresangabe, es wird aber das Jahr 1532 als Publikationsjahr angenommen. Siehe z. B. Deppermann (I979), S. 348. Da die Schrift auch bei Albert Paffraet in Deventer gedruckt wurde (der Vergleich mit Een waraftyghe tuchenisse zeigt, dass es sich um denselben Drucker handelt), ist das Erscheinungsjahr I 532 zudem naheliegend. Deppermann nimmt aufgrund der niederländischen Traktate an, dass Hoffman sich zu der Zeit in den Niederlanden aufhielt, gibt aber fälschlicherweise an, dass Hoffman ausschließlich niederländische Traktate in der Zeit veröffentlicht habe. Deppermann (I979), S. 286f. Deppermann vergisst offensichtlich die hochdeutsche Schrift Magestadt gottes. Gleichwohl bestätigt der Druckort Deventer die Niederlande als Aufenthaltsort Hoffmans. 
Menschen bereits bei Geburt für die Erlösung oder Verdammnis vorbestimmt sind, und konstatiert die grundsätzliche Seligsprechung aller Menschen durch Gott. Lediglich der freie Wille des Menschen könne ihn in die Verdammnis treiben, denn wenn er zum Bösen tendiere, nachdem er „erleuchtet“ worden sei, sei jegliche Erlösung unmöglich. Insofern sei nicht Gott für die Verdammnis verantwortlich, „sunder allein der fel am menschen ist und auch ewig sein würt, so das er mer geliebet würt haben die finsternus dann das worre und ewige liecht [...]“ (FZ, S. 430). ${ }^{67 \mathrm{r}}$

In der drittgenannten Schrift wird zunächst das „26. gesicht der prophetin Vrsula“ abgedruckt, ${ }^{672}$ das Hoffman als Bestätigung seiner monophysitischen Christologie sieht, denn er ist der Auffassung, Christus


tes geist vnd muth / ia der sun des aller höchsten / vnd das ewige wort gottes selber" (MG, A 5 r). Die Überzeugung, dass Jesus Christus nicht menschlicher Natur, sondern das verkörperte Wort Gottes sei, erklärt und diskutiert Hoffman dann - wie bereits oben erwähnt - nachfolgend auf mehr als 27 Seiten anhand einer Vielzahl von sowohl alt- als auch neutestamentlichen Bibelstellen, indem er z. B. die Gegenfrage klärt, wieso geschrieben stehe, dass „christus JEsus auß dem samen Dauids geboren sey“ (MG, BIV).

\section{Die unsichtbare polemische Instanz bei indirektem Polemisieren}

Bei näherer Betrachtung der Polemik in den drei Traktaten fällt zunächst auf, dass in den Vorreden ausschließlich die Form des indirekten Polemisierens vorkommt: Es wird durchgehend in der 3. Person über das polemische Objekt - hier stets der ,lutherische und zwinglische Haufen“ (FZ, S. 43I) bzw. der „Lutersche vn̄ Zuyngelsche hupe “ $(E W T, A 2 r)$ - gesprochen. Interessanterweise trifft man die

\footnotetext{
${ }^{671}$ Vgl. auch: „Tho den. i Js dat vaste onwādelbare ewige onentlike tuchenisse der ewigen waerheit dat God alle menschen tho der salichkeit geschapēheft / ia ock niet een enigen wtgename $/ \mathrm{v} \bar{n}$ see ock met ganssen eerrenste alle tho der eewigen salicheit begeret." (EWT, $\left.\mathrm{A}_{3} \mathrm{r}\right)$.

${ }^{672}$ Zuerst wird in kurzen Sätzen die Erscheinung Ursulas beschrieben: Ein Licht, das sich in drei Lichter (übereinander) geteilt habe. Im mittleren Lichtschein sei das Gesicht eines Neugeborenen zu sehen gewesen. Dann vereinten sich die Lichter wieder und verschwanden. Auf diese Beschreibung folgt die Interpretation der Erscheinung: „Diß edle vn̄ hohe gesicht / weisset yhn einer kurtzē sum waß die helgē dreyfaltigè einigē gotheit sey“ (MG, A2v).
} 
direkte Anrede in den Vorreden ohne Widmung überhaupt nur selten an, so dass selbst die polemische Instanz auf der Textebene nicht als direkter Adressat konstruiert wird. Gleichwohl kann eine Ansprache der Leserschaft in den Begrüßungsworten von Een waraftyghe tuchenisse und Magestadt gottes in der 3. Person beobachtet werden: Den zeitgenössischen Konventionen durchaus entsprechend hält Hoffman die salutatio förmlich, indem er sowohl sich selbst als auch die begrüßten Leser in der grammatischen 3. Person nennt. ${ }^{673} \mathrm{Im}$ Gegensatz $\mathrm{zu}$ den meist nur wenige Zeilen umfassenden Begrüßungsworten wird eine Leserschaft in den darauffolgenden Vorreden nicht auf der Textebene angelegt, sondern verbleibt eine im Text unsichtbare Instanz. Formal betrachtet führt Hoffman demgemäß auf der Textebene einen Monolog. Einen offenkundigen Adressaten, wie z. B. den Widmungsempfänger in der Außlegūg der heimlichē Offenbarung, gibt es hier nicht.

Ausgehend von diesem Befund fällt auch bei weiteren vergleichenden Beobachtungen der Texte Hoffmans gemeinhin auf, dass es einen Zusammenhang zwischen der Präzisierung des Empfängers in der salutatio und der direkten Anrede der polemischen Instanz gibt: Existiert ein namentlich genannter Widmungsempfänger oder ist die Gruppe der ,Begrüßten“ durch eine konkrete Bezeichnung eingegrenzt, so wird zumeist auch derselbe Adressat in der Vorrede konstruiert. ${ }^{674}$ Bei den Vorreden ohne Widmung, die zudem einen sehr allgemein gehaltenen Empfängerkreis, wie z. B. „alle[] glaubigē liebhaber[] der worheit vnd gottlichē gerechtikeit" (MG, AIv), angeben, verbleibt die Vorrede auf der Textebene in der Regel unadressiert. Die Folge davon ist eine Verallgemeinerung der polemischen Situation: Das polemische Objekt soll von allen verworfen werden, nicht nur von einem ausgewählten Kreis.

${ }^{673}$ „Melchior Hoffman ein knecht des aller hochsten [...] wūschet allen glaubigē liebhabern der worheit vnd gottlichē gerechtikeit / Gnad / vnd frid vnd das ewige heyl.“ Hoffman [1 532 ?], Magestadt gottes, Arv. Eine fast wortgetreue salutatio ist in Een waraftyghe tuchenisse (A2r) auf Niederländisch zu finden. Dort gibt Hoffman jedoch lediglich seine Initialen M. H. an.

${ }^{674}$ In seiner Daniel-Auslegung ( 1526 ) beispielsweise richtet sich Hoffman in der salutatio an die ,außerwelten gottis heyligen inn Lieflandt / vnd forrnemlich den geliebtē zu Derpten“ (Iv), die er auch nachfolgend weiter direkt anspricht: „[...] lieben fründe in Christo / próbet ein yden geist [...]“ (ebd.). Die direkte Anrede der Liefländer wird in der Vorrede konstant benutzt. 


\section{Polemische Exordialtopoi}

Das polemische Ziel, die Imagezerstörung des polemischen Objekts (vor den Augen der polemischen Instanz), wird in den Vorreden insbesondere mit den Eigenschaften der Textsorte verwoben. In allen drei Schriften sind dementsprechend Exordialtopoi zu finden, die sich mit der Polemik paaren: Ihre Wirkung entfaltet sich im Wechselverhältnis mit der Polemik. In der Vorrede von Das freudenreiche zeucknus findet man z. B. Formulierungen über mehrere Zeilen, die man ohne Probleme als ,polemischen Exordialtopos' bezeichnen könnte:

Die weil ich nu mit offendlicher erfarenheit deglich merck sich und erken, das gar kein vermanen schreiben leren, süsses noch saures, an dem lutherischen und zwinglischen haufen helfen wil oder geholfen hat, sunder in solchem fal nur noch erst vil tiranischer mutwilicher halsstarricher und herter geworden seint, $\mathrm{dz}$ sie auch gantzs ernstlich vermeinen, irer lügenhaftigen ler und sathanischer ketzerischer zeucknus mit nichten abzustan, sunder mit tiranischer gewalt ein solchen saurdeig menschliches drecks und gestancks zu erhalten, derhalben ist mein Muth auss gottes gnaden gar fleissig gericht und gesinet, in einem solchen grad dem Luthrischen und Zwinglischen haufen all irren ketzerischen irthom gantzs grundlich in alle weg aufzudecken etc. $(F Z$, S. $429 \mathrm{f})$

Bereits der Einstieg („Die weil“) kündigt einen kausalen Zusammenhang an: Hoffman liefert eine Begründung für die Entstehung des folgenden Textes und sein damit verbundenes diskursives Eingreifen. Er legitimiert sein Schreiben und wertet es gleichsam auf, indem er es als Notwendigkeit darstellt, die sich aus den äußeren Umständen ergibt. Bei gleichzeitiger Abwertung der „lutherischen und zwinglischen haufen“, die sich durch keinerlei „vermanen schreiben leren, süsses noch saures“ davon abbringen ließen, ihrer „lügenhaftigen ler und sathanischer ketzerischer zeucknus [...] abzustan, sunder mit tiranischer gewalt ein solchen saurdeig menschliches drecks und gestancks zu erhalten“ versuchen, stilisiert Hoffman sich selbst als uneigennützig. Er betont insbesondere, wie er sich der Verantwortung stelle, die ihm Gott auferlegt habe. Mit seinen Formulierungen setzt er auf den gebräuchlichen Topos „der Besitz von Wissen verpflichtet zur Mitteilung “. ${ }^{675}$ Der Topos funktioniert zum einen als Charakterisierung Hoffmans als vir bonus und zum anderen als Aufwertung des Geschriebenen und fungiert so

${ }_{75}$ Curtius (I993), S. 97. 
als captatio benevolentiae. Das Wissen, an dem Hoffman die Leser teilhaben lassen will, beinhaltet nicht nur die konkreten Punkte der „ketzerischen irthom “ der Lutheraner und Zwinglianer, sondern auch den polemischen Antagonismus und die damit verbundenen oppositären Freund- und Feindimages: Die Leser sollen laut Hoffman wissen, dass die Lutheraner und Zwinglianer Lügen verbreiten und trotz seiner schriftlichen Bemühungen „nur noch erst vil tiranischer mutwilicher halsstarricher und herter geworden seint".

Mittels dieser Darstellung legitimiert Hoffman nicht nur sein Schreiben an sich - schließlich ist dieses Anliegen „auss gottes gnaden " entstanden -, sondern auch seinen unverblümt polemischen Ton. Wie zuvor in der Kontroverse mit Nikolaus von Amsdorf kommentiert Hoffman damit implizit die Regeln der Streitkultur: Er greift der Antizipation einer Grenzüberschreitung vorweg, indem er nachstehende Regelverletzungen einerseits mit der Belehrungsresistenz seiner Gegner und andererseits mit seinen guten Absichten als regelkonform rechtfertigt. Insofern ist es nicht überraschend, dass die Schrift auch im Haupttext polemisch bleibt. Vermutlich um die Gunst der Leser zu sichern, verwendet Hoffman auch dort Strategien zur Legitimierung seiner Polemik:

Ich habe nun in das dritte jar geschrien und den preiss Gottes begert, aber ich sich ir noch nit die die warheit begeren zu hören. Darum will ich auch schreiens nit aufhören, sunder schelten straffen und schrein das himmel und erden erbidmen sol, so lang biss das dem hohen Gott sein preiss und ehr wieder geleuffert und dargereicht werde. (FZ, S. 43 If $)$

An dieser Stelle setzt Hoffman nochmals gesteigerten Pathos ein, indem er den Topos des Gotteslobs mit ins Spiel bringt und seine Bemühungen als dramatische Handlung - „schrein das himmel und erden erbidmen sol“ veranschaulicht. Sein „schelten straffen und schrein“, das besonderen Nachdruck durch die Alliteration bekommt, wird erneut, hier durch die aus christlicher Perspektive höchste Maxime der Preisung des Herrn, legitimiert.

\section{Das inszenierte Urteil der Obrigkeit als polemische Ermächtigung}

Während Hoffman in Das freudenreiche zeucknus lediglich andeutet, dass seine Gegner sich u. a. tyrannisch aufführen, erklärt Hoffman in Een waraftyghe tuchenisse konkreter, wie er zu dieser Auffassung kommt: Nicht nur benutzen sie ihr eigenes ,valsche[s] zueert [= Schwert]“ 
(EWT, A2r), sondern sie rufen auch das „werklike zueert“ (ebd.) der Obrigkeit zu ihrer Hilfe:

daer moet dan de bodel eñ hēker date beste doen / vnde de disputacio vorder met den armen Godes tugen vollenbrengē / Ja met veriagen / berouen / ryten / stocken / blocken / myt hunger / brant / fuer / water / zweert / galgen / vñ der gelijken mennigerlei[.] (Ebd.) ${ }^{676}$

Erst nachdem Hoffman hier mittels einer sich steigernden Aufzählung die Missetaten seiner Gegner und sich selbst durch den Opfertopos dargestellt hat, verwendet er - für das niederländische Publikum - ähnliche Formulierungen wie in der hochdeutschen Schrift Das freudenreiche zeucknus: Er stellt die Lutheraner und Zwinglianer als Lügner dar und berichtet davon, dass er gegen diese „Zeugen der ewigen Unwahrheit“ bereits gekämpft habe. Doch habe er in den Jahren, die er gegen sie vorgegangen sei, keine Besserung an ihnen erreichen können. Sie seien sogar nur „erger en [= und] tijrannischer geworden“, sie möchten Hoffman töten und ins Gefängnis werfen, so dass nur die Gnade Gottes, seines Herrn, ihn davor bewahrt habe, in die Hände seiner Gegner zu fallen. ${ }^{677}$ Auch hier erklärt Hoffman, dass er bereits Jahre gegen sie gekämpft habe, während sie ihn nur noch mehr verfolgen würden, um dann strategisch zum Gegenschlag auszuholen:

Aadermael / Ick see datt et niet anders syn mach / bin Ick bereit in alle wege den Lutersschē eñ ock den Zwingelscen hupen. alle hoer dwalinge / gans apentlick voer al de werrelt optodecken / vp dat alle de werrelt. hoer doerheit seen mach". (EWT, A2v) $)^{678}$

${ }^{676}$ „da muss dann der Büttel/Gerichtsdiener und Henker das Beste tun, und die Disputation zuvor mit dem armen Zeugen Gottes zu Ende bringen, ja mit Verjagen, Berauben, Reißen, ins Gefängnis Werfen, mit den Füßen an den Block Fesseln, mit Hunger, Brand/Verbrennen, Feuer, Wasser, Schwert, Galgen und dergleichen mehr“.

677 „Ja voer den morderscehn [sic!] bloetsuperschē bosen meer [...] welker morderssche thugē der ewigen onwaerheit Ick gaer flitich vnde mennichuoldich [ver]focht hebbe / Ja ock met eerenste ytlike iaer. hier heer. aengestotē hebbe / of see syk wolden beteren / mer alles gaer niet geholpē heft. nu eerst volle erger ē tijrannischer geworden sint / dat sie ock heftich of flitich trachtē Ho se mij armen in die hellekule des dodes stotē mochten / in geuankenisse met eewige bandē / de hogeste ende groeste gnade solde syn Heer de barmhartoge godyge God vn̄ vader / synen armen knecht $\mathrm{v} \overline{\mathrm{n}}$ dener niet in horen handē heft kommen laten " $\left(E W T, \mathrm{~A}_{2} \mathrm{v}\right)$.

${ }_{778}$ „Da ich erneut sehe, dass es nicht anders geht, bin ich bereit, den lutherischen und zwinglischen Haufen in jeder Weise sämtliche ihrer Irrtümer ganz öffentlich vor der Welt aufzudecken, auf dass alle Welt ihre Torheit sehen mag.“ 
Auch in der niederländischen Schrift bedient sich Hoffman einer ähnlichen Formulierung und des gleichen Exordialtopos, Wissen verpflichtet zur Mitteilung'. Der Anlass seines Schreibens wird auch hier als Aufdecken der Irrtümer seiner Gegner inszeniert. Nachfolgend kündigt Hoffman sogar an, dass er auch bereit sei, sich auf einem Konzil zu verteidigen und sich gegenüber der Obrigkeit zu verantworten: „vnde woer ick anders dan in waraftige getuchenisse geuōdē worde / so heft geordineerde gewalt Godes. vnde keiserlike macht / dat zuueert vnde ick dē hals “ (ebd.). ${ }^{679}$ Hoffman macht hier von der gleichen Strategie Gebrauch wie bereits I $_{52} 8$ in Nasen geist: Indem er ein Konzil bzw. eine Art Gerichtsverhandlung vorschlägt, in der seine Lehre von der Obrigkeit beurteilt und eventuell mit dem Tod bestraft werden soll, nimmt er eine positive Bewertung seiner Lehre und dessen Wahrheitsgehalt bereits vorweg und inszeniert sich auf diese Weise als Märtyrer. Dass Hoffman dieses Angebot lediglich als Strategie verwendet, wird daran ersichtlich, dass er nur wenige Zeilen später erklärt, dass sich das Schwert der Obrigkeit alsbald gegen die Lutheraner und Zwinglianer richten wird, „want se moten voer alle de werrelt tho scanden staen / dat see lasterlijke logenaftige tugē tegen de hoge maiestat Godes vñ tegen de onentlike ewige waerheit gewast synt" (EWT, A3r). ${ }^{680}$ Hoffman bringt hier erneut die Obrigkeit mit ins Spiel und inszeniert ihre Unterstützung, indem er seine eigene Auffassung, dass die Lutheraner und Zwinglianer von der Welt geächtet werden sollen, als allgemeines Gedankengut bzw. als Standpunkt der Obrigkeit ausgibt.

Durch die Form des indirekten Polemisierens ist diese Objektivierung möglich, denn mit einer direkten Anrede würde auch die Figur des sprechenden Ichs auf Hoffman verfallen. Dadurch, dass Hoffman weder ein ,Ich“ noch ein ,Du', sondern nur die 3. Person für sowohl das polemische Objekt als auch die Obrigkeit einsetzt, entstehen ausschließlich „Verweis-Räume“681 außerhalb der Kommunikationssituation. ${ }^{682}$ Das polemische Subjekt nimmt sich dadurch zurück, während die

679 „und sollte es mir nachgewiesen werden, dass ich etwas anderes als wahre Zeugnisse ablege, so hat die von Gott eingesetzte Gewalt und kaiserliche Macht das Schwert und ich den Hals."

680 „denn sie müssen vor aller Welt dafür in Schande stehen, dass sie lasterhafte, lügnerische Zeugen wider die hohe Majestät Gottes und wider die unendliche ewige Wahrheit gewesen sind“.

68. Schwitalla (2010b), S. I 64.

${ }^{682}$ Die grammatische 3. Person ist in der Kommunikation zunächst eine theoretisch abwesende Kategorie (die Anwesenheit dieser Person ist allerdings praktisch möglich). Vgl. Gehling, Thomas (2004): ,Ich', ,du' und andere. Eine sprachtypologische 
Obrigkeiten als Akteure in den Vordergrund rücken, so dass die Aussage mit ihnen in Verbindung gebracht wird und nicht mit Hoffman.

Hoffman setzt an dieser Stelle eine Situation als Realität in Szene, die der religionspolitischen Lage um I 532 nicht entspricht. ${ }^{683}$ Für die Beeinflussung des intendierten Publikums vermag dieser Bruch mit dem Kontext kein Problem dargestellt zu haben, da ein potenzielles, von Hoffmans Anhängern erwünschtes Szenario entworfen wird, das im Text durch seine Performativität gleichsam als Legitimation durch die Obrigkeit dient. So rechtfertigt Hoffman sein (polemisches) Schreiben nicht nur als von Gott auferlegten Kampf gegen das tyrannische Verhalten der Lutheraner und Zwinglianer, sondern er schreibt sich im wörtlichen Sinne auch den Beistand der weltlichen Gewalt zu.

\section{Seelsorge als De-Inszenierung des Streits}

In der Vorrede von Magestadt gottes legitimiert Hoffman sein Schreiben damit, dass er ein seelsorgerliches Anliegen als Hauptmotivation in Szene setzt. Er entwirft für diesen Zweck den Antagonismus nicht zwischen sich selbst und seinen Gegnern, sondern zunächst ganz allgemein zwischen den Gelehrten und den ,Armgeistigen'. Auch hier polemisiert er indirekt, da insbesondere die generalisierenden Aussagen durch das indirekte Polemisieren den Anschein der Objektivität erhalten. In einem narrativen Stil erklärt Hoffman:

Es ist zu disser farlichē letzstē zeitt / am end der vorgencklichē welt / der althar / vnd der disch des allerhochstē gantzs villē yhn ein falstrick gerothen / ia auch darzu in ein verblindnusz vnd ergernus / vnd zum stein des anlauffs / das auch die aller klugstē / vnd gelerdstē wider cristū Jesun [sic!] kennē noch yhn d[er] worheit habē. Sundern der selbige berck yhn welchem alle schetzs verborgē ligen / dē allergrostē schrifthglerdē verborgē vnd gantzs vnbekandt / vnd an yhnnē erfullet das althe sprichwort / yhe gelerther / yhe vorkertter / das bey dē hochstē vnd berumpstē schribenttē kein worre erkandnus gottes ist / ia auch weder glaubē noch euāgelion mer habē,

Studie zu den grammatischen Kategorien ,Person` und „Numerus'. Münster: Lit Verlag, S. 4 .

${ }^{683}$ In den meisten nieder- und mitteldeutschen Gebieten hatten die Lutheraner auch die politische Unterstützung, in den oberdeutschen Gebieten, der Schweiz und Ostfriesland dominierten unter den Reformbewegungen die Zwinglianer. Die Wiedertaufe, die auch Hoffmans Täuferbewegung praktizierte, wurde in den deutschen Gebieten meist mit der Todesstrafe bestraft. Auch in den Niederlanden genossen die Melchioriten keine politische Unterstützung und mussten harte Rückschläge, z. B. durch Hinrichtungen, erleiden. 
vnd die weil alsz zu yhrē eygnē vrtheil die blīdheit sy vorstreckt hat / vnd yhrige weg wandlen / furen sie auch mit sich die einfaltigen hertzen in solche falstrick vnd vorblendung / vnd das also vil gotforchtiger sellen durch solche die yhrige weg geleydet vnd geschleift werdē[.] (MG, Arv)

Diese der salutatio folgenden, einleitenden Worte konstruiert Hoffman im Stil eines Berichts, er äußert keine Meinung - ein ,Ich' sucht man vergeblich -, sondern er formuliert seine Aussage so, dass es klingt, als zähle er lediglich selbstverständliche und allseits bekannte Fakten auf: Sprachlich wird dies mittels Formulierungen wie „Es ist“ und dem durchgehenden Gebrauch des Indikativs umgesetzt. Ebenfalls spricht Hoffman in einem sachlichen Ton; von den emotionalen Schimpftiraden, die er oftmals in anderen Schriften auf seine Gegner ergießt, sieht er hier $a b$.

Trotz des sachlichen Tons ist die Polemik auch hier deutlich zu identifizieren. Es ist insbesondere an dieser Stelle auffällig, wie Hoffman sich an bereits bestehenden Wendungen, zum Teil aus der Bibel entlehnt, bedient: Zunächst greift Hoffman hier das biblische Bild des ,Steins des Anlaufes/ Anstoßes' auf, das zur stehenden Wendung geworden ist, aber dennoch in seiner komprimierten Form eine Fülle an polemischen Implikationen aus der Bibel mit sich bringt: Erstmals taucht dieses Bild in Jes 8: I4 auf, wo Gott zu einem solchen Stein und einem „Fels des Ärgernisses“684 für die Ungläubigen wird. Nach I Petr 2: $6-8^{685}$ steht der (Eck-)Stein symbolisch für Christus: Dabei handelt es sich um einen Stein, der nur denjenigen zu einem „stein des anlauffs“ wird, die nicht an ihn glauben. Durch Röm 9: $3 \mathrm{I}-33^{686}$ wird dieses Bild des festen Glaubens an Christus noch verstärkt, indem der Glaube mit

${ }^{684}$ Jes 8: I 2-I 5: „Fürchtet ihr euch nicht also, wie sie tun, und lasset euch nicht grauen, sondern heiliget den HERRN Zebaoth. Den lasset eure Furcht und Schrecken sein, so wird er ein Heiligtum sein, aber ein Stein des Anstoßes und ein Fels des Ärgernisses den beiden Häusern Israel, zum Strick und Fall den Bürgern zu Jerusalem, daß ihrer viele sich daran stoßen, fallen, zerbrechen, verstrickt und gefangen werden. “ $w w w$. bibel-online.net, nach Luther I9I 2.

685 „Darum steht in der Schrift: ,Siehe da, ich lege einen auserwählten, köstlichen Eckstein in Zion; und wer an ihn glaubt, der soll nicht zu Schanden werden.' Euch nun, die ihr glaubet, ist er köstlich; den Ungläubigen aber ist der Stein, den die Bauleute verworfen haben, der zum Eckstein geworden ist, ein Stein des Anstoßens und ein Fels des Ärgernisses; denn sie stoßen sich an dem Wort und glauben nicht daran, wozu sie auch gesetzt sind. " www.bibel-online. net, nach Luther I9I2.

686 „Israel aber hat dem Gesetz der Gerechtigkeit nachgetrachtet, und hat das Gesetz der Gerechtigkeit nicht erreicht. Warum das? Darum daß sie es nicht aus dem Glauben, sondern aus den Werken des Gesetzes suchen. Denn sie haben sich gestoßen an den Stein des Anlaufens, wie geschrieben steht: ,Siehe da, ich lege in Zion 
dem Einhalten des äußerlichen Gesetzes kontrastiert wird - ohne den wahren Glauben wurde der Stein auch denjenigen, die nach dem Gesetz handelten, zum „stein des anlauffs“. Indem Hoffman die Wendung benutzt, polemisiert er gegen die Gelehrten und unterstellt ihnen, keinen wahren Glauben, sondern lediglich die Gelehrtheit zu haben. Hoffman trennt hier deutlich eine weltliche Gelehrtheit von einer christlichen Eingebung und unterstreicht das zusätzlich, indem er deutlich auf die ,blinden Blindenleiter' anspielt. Mit der Aussage „vnd die weil alsz zu yhrē eygnē vrtheil die blīdheit sy vorstreckt hat / vnd yhrige weg wandlen / furen sie auch mit sich die einfaltigen hertzen in solche falstrick vnd vorblendung “ stellt Hoffman einen klaren Bezug zu Mt I 5: I4 ${ }^{687}$ und zu Mt 23 (insbesondere 23: I 6 \& 24) her. Damit schließt Hoffman an die Polemik gegen die Pharisäer und Schriftgelehrten an, die - laut Matthäus-Evangelium - von Jesus Christus selbst geäußert wird. Mit dem biblischen Bezug instrumentalisiert Hoffman diese bereits existierende und autoritätsträchtige Polemik. Nicht zuletzt macht das Wort „schrifthglerdē" die Analogie zu den Pharisäern des Evangeliums evident. Hoffman hat damit eine klare Negativ-Bezugsfolie, vor deren Hintergrund er gegen die gelehrten Theologen seiner Zeit polemisiert: Wie die Pharisäer zu Jesu Christi Zeit, sind die Gelehrten seiner Zeit für ihn die Verkehrten, die zwar äußerlich der Schrift kundig sind, eine wahre innerliche Gotteserkenntnis dennoch nicht besitzen.

Hoffman nutzt für seine Polemik gegen diese ,falschen Gelehrten' aber nicht nur die Bibel, sondern auch ein seit etwa dem I 5 . Jahrhundert gebräuchliches Sprichwort: ${ }^{68}$ „yhe gelerther / yhe vorkertter“, das prinzipiell nicht Bildung im eigentlichen Sinne verwirft, sondern sich gegen „die Unterdrücker der ,Kleinen“, die Hochgebildeten im Dienste der kirchlichen und weltlichen Macht“, ${ }^{689}$ richtet. In der Reformation

einen Stein des Anlaufens und einen Fels des Ärgernisses; und wer an ihn glaubt, der soll nicht zu Schanden werden.““ www.bibel-online.net, nach Luther I9 2.

687 „Lasset sie fahren! Sie sind blinde Blindenleiter. Wenn aber ein Blinder den andern leitet, so fallen sie beide in die Grube. “www.bibel-online.net, nach Luther I9 2.

${ }^{688}$ Gilly, Carlos (I99I): „Das Sprichwort ,Die Gelehrten die Verkehrten“ oder der Verrat der Intellektuellen im Zeitalter der Glaubensspaltung “. In: Rotondò, Antonio (Hg.): Forme e destinazione del messaggio religioso. Aspetti della propaganda religiosa nel cinquecento. Florenz: Leo S. Olschki, S. 229-375, hier S. 233. Die Variante Hoffmans ist in engem Zusammenhang mit dem beinahe gleichlautenden Sprichwort: „Die Gelehrten, die Verkehrten“ zu sehen. Gilly stellt einen Katalog der Verwendung des Sprichwortes zur Verfügung, der den Bekanntheitsgrad des Sprichwortes im I 5. und I6. Jahrhundert deutlich macht. An dieser Stelle wird daher lediglich auf Gillys Aufsatz verwiesen.

689 Ebd., S. 235 f. 
gelangte das Sprichwort zu programmatischer Verwendung seitens der Reformatoren gegen die Altgläubigen, vor allem auch durch Luther. ${ }^{690}$ Aber mit einer sich steigernden Aufwertung der Laien wurde es alsbald auch gegen die Reformatoren selbst gerichtet, ${ }^{691}$ so dass Hoffman sich der allmählich eingebürgerten polemischen Verwendung gegen die Theologen im Allgemeinen bedient, um zunächst seine noch indeterminierten Gegner zu diskreditieren.

In dem kurzen zitierten Abschnitt ist aber nicht nur Polemik gegen die Gelehrten im Allgemeinen, sondern auch mehr zielgerichtete Polemik identifizierbar: Dass „der althar / vnd der disch des allerhochstē gantzs ville yhn ein falstrick gerothen " ist, ist deutlich Polemik gegen ein Abendmahlsverständnis, das von einer Realpräsenz Christi ausgeht, und vor allem gegen diejenigen, die die Realpräsenz lehrten und praktizierten. ${ }^{692}$ Jedoch sind die polemischen Angriffe hier noch weitgehend indeterminiert, ein polemisches Objekt noch nicht konkret genannt. Auf der Basis der möglichst faktisch-objektiv dargestellten Misere, dass die gottesfürchtigen Christen von den „allergrostē schrifthglerdē" auf den falschen Weg gebracht werden, baut Hoffman die Rechtfertigung seines Schreibens auf:

ausz solcher vrsach ich genottiget werd den hungrigē armgeistigen die hand zu reichē zu dē preisz des allerhochstē / so vil gott gnod verguneth vnd [ver] lichen [= verliehen] hatt / dan solche zu knurste [= zerknirschten/gebrochenen] hertzen sollē mit dē schatzs des hochstē getrostet vnd gespeisset werdē[.] (Ebd.)

Anders als in den bereits besprochenen zwei Vorreden verwendet Hoffman hier weniger den Exordialtopos, Wissen verpflichtet zur

${ }^{690}$ Ebd., S. 248. Vgl.: "The title chosen for this section is one of the best known slogans of sixteenth-century pamphlet literature. The phrase ,Die Gelehrten die Verkehrten has the attraction of rhyme, just as easily memorable as Affen und Pfaffen. Both proved to be powerful weapons in the heyday of the spread of pamphlet literature in the service of the Reformation - broadly speaking, in the decade from I 5 I 5 through I 525. Afterwards, this form of indoctrination tapered off noticeably, probably under the impact of the criminalization of what the authorities called the schlechten Prediger, who lost their livelihoods or lives in the aftermath of the peasants' revolt." Oberman, Heiko A. (I989): „Die Gelehrten die Verkehrten: Popular Response to Learned Culture in the Renaissance and Reformation“. In: Ozment, Steven (Hg.): Religion and Culture in the Renaissance and Reformation (= Sixteenth Century Essays \& Studies II). Kirksville/Missouri: Sixteenth Century Journal Publishers, S. 43-64, hier S. $46 \mathrm{f}$.

${ }_{691}$ Gilly (I99I), S. 256.

${ }_{692}$ Vgl. Deppermann (I979), S. 200. 
Mitteilung', sondern inszeniert vielmehr seine pastoralen Absichten. Seine Rolle ist nicht mehr nur die des Lehrers, sondern vornehmlich die des Seelsorgers. Durch die performative Äußerung des Handreichens macht er dieses Anliegen zusätzlich anschaulich.

Der pastoralen Rolle entsprechend, die er sich selbst in der Vorrede in Magestadt gottes zuschreibt, formuliert Hoffman die beiden Pole des polemischen Antagonismus mittels einer Bienen- und Spinnen-Allegorie:

vnd ist [der] schatzs gottes gar ein edle plom / ausz welchē das einfaltige yhmlein [= Immlein/Bienchen] nicht anderst sucht noch begereth / dā des edlen vnd kostlichē hanig zum preisz yhres koniges / auch nichts anderst sammelt noch bringen kan / dan das aller beste vnnd edelste / also auch die hungrige seel vā der edlen plumen cristo Jesu nicht dan alles gutt sucht begert vn̄ samlet. Aber weither so ists auch gewisz das kein plum oder rosz so edel vnd gut ist / noch sein mag / da nit ein spin gift herausz sucht vnd begerth / ia solche menschē die auch an den aller bestē gottes goben sich ergern / vnd schelten findē wider dē hohē gottes geist[.] (MG, Arv-A2r)

Durch die Allegorie wird der Antagonismus auf den zwei Bedeutungsebenen gebildet, die der Allegorie zugrunde liegen: Hoffman macht sich zunutze, dass Bienen im Volksmund hauptsächlich nutzbringende Eigenschaften (z. B. durch die Honigproduktion) zugesprochen werden, ${ }^{693}$ und überträgt diese allgemeingültige Konnotation auf „die hungrige seel“, die es in seinem geschilderten Fall vor den Gelehrten (den Spinnen) zu retten gilt. Die Bienen werden mit dem Diminutiv benannt, arbeiten emsig, um Honig aus der Blume zu ziehen, und haben nur den Preis ihres Königs im Sinn. Die Spinnen hingegen saugen Gift aus derselben edlen Blume. Die Allegorie von den Bienen und den Giftspinnen ist eine „Vorstellung im volkstümlichen Aberglauben, so daß davon ausgegangen werden kann, daß [sie] sofort jedem Leser verständlich ist.“ “694 Unterstützend ist zu nennen, dass Zeitgenossen Hoffmans, wie etwa

${ }^{693}$ Die Biene ist „Symbol der Liebe, der Seele, des Fleißes, des (inspirierten) Dichters und des Staatswesens.“ Butzer, Günter \& Joachim Jacob (Hg.) (20I2): Metzler Lexikon literarischer Symbole. Stuttgart: Metzler, S. 50. An dieser Stelle ist insbesondere der Fleiß gemeint, der „seit der Antike sprichwörtlich [ist]. “ Ebd., S. 5 I.

${ }_{694}$ Bremer (2005b), S. I 44. Bremer bezieht sich hier auf eine Schrift von Georg Scherer (I 586): Rettung der Jesuiter Vnschuld wider die Gifftspinnen Lucam Osiander, in der Scherer ebenfalls diese Metapher einsetzt, um Osianders Auslegung des Prager Bildes als falsch darzustellen. Vgl. auch: „In der deutschsprachigen Literatur des Mittelalters findet sich das Biene/Spinne-Modell schon häufig. Auch Sprichwörter belegen sein Alter. “ Schäfer, Walter E. \& Ernst Bogislav Moscherosch (I992): Moral und Satire. Konturen Oberrheinischer Literatur des 17. Jahrhunderts. Tübingen: Niemeyer, S. I I9. 
Sebastian Brant (Das Narrenschiff), ${ }^{695}$ Martin Luther und Sebastian Franck, ${ }^{696}$ das Sprichwort in ihren Schriften ebenfalls benutzen. ${ }^{697}$ Der allgemeine Sinn des Sprichwortes „Aus der Blume, aus der die Biene Honig saugt, saugt die Spinne Gift" ${ }^{698}$ dass ein guter Mensch und ein schlechter Mensch jeweils Gutes und Böses aus Worten, Dingen oder bestimmten Situationen ziehen können, wird hier erweitert. Hoffman geht es nicht nur darum, die Charakterisierung der Armgeistigen einerseits und der Gelehrten andererseits zu veranschaulichen, sondern es geht vielmehr um die Qualität der Bibelauslegung, denn „[d]ie BienenMetapher existiert seit der Antike zur Darstellung der literarischen imitatio. Sie wird im frühen Christentum dahingehend umgedeutet, daß sie die christliche Exegese versinnbildlicht. “699 Während Sebastian Brant seine eigene Dichtung mit der Blume, aus der jeweils Biene und Spinne ihre unterschiedlichen Säfte saugen, vergleicht, ${ }^{700}$ wird die Blume bei Hoffman als Jesus Christus selbst betitelt. Gemeint ist damit aber nicht die Figur Jesus Christus als solche, sondern „das leiplich vn̄ greůfflich wort gottes selber“ (MG, A 5v), welches Christus für ihn verkörpert.70r Unter das Gotteswort fällt wiederum die Heilige Schrift, welche die

${ }^{695}$ Sebastian Brant benutzt die Allegorie in Das Narrenschiff im Abschnitt „Entschuldigung des Dichters“. Dort setzt er die Allegorie als Apologie seines dichterischen Werkes ein, das für ihn die Blume darstellt und aus dem man jeweils Honig oder Gift ziehen kann. Insofern steht die Allegorie hier auch für die rechte oder falsche Interpretation eines Textes. Brant (I494), Das Narrenschiff, Kapitel I I I.

${ }^{696}$ Vgl.: „Ein von Franck besonders häufig gebrauchtes Bild, das im Werk mehrmals auftaucht, ist dasjenige von der Blume, aus der von der Spinne Gift, von der Biene Honig gesogen wird: Die bluom steckt voller honig/ zeühet aber die spinn das honig in sich/so wirdt es gifft/ aber der Binnen ist vnnd wirt es alles honig/ wie sy ist [Paradoxa, 40v]. “ Dellsperger (2008), S. 64.

697 Vgl. „SPINNE“, DWB I6, Sp. 25 I9.

${ }^{698}$ Wander, Karl Friedrich Wilhelm (I 867): Sprichwörter-Lexikon. Bd. I. A-Gothen. Leipzig: Brockhaus, Sp. 408, Nr. 4. Varianten dieses Sprichwortes und andere Sprichwörter mit der Biene und der Spinne gibt es unzählige, wie z. B. „Woraus die Biene Honig saugt, saugt die Spinne Gift“ (Sp. 374) und „Wenn die Biene Honig gewinnt, die Spinne nur ihrem eigenem Frass nachsinnt“ (Sp. 373).

699 Bremer (2005b), S. I 44 .

${ }^{700}$ „Daß man für gut es nehme an I Und leg' es nicht zum Argen aus I Noch ziehe Aergerniß daraus. I Denn darum ließ ich's nicht entstehn. I Aber ich weiß, es wird mir gehn I Gleichwie der Blume, die schön blüht, | Aus der das Bienlein Honig zieht, I Doch kommen dann darauf die Spinnen, I So suchen sie Gift draus zu gewinnen. I Das wird auch hierbei nicht gespart, I Denn Jedes thut nach seiner Art, I Und wo nichts Gutes ist im Haus, I Trägt man auch Gutes nicht hinaus. “ Brant (I949), Das Narrenschiff, Kapitel I 13.

701 Zu Hoffmans monophysitischer Christologie siehe Deppermann (I979), S. I97-202. 
Bienen auf eine Gott preisende und die Spinnen auf eine Gott lästernde bzw. auf eine schlechthin falsche Weise auslegen..$^{702}$

Im Nachsatz zu der allegorischen Darstellung der einfältigen, armgeistigen und emsigen Laien im Gegensatz zu den Gelehrten, die den guten Saft der Blume Christi zu Gift werden lassen, macht Hoffman sein polemisches Programm schließlich deutlich: Er zielt darauf ab,

das an solcher Gottes schlechtheit die spin ein spin bleibe / vnd die hoffertigē auffgeplossnē zu dorē vnd naren werdē / ia die sehenden blindt / vnd das arm einfaltige heuflein durch solches gelert vnd der gottes weissheit erben[.] (MG, A2r)

Der polemische Antagonismus mit seinen sich gegenseitig ausschließenden Positionen ist an dieser Stelle besonders deutlich konstruiert: Das als selbstlos inszenierte Anliegen, das „arm einfaltige heuflein“ in der göttlichen Weisheit zu unterrichten und sie so auf den rechten Weg zu Gott zu führen, steht in zwangsläufiger Wechselwirkung mit der (Image-)Zerstörung der „hoffertigē auffgeplossnē“. Erst wenn diese als Spinnen, die sie laut Hoffman sind, entlarvt und offenbart werden, können die Einfältigen den genannten Weg zu Gott beschreiten. Hoffmans Beschreibung geht insofern über den normalen Gebrauch der Bienen- und Spinnen-Metaphorik hinaus. Während die Metapher nur andeutet, dass das Ergebnis des Umgangs mit der Bibel und dem Glauben je nach Persönlichkeit gut oder schlecht sein könne, konstruiert Hoffman eine sich gegenseitig ausschließende Interdependenz zwischen den Polen des Antagonismus: Die Einfältigen können nur gewinnen, wenn die Schriftgelehrten verlieren. Hoffman legitimiert dementsprechend anhand des ausdrücklich hervorgehobenen pastoralen Zwecks die Polemik und liefert noch vor einem konkreten Angriff auf seine Widersacher eine Apologie. Implizit formuliert Hoffman hier eine Regel der rhetorischen Streitkultur der Reformationszeit mittels des Ketzertopos: Das Vorgehen gegen Gotteslästerer erfordert und rechtfertigt den polemischen Angriff.

Im Anschluss an ihre Legitimation folgt schließlich unmittelbar darauf - allerdings erst ungefähr in der Mitte der Vorrede - die personalisierte Polemik, indem Hoffman erstmals „dē Lutrischē vnd zwinglischē

${ }^{702}$ Hier decken sich die Beobachtungen mit denen, die Kai Bremer im Hinblick auf die Bienen-Spinnen-Allegorie Georg Scherers macht. Bremer (2005a), S. 528f. \& (2005b), S. I44f. Die Übereinstimmung der Befunde erweckt den Eindruck, dass diese konkrete Verwendung im I6. Jahrhundert geläufig war. Eine solche Hypothese bedürfte jedoch weiterer Beispiele. 
hauffen“ (A2r) nennt, mit denen er "gar hoch hett dran mogē sein / so [er] yren saurdeig wolt gelopt vnd fur die worheit predigt habe“" (ebd.). In einer kurzen narratio rekapituliert Hoffman seine mögliche Zugehörigkeit zu den Reformatoren, fasst aber zusammen, dass er sich aus freien Stücken gegen eine solche entschieden habe:

es ist mir basz mit der gottes weissheit ein nar zu sein / dā mit der welt kluck / mir liber erwel / mit dē gottes kindern yhm spott vnnd dreck zu sitzen / dan das ich der welt hoheit hab / ia vil lieber mit dē gottes [pro]pheten vnd [pro]phetinē ein schwermer vñ treumer zu sein / dan lob vnd rum der welt / es ist mir basz mit solchē nacket / arm hunger vnd durst zu leidē / dan mit den luthrischē blindenleithern ein follen madensack zu haben“. (A2r)

Der bisher entworfene Antagonismus zwischen den Gelehrten und den Armgeistigen wird an dieser Stelle noch um Hoffmans Perspektive erweitert, der sich nach dem Prinzip des Tertium non datur für eine der beiden sich gegenüberstehenden Positionen entschieden hat. ${ }^{703}$ Hoffman setzt insofern das Ausschlussprinzip in Szene: Es gibt nur ,entweder oder', wobei das eine besser als das andere bewertet wird. Sich selbst setzt er als Beispiel ein, dem das Publikum nachfolgen soll „da mit die follen vnd reichē / arm / ledig vnd blindt bleibē / vnd da gegen die armen ledigen / fol reich vnd sehendt werde" (A2r).

Durch das Sprechen über sowohl die „lutrischē blindenleither[]“ (ebd.) als auch die "gottes kinder[]" (ebd.) in der grammatischen 3. Person gelingt die Konstruktion des Antagonismus in Form des Chiasmus besonders gut, da sich beide Möglichkeiten außerhalb der Kommunikationssituation befinden und demselben Verweisraum angehören. ${ }^{704}$ Hoffman inszeniert sich selbst in der Rolle eines Dritten, der sich zwischen den Polen entscheidet. Diesem Dritten wird aufgrund „seiner Beobachtungsperspektive“ ein objektiveres Urteil zugesprochen. ${ }^{705}$ Mittels des indirekten Polemisierens gegen die Lutheraner und Zwinglianer einerseits und des indirekten Lobs der armen „gottes kin$\operatorname{der}[]^{\text {“ }}$ andererseits intensiviert Hoffman den Eindruck von Objektivität und den Anspruch auf Allgemeingültigkeit seiner Auffassung hinsichtlich des polemischen Objekts.

Trotz der offensichtlich polemischen Absicht, das Image der zwei großen Reformatorenlager öffentlich zu denunzieren, betont Hoffman

703 Eine Analyse dieses Textabschnitts hat die Verfasserin bereits vorgelegt: Siehe Lundström (20II), S. $228 \mathrm{f}$.

${ }_{704}$ Vgl. Gehling (2004), S. 4 und Schwitalla (20IOb), S. I64.

705 Fischer (2000), S. I 28. 
auch am Ende der Vorrede ein weiteres Mal, dass seine bisherige Ausrichtung auf die Zerstörung der feindlichen Parteien nicht mehr sein Anliegen sei: „dan der mortgirichē bluttseuffrischen geister halber ich numer ein bugstab in solcher weissheit gottes schreibē wolt / der dinst geschicht nur dē glaubigē gottes helgē denen solche weissag zu stan sollen " (MG, A2r). Es wird deutlich, wie Hoffman seine Rolle und sein Schreiben damit rechtfertigt, dass er allein den Gläubigen dienen will. Seinen Gegnern hingegen entzieht er vorgeblich die Adressatenrolle, was allein in Kombination mit dem indirekten Polemisieren glaubhaft umgesetzt werden kann, da das polemische Objekt in dieser Form auf Textebene nicht adressiert wird. Obwohl Hoffman an dieser Stelle sein pastorales Anliegen in Szene setzt und versucht, die Illusion zu kreieren, es ginge ihm nicht um die Gegner, kann er diese Inszenierung nur wenig später nicht mehr aufrechterhalten. Nach der Ankündigung des darauf folgenden Abdrucks des 26. Gesichts der Prophetin Ursula wird in Hoffmans Begründung noch eine zweite, rein polemische Absicht mit dem Druck des Gesichts evident: „auff das ia volkomlich den lastergeister ein ruch ${ }^{706}$ zum dot bereith werd / vnd die nachtrabē / ewllen / zuhu [sic!] solchs zur vorblendung volkomlich gerothē $\operatorname{mog}(M G, \mathrm{~A} 2 \mathrm{v})$. Dass Hoffman doch davon spricht, seine Gegner zum Schweigen zu bringen, unterstreicht das polemische Vorhaben, das Hoffman außerdem mit dieser Vorrede verfolgt. Der im Kontrast dazu auffällig unpolemische Haupttext, in dem Hoffman gemäß dem Stil der gelehrten Abhandlung sachlich für seine theologischen Anschauungen argumentiert, lässt die Polemik in der Vorrede besonders prägnant hervorstechen. Die Rechtfertigung durch die inszenierte Seelsorge kann insofern als Streitverschleierung interpretiert werden, denn die geäußerte Polemik wird nicht legitimiert, sondern geleugnet.

706 „ruch“ ist die Lesart der Verfasserin dieser Arbeit, aufgrund der undeutlichen Drucktype könnte es aber unter gewissen Umständen auch „tuch“ heißen. Beide Lesarten würden einen Sinn ergeben. Die inhaltliche Deutung verbleibt jedoch generell ambivalent: Mit „ruch“ könnte Geruch, Rauch oder Saatkrähe gemeint sein. Vgl. „RUCH“, DWB I4, Sp. I340-I34I. Der Geruch könnte als Leichengeruch ausgelegt werden, der Rauch auf einen Scheiterhaufen verweisen. Die Saatkrähe bzw. der Rabe könnte symbolisch aufgefasst werden und insofern u. a. für den Tod, das Böse, die Sünde und das Teuflische stehen. Vgl. Butzer \& Jacob (20I2), S. $334 \mathrm{f}$. Der Symbolgehalt des Vogels böte dementsprechend die Anknüpfungspunkte an „dot“. Die etwas unwahrscheinlichere Lesart „tuch“ würde das Leichentuch vermuten lassen. 


\section{Die polemische Funktion der Vorrede bei Melchior Hoffman}

Aufgrund ihrer grundlegenden Funktionen der Kontaktaufnahme mit der Leserschaft sowie des Gewinnens ihrer Gunst und Aufmerksamkeit erweist sich die Vorrede für polemische Zwecke dienlich. In Kombination mit Polemik erfüllt die Vorrede eine Doppelfunktion: Sie stimmt den Leser nicht nur wohlwollend für die Aufnahme des Haupttextes, sondern auch für die Beeinflussung durch die Polemik. Der üblicherweise affirmativen Funktion der Vorrede in Bezug auf das Ethos von Autor und Haupttext wird insofern ein pejoratives Gegenstück zur Seite gestellt: Eine bereits vorhandene oder potentielle Gegnerschaft des Autors oder Textes soll in den Augen der Leserschaft bereits mit der captatio benevolentiae als unwürdig erscheinen.

Es hat sich gezeigt, dass die Vorreden in Hoffmans religiösen Abhandlungen und Bibelkommentaren - sowohl mit als auch ohne Widmung - einen Ort des indirekten Polemisierens darstellen. Da sich die Vorrede grundsätzlich an die Leserschaft richtet, eignet sie sich nicht für die Inszenierung eines Dialogangebots an das polemische Objekt in Form der direkten Rede. Auf der Textebene ist der konstruierte Adressat folglich entweder ein Widmungsempfänger und/oder eine determinierte Gruppe als Leserschaft (z. B. alle Gläubigen oder die Gemeinde in Livland). Solch eine Adressierung muss jedoch nicht immer mit der direkten Rede verbunden sein, sondern kann auch allein in der 3 . Person geschehen (z. B. in der salutatio).

In Bezug auf das Vorhandensein einer Zueignung zeigen Hoffmans Schriften eine unterschiedliche Verwendung von Polemik, je nachdem, ob eine polemische Instanz auch nach der salutatio auf der Textebene angelegt ist oder nicht. Hinsichtlich des Tons der Polemik, des Maßes an Unsachlichkeit und der Determination bzw. Personalisierung der Polemik ist merklich festzustellen, dass die Polemik in einem Wechselverhältnis mit der Konstruktion der polemischen Instanz steht: Wird etwa. ein Widmungsempfänger als polemische Instanz im Text angesprochen, wird Polemik indeterminiert und rational geäußert. Bei einer breit angelegten polemischen Instanz hingegen zeigt sich Hoffmans Polemik personalisiert und wesentlich schärfer.

Im Allgemeinen zeigt sich in Hoffmans Schriften, dass die Vorrede durch ihre Funktion, eine Metaebene zum darauffolgenden Haupttext zu bilden, einen idealen Ort der Rechtfertigung des Schreibens bildet. Diese Rechtfertigung kann so weit gehen, dass nicht nur das diskursive Eingreifen an sich seine Berechtigung erhält bzw. die Relevanz des Themas geltend gemacht wird, sondern auch ein noch folgender und vor 
allem beabsichtigter Regelverstoß gegen die rhetorische Streitkultur die scharfe Polemik - im Vorhinein legitimiert wird.

\subsection{Fiktionen beim verdeckten Polemisieren}

Hoffman nutzt in seinen späteren Schriften mehrfach die Form des verdeckten Polemisierens. Die Gründe, die Hoffman jeweils dazu bewegt haben, diese Form des Polemisierens zu wählen, sind dabei verschieden. Erstmals polemisiert Hoffman (zusammen mit Karlstadt) verdeckt in dem I 529 anonym veröffentlichten Dialogus, der zunächst in Straßburg bei Balthasar Beck, im gleichen Jahr aber auch in Augsburg bei Philipp Ulhart, d. Ä. erschien. ${ }^{707}$ Die anonyme Veröffentlichung kann auf die Funktion der Schrift als Augenzeugenbericht zurückgeführt werden, wie nachfolgend erörtert wird.

Ab I533 polemisierte Hoffman ausschließlich verdeckt - jedoch vordergründig nicht infolge textrelatierter Wirkungsabsichten, sondern bedingt durch seine Lebensumstände: Ein Schreibverbot machte es Hoffman zwar nicht unmöglich, Schriften zu produzieren, aber sie unter seinem eigenen Namen zu veröffentlichen. In den späteren Jahren ließ Hoffman daher seine Schriften unter dem Pseudonym Caspar Beck(er) und unter den Namen seiner Anhänger (Cornelius Poldermann und Johannes Eisenburgk) publizieren.708

\subsubsection{Die fiktive Handlung und das Fehlen des polemischen Subjekts im Dialogus}

Bei der Veröffentlichung des DJalogus vin gründtliche berichtung gehaltner disputation im land zi Holsten vnderm Künig von Deñmarck

707 Anonymus [i. e. Hoffman und Karlstadt] (I 529), Dialogus. Der Augsburger Nachdruck von I 529 (mit anderer Schreibung und Paginierung) liegt ebenfalls vor (siehe Literaturverzeichnis). Zitiert wird ausschließlich aus der Straßburger Ausgabe.

${ }^{708}$ Die Bearbeitung der hoffmanschen Schriften durch Johannes Eisenburgk ist anhand stilistischer Unterschiede nachgewiesen worden. Siehe dazu Deppermann (I979), Husner (I946) und Kawerau (I958). Gegen eine Autorschaft Eisenburgks spricht jedoch, dass typische (polemische) Formulierungen Hoffmans in den Texten vorkommen oder sich gesamte Textabschnitte gleichen, wie z. B. die Titel und Vorreden der Auslegung des Judasbrief, die unter Poldermanns Namen herausgegeben wurde und die Auslegung des Jakobsbrief, deren Autorschaft Eisenburgk offiziell übernimmt: Eisenburgk, Johannes [vermutlich zusammen mit Melchior Hoffman] (I 534): Die

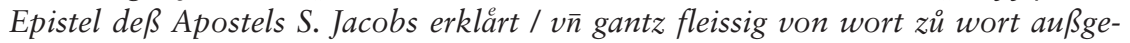
legt / zu eyner ernsten warnung lauch zu eynem kostlichen nutz vnd trost / allen gotsforchtigen liebhabern der ewigen warheyt. [Hagenau: Valentin Kobian]. 
vom hochwirdigen Sacrament oder Nachtmal des Herren. In gegenwertigkeit Kü. Ma. Sun Hertzog Kersten sampt Kü. Råten / vilen vom Adel / und grosser versamlung der Priesterschafft. Yetzt kurtzlich geschehen den andern Donderstag nach Ostern / im jar Christi. Als man zalt. M. D. xxix, zogen Hoffman und Karlstadt es vor, anonym zu bleiben. Im Schrifttum Hoffmans nimmt der Dialogus aber nicht allein deshalb eine Sonderrolle ein, sondern vielmehr, weil er als Reformationsdialog die einzige Schrift Hoffmans ist, die aus heutiger Sicht nicht genuin als Gebrauchsliteratur gilt. Sowohl die zwei Figuren Ypolitus und Erhart als auch deren Aufeinandertreffen zu einem Gespräch sind Teil der Fiktion. Allein das Gesprächsthema hat einen ,realkontextuellen' Bezug.709

Die literarische Form des Dialogs ist eine in der Reformation vielfach verwendete fiktionale Gattung - das Wort ,fiktional' muss allerdings für das I6. Jahrhundert eher unter der Bedeutung von ,exemplarisch'verstanden werden. Es geht weniger um das ,Erfinden“ von Figuren, sondern vielmehr um das ,Auffinden' exemplarischer Szenarios - so dass mit dem Einsatz von „mimetischen Elementen“ eine „fiktive Lebensechtheit“ geschafft werden soll.710 Insofern beansprucht der Reformationsdialog als literarische Form, die Wirklichkeit zu repräsentieren. Beim Dialogus wird dieser generelle Anspruch noch zusätzlich ausgeschöpft, was dem vollständigen Titel ablesbar ist: Die Bezeichnung „gründtliche berichtung“ und die genaue Datumsangabe der Disputation stellen unmissverständlich den Kontextbezug her. Der Authentizitätsanspruch ist dementsprechend hoch.

Die literarische Textgestaltung des Berichts der Flensburger Disputation als Reformationsdialog bietet die Möglichkeit, als Autor hinter der Fiktion auf Textebene zu verschwinden. Die zwei fiktiven Dialogpartner fungieren als Interpreten der Geschehnisse vor und auf der Disputation von Flensburg. Dafür wird eine absichtlich informelle Gesprächssituation zwischen den Freunden Ypolitus (alternierend auch Hypolitus) und Erhart gewählt. Ypolitus ist laut eigener Aussage bei der Flensburger Disputation „selbs dabey gewesen / vom anfang

709 Eine Analyse der Polemik im Dialogus hat die Verfasserin bereits an anderer Stelle vorgelegt. Siehe Lundström (20II). Aus diesem Grund wird die Analyse des Dialogus in der vorliegenden Arbeit auf die Untersuchung der kommunikativen Situation des Polemisierens beschränkt.

${ }_{710}$ Senger, Matthias W. (I986): „,Ich han almit meiner Nachtigall zu essen geben.‘ Zur Typologie des mimetischen Elements im Reformationsdialog “. In: Worstbrock, Franz Josef \& Helmut Koopmann (Hg.): Formen und Formgeschichte des Streitens. Bd. 2. Der Literaturstreit. Tübingen: Niemeyer, S. 55-62, hier S. 56. 
biß zum end" (AIv) und übernimmt daher die Rolle eines berichtenden Augenzeugen. Durch die Hervorhebung seiner Anwesenheit wird Ypolitus indirekt zu einer vertraulichen Quelle erhoben. Damit dies auch dem Leser bewusst wird, wird seine Glaubwürdigkeit postwendend durch den dialogischen Gegenpart Erhart bestätigt: „Das hơr ich gern / das ich von dir die rechtē warheit mag erfaren / dan̄ es haben sich manigfeltige red / von wegen solcher Disputacion alhie begebe “" (Arv). Indem die Figur Erhart davon spricht, dass sich bereits Gerüchte verbreitet haben, und dass er nun endlich die richtige Wahrheit erfahren wird, wird gleichsam die Glaubwürdigkeit des Dialogus in selbstreferenzieller Weise konstituiert. Nicht nur an dieser Stelle hat die Figur Erhart eine Schlüsselfunktion: In seiner Rolle des zu informierenden Zuhörers ist er nicht allein ein Stellvertreter des unwissenden Lesers, sondern übernimmt die Rolle der Gesprächsführung. Er stellt Nachfragen, kommentiert Ypolitus' Bericht und äußert mitunter Zweifel. Seine Aufgabe ist aber weniger die eines echten Kritikers oder Zweiflers; vielmehr fungiert Erhart als bestärkende Instanz, indem er Ypolitus niemals in Frage stellt und sich durchgehend von Ypolitus informieren und überzeugen lässt. Der Wahrheitsgehalt von Ypolitus' Bericht wird durch die Prüfung, die Erhart implizit durchführt, noch unterstrichen.

Durch das verdeckte Polemisieren im Dialogus können Hoffman und Karlstadt im Text über Melchior Hoffman in der 3. Person sprechen. Durch das Zusammenspiel von anonymer Veröffentlichung und literarischer Form wird Hoffman zum inhaltlichen Thema innerhalb des Dialogs der fiktiven Figuren Ypolitus und Erhart. Sie tauschen sich über den „kürßner“ (AIv) aus, rekapitulieren seinen Lebensweg und besprechen seine Aussagen und Lehren von der Disputation. Sämtliche Aussagen über Melchior Hoffman werden so, wie generell üblich beim verdeckten Polemisieren, von einer „Beobachterperspektive“ "7II aus gemacht. Auf gleicher Ebene des Verweisraumes der grammatischen 3. Person wird auch Polemik gegen die Disputationsgegner Bugenhagen und die lutherischen Prediger geäußert - es wird dementsprechend die Form des indirekten Polemisierens angewandt.

Das Besondere des Dialogus ist jedoch, dass sich die auf der Textebene entworfene polemische Situation, den entwickelten Kategorien gleichsam zu entziehen droht. Die Autoren Hoffman und Karlstadt sind zwar nicht als polemisches Subjekt im Text eingeschrieben, ein solches scheint aber generell zu fehlen, da eine die Verfasserschaft vertretene

$\overline{{ }^{11} \text { Fischer (2000), S. I } 28 .}$ 
Ich-Position vollkommen fehlt. Die einzigen Ich-Positionen sind die beiden fiktiven Dialogpartner, die sich aber nicht zu der Autorschaft bekennen. Das Konzept kann insofern nur durch eine Anpassung an die Gegebenheiten des Dialogus geschehen: Eine polemische Situation kann identifiziert werden, ist jedoch in den fiktiven Rahmen integriert. Ypolitus kann in erweitertem Sinne als das fiktive polemische Subjekt gelten, denn schlussendlich ist er es, der indirekt gegen die Lutheraner polemisiert.

Bugenhagens Rezeption des Dialogus bestätigt, dass die fiktiven Figuren klar als Stellvertreter für die Autoren wahrgenommen wurden. In der gedruckten Acta der disputation zu Flensburg / die sache des Hochwirdigen Sacraments betreffend ${ }^{72}$ bespricht Bugenhagen gegen Ende der Schrift den Dialogus und stellt fest:

Das aber Melchior Hoffman / odder der Peltzer odder Kürsner (wie er sich selbs in seinen Actis / zu Strasburg gedruckt / nennet vnd gerne heissen wil) so sere geeilet hat mit seinen Actis zuuorn kommen / vnd im Dialogo seinen Ehrhart odder Ehrlós / so fleissig berichtet hat / da hat ihn die grosse not gedrungen / er hat gefurcht das die rechten Acta mo̊chten zuuorn kommen..$^{713}$

Bugenhagen identifiziert Hoffman mit seiner Figur Ypolitus und deckt damit die Fiktion des Dialogus als Strategie des Streitens auf. Die Fiktion wird damit für ihn zur Lüge, der Dialogus zur „lugen Acta“.714 Bugenhagen diskutiert zudem die Verfasserschaft von Hoffman und macht ihn für die Schrift verantwortlich, denn „wer solte solchs anders schreiben / on das ihm Er Ehrlos geholffen hat".715 Hier zeigt sich, dass mit der Form des verdeckten Polemisierens nicht zugleich die NichtErkennung des Autors garantiert wird. Trotzdem bleibt die Vagheit dieser Autor-Zuordnung bestehen. Ein Beweis muss erst geliefert werden, so dass der Text in seiner verdeckten Form zunächst auch weiterhin funktionieren kann.

Abschließend lässt sich festhalten, dass der Dialogus aufgrund der erörterten Konstruktion als fiktives Szenario, in dem ein polemisches Subjekt in der typischen Form nicht vorhanden ist, eine ausgefallene

${ }^{\text {72 }}$ Bugenhagen, Johannes (Hg.) (I 529): Acta der disputation zu Flensburg / die sache des Hochwirdigen Sacraments betreffend / im I 529. Jar / des Donnerstags nach Quasi modo geniti / geschehen. Wittenberg: Joseph Kluck.

${ }_{713}$ Ebd., Mir.

${ }^{714}$ Ebd., M6v.

${ }_{715}$ Ebd., M2v. 
Form darstellt. Die Polemik, die im Zuge des Disputationsberichts gegen Hoffmans Opponenten geäußert wird, ist doppelt verdeckt: Zum einen bleibt das polemische Subjekt durch die anonyme Veröffentlichung ohne ,realkontextuell' besetztes Pendant, so dass die Verfasserposition im Unklaren bleibt. Zum anderen wird das Vorhandensein der Position eines textinternen polemischen Subjekts hinter der Figurenrede verdeckt, denn bei (Reformations-)Dialogen

handelt es sich [vielmehr] um [...] Texte, in denen der Autor, anders als im Traktat und trotz seiner textimmanenten Omnipräsenz, eben nicht unmittelbar spricht, sondern - vielleicht gerade wegen dieser Omnipräsenz letztlich ungreifbar bleibt. ${ }^{76}$

Die Folge dieser unsichtbaren Omnipräsenz bzw. der Abwesenheit einer sichtbaren Subjekt-Position auf der Textebene ist das Fehlen einer polemischen Situation, die mit dem ,Realkontext' abgeglichen werden kann.

\subsubsection{Der fingierte Privatbrief als offener Brief in Eyn sendbrieff an [...] Michel wachter}

In der Vielzahl verdeckter polemischer Schriften setzt Hoffman insgesamt zweimal ein Pseudonym ein, indem er die fiktive Figur Caspar Beck bzw. Caspar Becker als Autor und polemisches Subjekt konstruiert. Bei beiden Schriften handelt es sich um die literarische Form des Briefs. Während der erste Eyn sendbrieff an alle gottsförchtigen liebhaber der ewigen warhey $t^{717}$ ist - also ein offener Brief an ein breites

${ }^{716}$ Häsner, Bernd (2004): „Der Dialog. Strukturelemente einer Gattung zwischen Fiktion und Theoriebildung“. In: Hempfer, Klaus W. (Hg.): Poetik des Dialogs. Stuttgart: Franz Steiner, S. I3-65, hier S. I 5 . Häsner führt im Folgenden weiter aus, dass der Dialog zwei Kommunikationsebenen hat, eine „textexterne“ (zwischen Autor und Leser) und eine „textinterne“ (zwischen den miteinander kommunizierenden Figuren). Ebd. S. 2I. Diese sind einerseits getrennt voneinander zu betrachten, obgleich sie andererseits in einer Beziehung zueinander stehen: So kommt Häsner zu dem Schluss: „Doch läßt sich schon hier festhalten, daß der Dialogtext, wie jeder fiktionale Text, als ,Makroproposition“ eines Autors zu behandeln wäre, die semantisch komplexer ist als jede der in ihr enthaltenen Teilpropositionen". Ebd. S. 2 I. Die Autorposition ist demnach nicht auf gleiche Weise zu identifizieren wie in anderen literarischen Formen von Gebrauchstexten (Traktat usw.). Bei diesen Überlegungen muss zudem darauf hingewiesen werden, dass hier vom „dramatischen Dialog “ die Rede ist. Ebd. S. 30.

${ }_{717}$ Becker, Caspar [i. e. Melchior Hoffman zusammen mit Johannes Eisenburgk] (I533): Eyn sendbrieff an alle gottsförchtigen liebhaber der ewigen warheyt, inn welchem angezeyget seind die artickel des Melchior Hofmans [sic!], derhalben 
Publikum - gibt Eyn sendbrieff an [...] Michel wachter ${ }^{718}$ hingegen vor, ein Privatbrief zu sein. ${ }^{719}$ Als Absender des Briefs wird Caspar Beck, als Adressat Michel Wachter genannt, die durch persönliches Duzen und Anreden wie „lieber Michael Wachter“ (A2r) und „Meyn lieber Michel“ (6av) in freundschaftlichem Verhältnis zueinander stehend dargestellt werden. Allerdings ist nicht nur die Verfasser-Figur Caspar Beck(er), sondern auch der angebliche Adressat Michel Wachter, eine Erfindung Hoffmans. ${ }^{720}$ Die Kommunikationssituation eines Privatbriefs zwischen zwei Freunden kann insofern als reine Fiktion betrachtet werden.

Mit der Konstruktion des fingierten Privatbriefs wählte Hoffman eine Inszenierungsstrategie, die für das Reformationsschrifttum eher unüblich ist. Da Hoffman dabei mit dem Echtheitsanspruch der literarischen Form des Briefs bricht, wählt er ein für die ,rhetorische Streitkultur seiner Zeit grenzüberschreitendes Verfahren. Die Seltenheit solch einer

$y$ hn die lerer zu Straßburg als eyn ketzer verdampt vnd inn gefenknüß mit trübsal, qual, spott unnd schand gekrönet und besoldet haben. [Hagenau: Valentin Kobian]. Abschrift in TAE II, Nr. 399, S. IOI-I IO. Diese höchstwahrscheinlich von Melchior Hoffman verfasste und von Johannes Eisenburgk bearbeitete und herausgegebene Schrift fasst die Artikel von Hoffmans Lehre zusammen, wegen derer er sich auf der Synode (I 533) gegen Bucer verteidigen musste.

${ }^{718}$ Beck, Caspar [i. e. Melchior Hoffman] (I 534): Eyn sendbrieff an den achtbaren Michel wachter / in welchem eroffnet würt / die vberauß greuwliche mißhandlung / die den vergangnen zeyten zu Jerusalem wider dye ewige worheit vnd der selbigen zeugen gehandlet ist / vnd auch noch teglich verbrocht wurt / ohn alle forcht Gottis. [Hagenau: Valentin Kobian]. Kurztitel: Eyn sendbrieff an [...] Michel wachter. Benutzte Abschrift (mit einer Einleitung): Kohls, Ernst Wilhelm (Hg.) (I96I): „Ein Sendbrief Melchior Hofmanns aus dem Jahre I 534 “. Theologische Zeitschrift I7, S. 356-365. Im Folgenden werden - wenn nicht anders ausgewiesen - Zitate aus Hoffmans Text aus dieser Ausgabe (mit Originalpaginierung) angegeben. Zitate aus der Einleitung Kohls” werden mit „Kohls (I96I)“ ausgewiesen. Eine weitere Abschrift des Sendbriefs ist zu finden in TAE IV, Nr. 595a, S. 522-527. Die Schrift zählt insgesamt zwölf Seiten, zehn davon sind Text. Kohls gibt dazu an: „Das Original des Sendbriefs zählt ohne Numerierung sechs Blätter in $8^{\circ}$ und ist in Schwabacher Type gesetzt." Kohls (I96I), S. $35^{8}$. In den Täuferakten wird jedoch das Format $4^{\circ}$ angegeben. TAE IV, Nr. 595 a, S. 526. Die Paginierung ist wie folgt: Titelblatt Ara, Arb (leer), A2a-A6b (Text). Kohls Paginierung wurde in dieser Arbeit folgendermaßen wiedergegeben: $\mathrm{a}-$ Seite $=$ recto, $\mathrm{b}$-Seite $=$ verso. Zitate werden in diesem Kapitel allein mit Folienangabe in Klammern nachgestellt.

${ }^{19}$ Inhaltlich geht es allein darum, wie Hoffman von den Straßburger Reformatoren verfolgt und gequält wird. Die Schrift funktioniert insofern als reine Schmähschrift.

${ }^{720}$ Hoffman selbst gestand in einem Verhör am 2I. September I 534, den Sendbrief geschrieben zu haben. Er behauptete zwar, dass die Namen Caspar Beck und Michel Wachter keine Erfindungen seinerseits wären, die Existenz solcher Personen ist jedoch nicht nachweisbar und ändert zudem nicht den fiktiven Charakter des Briefs. TAE II, Nr. 6Iо, S. 387-389. 
Inszenierung bestätigt Bremer, der für die Vorrede von Luthers De votis monasticis iudicium ( I $52 \mathrm{I}$ ), ,Brief an den Vater', ebenfalls feststellt, dass „[d]ie Briefform der Vorrede [...] eine Fiktion“ ist. ${ }^{721}$ Er führt dazu aus:

Wir kennen aus den Dialogen und den Streitschriften und auch aus einigen Predigten zwar inszenierte Dialoge. Diese sind dann aber üblicherweise solche, in denen ein Streitpunkt verhandelt wird - mal gelehrt mittels disputatorischer Kontroverstechniken, mal ausfallend-aggressiv in Form von Verunglimpfungen oder Stigmatisierungen. Auch kennen wir natürlich Dialoge zwischen Vater und Sohn. Aber soweit ich sehe, kennen wir sonst keinen fiktiven Dialog in einer Textsorte, die grundsätzlich Authentizität reklamiert. ${ }^{722}$

Die üblichen fingierten Dialoge im Reformationsschrifttum - so macht Bremer hier deutlich - sind in der Regel nicht als scheinbar echte Privatbriefe verpackt. Durch die Fiktion einer privaten Kommunikation zwischen zwei Freunden erweckt Hoffman eine besonders vertraute Atmosphäre und lässt die fiktiven Figuren für seine Sache sprechen, was sich positiv auf die Rezeption auswirken kann.

Die Illusion eines privaten Briefs scheint sich aus heutiger Perspektive zwar allein durch die Veröffentlichung im Druck als ebensolche zu enttarnen, im I6. Jahrhundert war es aber ein gängiges Verfahren, ursprünglich private Briefe in den Druck zu geben. Der Privatbrief in seiner heutigen Form existierte im I6. Jahrhundert generell nicht, denn noch im Mittelalter waren Briefe überwiegend Orte für Urkunden, Kaufverträge und offizielle Dokumente. Den Distributionsbedingungen und den Gepflogenheiten der Handhabung von Briefen allgemein (ein Briefgeheimnis gab es noch nicht) geschuldet, wurden Briefe nicht als intime Schriftstücke betrachtet. ${ }^{723}$ Dass Briefe weitergereicht, ${ }^{724}$ öffent-

${ }_{721}$ Bremer (20II), S. 59.

722 Bremer (20II), S. 59f.

${ }^{723}$ Vgl. dazu: „Persönliches oder Privates konnte zwar auch in den Briefen Platz finden, spielte aber nur eine Nebenrolle. [...] Aufgrund der besonderen Umstände der Briefbeförderung muß das Wort „Brief‘ im I6. Jahrhundert die Konnotation von ,offizielles Schriftstück“ gehabt haben.“ Körber, Esther-Beate (I996): „Der soziale Ort des Briefs im I6. Jahrhundert“. In: Wenzel, Horst (Hg.): Gespräche Boten - Briefe: Körpergedächtnis und Schriftgedächtnis im Mittelalter. Berlin: Erich Schmidt, S. 244-258, hier S. 257.

${ }^{724}$ Vgl. dazu: „Vor dem Druck, der es grundsätzlich ermöglicht, jedem Leser einen Text zu geben, steht die Handschrift als ein Zirkular, das tendenziell durch viele Hände geht. Die Reflexion auf Zweit- und Drittleser entspricht den Usancen der Zeit.“ Wenzel, Horst (200I): „Luthers Briefe“. In: Brady, Thomas A. (Hg.): Die deutsche Reformation zwischen Spätmittelalter und Früher Neuzeit. München: Oldenbourg 
lich vorgelesen oder sogar publiziert wurden, war keine Seltenheit, so dass sehr persönliche Nachrichten eher mündlich, durch den Boten selbst überbracht wurden. Teilweise wurde Briefen sogar die Funktion einer Art Zeitung zuteil, indem man offizielle Meldungen separat beifügte oder im Brief integrierte. ${ }^{725}$

Durch den Humanismus und die Reformation beeinflusst, avancierte die Form des Briefs mehr und mehr zum Ort des persönlichen Austausches über gelehrte und religiöse Themen: ${ }^{726}$ „In ihren privaten Briefen schaffen sich die Reformatoren eine sekundäre Öffentlichkeit, die auf den öffentlichen Raum bezogen bleibt, aber in den Kategorien der Freundschaft und der persönlichen Nähe geführt wird. “727 Vielfach wurden die Themen der Reformation auf brieflichem Weg mit Freunden oder Gleichgesinnten diskutiert. Der Druck dieser ursprünglich privaten Kommunikation war manches Mal nur ein Schritt, der sich an eine zunächst im kleinen Rahmen geführte Diskussion anschloss. Infolgedessen war der abgedruckte Brief als Reformationsflugschrift entweder offen bzw. „ein Brief, der - obwohl an eine Person oder Institution gerichtet bestimmt ist, von vielen gelesen zu werden, und deshalb veröffentlicht wird“, oder wurde nachträglich veröffentlicht. ${ }^{728}$ Einen persönlichen Brief auch einer größeren Leserschaft zukommen zu lassen, war dementsprechend nichts Außergewöhnliches.

In seinem sendbrieff an [...] Michel wachter simuliert Hoffman eine ebensolche Situation, denn auch in Hoffmans Inszenierung ist der Brief keinesfalls privat nach heutigem Verständnis. Gleichwohl wird eine

Verlag, S. 203-23 I, hier S. 2I 8. Wenzel gibt einige Zitate an, die verdeutlichen, dass Martin Luther, Erasmus von Rotterdam u. a. dieses Prozedere kannten und es auch selbst nutzten. Vgl. auch Essig, Rolf-Bernhard (2000): Der offene Brief: Geschichte und Funktion einer publizistischen Form von Isokrates bis Günter Grass. Würzburg: Königshausen \& Neumann, S. 69 f.

725 Körber (I996), S. 252.

726 Vgl. dazu: „Ein Brief war im I6. und I7. Jahrhundert wohl eine persönliche, aber selten eine private oder gar intime Mitteilung. Er gab keine Geheimnisse preis, denn das wäre für Absender wie Empfänger zu gefährlich gewesen. “ Körber (I996), S. 257 .

727 Wenzel (200I), S. 219. Am Beispiel der unterschiedlichen Brieftypen Martin Luthers verdeutlicht Wenzel, dass zwischen privaten und öffentlichen Briefen durchaus unterschieden wurde. Luther hatte z. B. einen Teil seiner Briefe, die ihm zu privat waren, nicht zu seinen Lebzeiten herausgeben lassen. Ebd., S. 2I7-2I9.

${ }^{728}$ Essig (2000), S. I 2. Als Abgrenzung des Begriffs macht Rolf-Bernhard Essig deutlich: „Gibt es keine doppelte Adressierung, oder handelt es sich um einen begrenzten Adressatenkreis, spricht man besser von veröffentlichten, nicht aber von Offenen Briefen. “ Ebd., S. I6. 
vertrauliche Atmosphäre inszeniert: So wird z. B. betont, dass Caspar Beck mit dieser Mitteilung einer Bitte des Freundes Michel Wachter nachgeht, indem er schreibt, dass er den Brief verfasst, „[n]achdem du an mich begerst, daß ich dir sol kunt thun, wie es stant mit dem diener Gottis und zeugen der ewigen worheit" (A2r). Der Wunsch des Freundes wird somit als Motivation für die Schrift angegeben.

Die in der Tiefenstruktur angelegte polemische Funktion der Schrift der Aufbau eines Feindbildes, Denunzierung, Meinungsbildung und Persuasion - tritt so auf der Textebene bzw. in der Oberflächenstruktur hinter der scheinbaren Motivation, dem Freund Bericht zu erstatten, zurück. ${ }^{729}$ Ebenso verschwindet die (Teil-)Öffentlichkeit, welche im Titel (Sendbrief) impliziert ist, unter dem Deckmantel einer persönlichen Kommunikation. So wird die Fiktion des Briefs zwischen freundschaftlich Vertrauten fast durchgängig aufrechterhalten und vor den Schlussworten noch einmal durch die erneute Anrede „Meyn lieber Michel“ (A6v) nachhaltig bestärkt.

Die Fiktion des Privatbriefs erhöht vor allem die Authentizität des Gesagten, so dass die vorgetäuschte Privatheit nur mehr den Anspruch auf Echtheit generiert. Infolgedessen erscheinen Aussagen als glaubwürdiger. Da Hoffman mit den beiden Figuren scheinbar ,gemeine Männer‘ (z. B. indizieren die Namen keine adlige Herkunft) in einer vertrauten Sprechsituation auftreten lässt, erscheinen die Motive als aus persönlicher Erfahrung gespeist. Darüber hinaus wird das kommunizierte Anliegen personalisiert und entpolitisiert. Damit verfolgt die Schrift Eyn sendbrieff an [...] Michel wachter typische Strategien des offenen Briefs: „Individuelle Betroffenheit beansprucht, als allgemeine, potentiell jeden betreffende Erfahrung zu gelten. " $73^{\circ}$ Insbesondere die nachträgliche Veröffentlichung des Briefs deutet an, dass der Briefeschreiber sein Anliegen als ein für die Allgemeinheit wichtiges einstuft. Hoffman fingiert insofern, dass es sich bei dem Brief nicht nur um einen privaten, sondern auch um einen mit Absicht veröffentlichten Brief handelt. So bedient er zudem das Spannungsfeld zwischen individueller Erfahrung und gesellschaftlicher Mitteilungsnotwendigkeit, das der offene Brief

729 Zur Oberflächen- und Tiefenstruktur vgl. Barner, Wilfried (2000): „Was sind Literaturstreite? Über einige Merkmale“. In: Bachorski, Hans-Jürgen, Georg Behütuns \& Petra Boden (Hg.): Literaturstreit. (= Mitteilungen des Deutschen Germanistenverbands 47: 4). Bielefeld: Aisthesis Verlag, S. 374-380.

${ }_{730}$ Dücker, Burckhard (I992): „Der offene Brief als Medium gesellschaftlicher Selbstverständigung “. Sprache und Literatur in Wissenschaft und Unterricht 69, S. 32-42, hier S. 35 . 
entwirft. Dies wird sogar besonders hervorgehoben, indem der fingierte Absender Caspar Beck am Ende der Schrift dem Empfänger Michel Wachter in Auftrag gibt, den Brief zu veröffentlichen:

Das buechlein von den fünf articlen loß aufs erst in brobendisch [Brabantisch?] trucken und auch disen sendprief darbey. Kanstu darnach eyn solchs in englisch, franßosisch und westrisch [Westflämisch?] trucken lan und fleissig fertigen, so seum nit, dan gelt sol nit gespart werden, auf daß, so ich kom, alles fertig sey, das man dan weyther ander sach trucken mag, dye ich mit werd prengen. (A6r-v)

Zwar werden hier vordergründig Anweisungen für den Druck des ersten Sendbriefs, Caspar Beckers' gegeben, aber es wird auch der Auftrag erteilt, den vorliegenden Brief zu veröffentlichen. Solche Druckaufträge selbst mit abzudrucken, ist eher untypisch für Reformationsschrifttum. Es ist nicht direkt ersichtlich, warum Hoffman diese Anweisungen in den Text integrierte. Zunächst einmal erscheint die Thematisierung der Veröffentlichung im Widerspruch zu der im Text aufgebauten Suggestion zu stehen, dass es sich ursprünglich um einen privaten Brief zwischen zwei Freunden handele und thematisch ein eher persönliches Anliegen besprochen werde.

In einem Verhör am 21. September I 534 erklärte Hoffman, er habe nicht befohlen, die Schrift zu veröffentlichen, sondern lediglich unter seinen Glaubensgenossen zu verteilen. Zudem behauptete er, er habe eine weitere Mitteilung an Cornelius Poldermann verfasst, in der er seine vorherigen Anweisungen zurückgezogen habe. ${ }^{73 \mathrm{I}}$ Aufgrund dieser Aussagen Hoffmans bleibt es ungewiss, inwieweit er nur den engeren Kreis seiner Anhänger oder eine breitere Veröffentlichung im Sinn hatte. Im Text schreibt Hoffman seiner Figur Caspar Beck jedoch unmissverständlich die Intention zu, die verhandelte Sache nicht für sich zu behalten:

[Es] ist mein fleissige bitt, das du alle frommen wolst warnen fur dem pluethund und mortgeister lugenbucher, daß sie keynem screyben glauben geben, uber den zeugen Gottis gethan und von den pluetseufern geendigt, dan es eythel verwante red seyndt und gewaldige, unverschampte lügen. (A6r, Einfügung nach Kohls)

Hier macht der Briefschreiber deutlich, dass seine eigenen Erfahrungen eines größeren Adressatenkreises bedürfen als der alleinigen

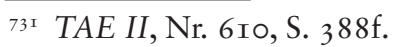


Aufmerksamkeit Michel Wachters: Die Frommen müssen gewarnt, die Lügen über den „zeugen Gottis“ als solche enttarnt werden.

Anhand der Erklärung seiner persönlichen Betroffenheit zeigt sich, wie Hoffman die „bekenntis- und subjektbezogene Funktion des offenen Briefes " 732 verwendet, um die Situation mit Pathos anzureichern und den emotionalen Druck auf mögliche Rezipierende zu erhöhen. Der Absender des Briefs macht deutlich, dass die abgehandelte Sache nicht im Privaten verbleiben könne, sondern ihrer Distribution und Verkündung bedürfe. ${ }^{733}$ Denn, da der Zeuge ${ }^{734}$ nicht mehr in der Lage sei, den „pluetseufern“ unter die Augen zu kommen, um ihnen ihre Lügen vorhalten zu können, wolle er „auß Gottis gnoden die lugen verantworten, daran leyb und ghůt hencken“ (A5v).

Der fiktive Briefeschreiber Caspar Beck übernimmt infolgedessen die Stellvertreterrolle für den im Gefängnis sitzenden Melchior Hoffman und nimmt Stellung zu den „Lügen“ über denselben. Erst am Schluss wird so die Motivation für die Publikationsabsicht ersichtlich:

Meyn lieber Michel, ich sich, daß die mortgeister gar verstockt und verplent seyn und gar ubergeben, ja der ungerechtikeyt eygen. Derhalben gelt mir nit lenger schloffen, sunder durch tag und nacht alle yre grawel und ungerechticheit in alle welt an dag zů prengen, das alle welt yr thorheit, narheit, unsinigkeit und falsche gleysnerische, mordrische heylickeit erkennen mag und sich für yrem grauwel hueten als für dem grausamen teüfel. ( $\left.\mathrm{A}_{5} \mathrm{v}\right)$

Die Motivation ist die Warnung vor den Feinden, die eine Gefahr für die Welt darstellen. Der Verfasser steht hier mit Leib und Seele für die Gerechtigkeit ein und stellt sich in die Verantwortung der Verbreitung dieser, Wahrheit‘. Die Veröffentlichung wird als eine persönlich motivierte Pflicht dargestellt. Diese Motivation am Schluss des Textes wirkt

732 Dücker (I992), S. 34 .

733 Hier wird deutlich, dass Hoffman mit dem Medium des ,offenen Briefs' spielt. Aber wie auch bei den Dunkelmännerbriefen, handelt es sich nicht um einen genuin ,offenen Brief‘ im Sinne Essigs: „Die Dunkelmännerbriefe sind keine Offenen Briefe, spielen sie ja mit der Fiktion, veröffentlichte Privatbriefe zu sein [...]“. Essig (2000), S. 72, Anmerkung I3. Da Hoffman die Veröffentlichung jedoch in der Schrift in Auftrag gibt, erscheint Hoffmans fingierter Brief als Sonderfall, der sich der Kategorisierung Essigs entzieht. Ebd., S. I6.

${ }^{734}$ Hoffman wurde von seinen Anhängern für einen der Zeugen der Apokalypse, Elias, gehalten. Er identifizierte sich selbst ebenfalls mit Elias, während Cornelius Poldermann mit Henoch gleichgesetzt wurde. Im Verhör am 2 I. September I 534 äußerte Hoffman etwa, „er sey der propheten einer, nemlich Helias, die gott zur letzten zit verhaissen hat: das woll er am jüngsten tag bezeugen. “ TAE II, Nr. 6ro, S. 388 . 
wie eine Schlussfolgerung oder ein Fazit aus dem bis dahin Gesagten. Nachdem der Freund informiert worden ist, offenbart sich nur mehr die Notwendigkeit, auch andere aufzuklären und $\mathrm{zu}$ warnen. Die Anweisungen für den Druck sind die Konsequenz.

Mit dem eher unüblichen Abdruck dieser Druckanweisungen scheint eine doppelte Inszenierung vollzogen zu werden: Hoffman setzt sowohl die persönliche Kommunikationssituation eines privaten Briefs als auch die beabsichtigte Veröffentlichung in Szene. Somit gelingt die Verknüpfung mehrerer Funktionen: Auf der einen Seite wird das Anliegen personalisiert und emotionalisiert, auf der anderen Seite wird die als persönlich deklarierte Intention zu einer Frage stilisiert, die eine breitere Öffentlichkeit betrifft.

Die Funktion der abgedruckten Aufforderung zur Übersetzung und Veröffentlichung der beiden Sendbriefe könnte aber auch darin bestehen, die Authentizität des Briefs zu unterstreichen. Die für ein Gesamtpublikum nebensächlich erscheinenden Angaben würden insofern die Originalität des Briefs unterstreichen und somit die vorherrschende Inszenierung einer persönlichen Kommunikation aufrechterhalten. Da der Brief im I6. Jahrhundert ein Medium war, das aufgrund seiner Öffentlichkeitswirksamkeit auch der Gefahr ausgesetzt war, verfälscht oder gefälscht zu werden, konnte eine Bestärkung der Authentizität wichtig sein. Hoffmans Brief ist zwar keine Fälschung eine solche würde bedeuten, dass der Brief etwa im Namen einer anderen ,realen' Person geschrieben wäre -, aber die Kommunikationspartner sind fingiert.

Die Konstruktion der Schrift als Brief und zwar als Privatbrief erfüllte gleich mehrere Funktionen: Zum einen stiftet schon allein die Form des Briefs selbst Authentizität, denn

zumindest einen Teil seiner Glaubwürdigkeit bezog der Brief aus dem Vertrauenskapital, das der Brief als eine Gattung ,offizieller' Prosa genoß. Das fingierte Produkt zehrte sozusagen von der Glaubwürdigkeit der Gattung insgesamt. ${ }^{735}$

So kann es auch Hoffmans Motivation gewesen sein, diesen ExtraZuschuss von Glaubwürdigkeit für sich beanspruchen zu wollen, als er die Form des Briefs für seine polemische Schrift wählte. Die Wahl eines Privatbriefs verstärkt diesen Effekt noch zusätzlich und spitzt das Anliegen zudem noch emotional zu.

$\overline{735 \text { Körber (I996) }, ~ S . ~} 256$. 
Das verdeckte Polemisieren mittels Pseudonym erfüllt zwar zunächst den Zweck, Hoffmans Identität als Autor nicht preiszugeben, ${ }^{736}$ ist aber zugleich Voraussetzung dafür, dass sich die Brieffiktion in der Form überhaupt aufrecht erhalten lässt. Da Hoffman seit Ende Juni I 533 offiziell Schreibverbot hatte, ${ }^{737}$ war offenes Polemisieren für ihn keine Option mehr. Darüber hinaus ermöglichte ihm das verdeckte Polemisieren bei der Textgestaltung, über sich selbst in der 3 . Person zu sprechen und somit Aussagen über die eigene Person aus einer anderen, fingierten Perspektive zu machen. Solche Statements eines ,Dritten' generieren Authentizität und Objektivität, was gleichzeitig die Glaubwürdigkeit der Aussagen bestärkt. Auch in dem bereits erwähnten [...] Sendbrieff an alle gottsförchtigen Liebhaber der ewigen Warheyt werden die wichtigsten Elemente von Hoffmans Lehrgebäude aus der Sicht des fingierten Caspar Beck(er)s dargestellt und kommentiert, so dass eine scheinbare Intersubjektivität zwischen Leser und Verfasser (in der Position des Dritten) geschaffen wird.

Dadurch, dass die Beteiligten der polemischen Situation auf der Textebene andere sind als diejenigen auf der Kontextebene, kann eine ,unbeteiligte' Person als polemisches Subjekt suggeriert werden, so dass Hoffman sich selbst den Beistand durch Dritte in den Text einschreibt. Die Bewertung einer Person und ihrer Ansichten in der 3. Person impliziert eine abwägende Auseinandersetzung mit der bewerteten Lehre und Person. Hoffman muss in diesem Fall das Publikum nicht erst rhetorisch auf seine Seite ziehen, um ein wirksames, glaubwürdiges Urteil über sich selbst aussprechen zu können; stattdessen übernimmt der am inszenierten Streit unbeteiligte Caspar Beck(er) die Rolle des Urteilsverkünders.

Abschließend lässt sich festhalten, dass Hoffman in Eyn sendbrieff an [...] Michel wachter eine hochgradig inszenierte Kommunikationssituation entwirft, die in mehrfacher Hinsicht strategisch angelegt ist: Das verdeckte Polemisieren geht eine gegenseitige Wechselwirkung mit sowohl

${ }_{736}$ Die unmittelbare Wirkung der Schrift war aufgrund der scharfen Polemik immens: Sämtliche Straßburger Drucker wurden zu Verhören vorgeladen und es wurde akribisch nach dem Verfasser der Schmähschrift gesucht. Hoffman und der Drucker Valentin Kobian wurden zwar schlussendlich der Autorschaft und der Drucklegung überführt, eine Weile blieben sie jedoch unerkannt.

737 Siehe dazu das Ratsprotokoll vom 30. Juni I 533: „Item dem Melchior Hofmann soll man kein dinten, feder und papier mehr geben, hab seines irthumbs gleich genug geschrieben [...].“ TAE II, Nr. 400, S. I IO. 
der Fiktion des Privatbriefs als auch mit der im Brief eingeschriebenen Notwendigkeit der Veröffentlichung zur Warnung aller Gläubigen ein. Inwiefern sich aus dieser hochgradig konstruierten Schrift die Möglichkeit der scharfen Polemik speist, wird im Anschluss erörtert.

\subsection{Die scharfe Polemik der zweifach verdeckten polemischen Situation in Eyn sendbrieff an [...] Michel wachter}

Die bereits eingeführte Schrift Eyn sendbrieff an den achtbaren Michel wachter ${ }^{73^{8}}$ ist einer der letzten veröffentlichten Texte Melchior Hoffmans. Diese kurze, höchst polemische Schrift erschien entweder im Juli oder August I 534. ${ }^{739}$ Da Hoffman erst in einem Verhör am 2 I. September 1534 seine Autorschaft bestätigte, ${ }^{70}$ zirkulierte das kleine „schmachbüchlein“741 somit etwa einen oder zwei Monate unter dem Pseudonym Caspar Beck. Aus diesem Grund kann davon ausgegangen werden, dass es den Rezipienten anfangs nicht bewusst war, dass es sich bei der polemischen Schrift um Hoffmans Werk handelte. Die Situation des verdeckten Polemisierens kam insofern in dieser Zeitspanne noch voll zum Tragen, wie die umgehenden Ermittlungsverfahren, den Drucker der Schrift ausfindig zu machen, bestätigen.

${ }_{73}^{8}$ Vollständige Angabe siehe Anmerkung 7 I 8. Zitate werden in diesem Kapitel allein mit Folienangabe in Klammern nachgestellt.

739 Der Zeitraum von Juli bis August ergibt sich aus den Daten der Veröffentlichung des Berichts Wolfgang Capitos über Claus Frey sowie aus den Verhören des Hagenauer Druckers Valentin Kobian und der Straßburger Buchdrucker „[w]egen M. Hoffmans schmachbüchlein“, die ungefähr Mitte August, höchstwahrscheinlich den 22., begannen. Da noch am I 5 . August in einem Gespräch der Straßburger Prediger mit Melchior Hoffman kein Wort über die Schrift gewechselt wurde, kann man eher eine spätere Veröffentlichung im August annehmen. Dies bleibt aber lediglich eine Annahme, da genaue Zeugnisse fehlen. Zu den Daten und Aufzeichnungen der Verhöre siehe TAE II, Nr. 594, S. 370 ; Nr. 596, S. 37 I; Nr. 597, S. 372-374. \& Nr. 600, S. 379 f. Der Bericht Capitos über Claus Frey, auf den Hoffman in dieser Schrift Bezug nimmt, ist laut Täuferakten nach dem I 2. Juni veröffentlicht worden, so dass Eyn sendbrieff an [...] Michel wachter erst danach geschrieben worden sein kann. TAE II, Nr. 564, S. 32I-342. Vollständige Angabe des Berichts: Capito, Wolfgang (I 534): Ein wunderbar geschicht vnd ernstlich warnung Gottes, so sich an eim wiedertäuffer genant Claus Frey zutragen, der mit vnerhörtem trutz und bochen sich hat ertrencken lassen, ehe dann er hat wöllen seine fromme ehefraw, bey der er XV jar fridsam gelebt unnd VIII kinnd gezenget, widerannemen unnd ein andere fraw begeben, so er im schein eins geistlichen ehestands an sich gehenckt hatt. Geschehen und beschriben zu Strassburg durch Wolffgang Capito. Anno MDXXXIIII. Abschrift in TAE II, Nr. 564, S. 32 I-342.

${ }_{740}$ TAE II, Nr. 6Io, S. $387 \mathrm{f}$.

${ }_{741}$ TAE II, Nr. 596, S. 37 I. 
Dass Hoffman nicht nur seine Autorschaft mit dem Pseudonym maskiert, sondern sogar die gesamte ,reale' polemische Situation verdeckt, wurde bereits im vorangegangenen Kapitel erörtert. Hoffman entwirft auf Textebene ein polemisches Subjekt und eine polemische (Teil-)Instanz, die keine ,realen' Entsprechungen auf Kontextebene besitzen. Darüber hinaus modifiziert er das polemische Thema, indem er die Perspektive eines Unbeteiligten am inszenierten Streit einnimmt und seine eigene Person zu einem Teil des polemischen Themas macht. Diese in mehrfacher Hinsicht modifizierte polemische Situation hat zur Folge, dass die Polemik, die Hoffman in dieser Schrift äußert, von den Bedingungen der ,realen' polemischen Situation gelöst ist. Um diese These bestätigen zu können, wird zunächst der bislang vernachlässigte Kontext der Schrift näher erschlossen, denn es muss deutlich herausgearbeitet werden, wo die Unterschiede zwischen ,Realkontext ${ }^{\star}$ und ,Kontextfiktion' liegen. Eyn sendbrieff an [...] Michel wachter stellt eine in mehrfacher Weise durchkonstruierte Streitinszenierung dar, weshalb das Offenlegen von Oberflächen- und Tiefenstruktur für ein umfassendes Verständnis der einzelnen Funktionen erforderlich ist. Infolgedessen wird zunächst der Entstehungskontext der Schrift erläutert. Daran wird sich die Erörterung der Verschlüsselung der Streitinszenierung auf Textebene anschließen. Eingehende Untersuchungen des polemischen Gehalts, der rhetorischen Gestaltung und der Funktionen der kurzen aber dichten polemischen Schrift komplettieren schließlich die Analyse.

\section{Der Entstehungskontext: Die Ereignisse rund um Claus Frey}

Wie bereits erörtert wurde, gibt der fingierte Briefeschreiber als Anlass des Schreibens vor, dem Wunsch Michel Wachters nachzukommen und ihn darüber zu informieren, „wie es [...] mit dem diener Gottis und zeugen der ewigen worheit" (A2r) stehe. ${ }^{742}$ Der eigentliche Anlass der Schrift war für Hoffman jedoch ein anderer. Unter dem Deckmantel des Sendbriefs sind dementsprechend andere Motive verborgen. Hoffmans Anlass, zur Feder gegen die Straßburger Reformatoren zu greifen, war zum einen seine Verhaftung am 20. Mai ${ }_{1533}{ }^{743}$ zum anderen die

${ }^{742}$ Der Gottesdiener ist Melchior Hoffman. Die Namen werden im gedruckten Brief selbst nicht genannt, sondern verschlüsselt. Eine handschriftliche Ergänzung am Ende des Sendbriefs löst dies jedoch auf. Dieser Umstand wird im Folgenden noch diskutiert werden.

743 Deppermann (1979), S. 255. Siehe auch den Bericht über das Verhör Melchior Hoffmans am 20. Mai I 533 in: TAE II, Nr. 364, S. I4. 
Publikationen diverser Schriften der Straßburger Prediger, die sich auf jene Ereignisse und Hoffman bezogen.

Die Verhaftung Melchior Hoffmans war prinzipiell nicht verwunderlich. Er war, wie bereits erwähnt wurde, schon im Jahre I 530 nur mittels der Flucht nach Ostfriesland einem Haftbefehl des Straßburger Magistrats entkommen. Als Hoffman I 533 nach Straßburg zurückkehrte, blieb seine Ankunft jedoch zunächst geheim, weshalb ihm keine Verhaftung drohte. Hoffman lebte und wirkte nur inoffiziell in Straßburg, bis seine Anwesenheit von einem seiner Mitstreiter, dem Kürschner Claus Frey, an den Rat weitergetragen wurde. Die Gründe dafür, dass Frey, der selbst Wiedertäufer war, einen seiner ehemaligen Glaubensgenossen verriet, lagen vor allem in anhaltenden Unstimmigkeiten zwischen ihm und Hoffman, die auf Freys Entwicklungen eines Lebensstils basierten, den Hoffman nicht guthieß.

Claus Frey war aufgrund seiner wiedertäuferischen Gesinnung aus seiner Heimat Windsheim (Bayern, Oberfranken) vertrieben worden. Bald darauf wurde er Vorsteher der fränkischen Täufer und war vermutlich mit der fränkischen Sekte der Träumer in Kontakt, „die gemäß ihren Eingebungen und Träumen ihre Ehepartner miteinander tauschten “. ${ }^{744}$ Auf dem Schloss des adligen Georg Groß, genannt Pfersfelder, hatte Frey dessen verwitwete Schwester Elisabeth Pfersfelder kennen gelernt, die er zu seiner "geistlichen Eheschwester" 745 ernannte. Seine Ehefrau, die sich geweigert hatte, mit ihm zu ziehen, und somit in Windsheim zurückgeblieben war, degradierte er zu einer „alten Schlange des Satans“. ${ }^{746}$ Nachdem Frey und seine neu ernannte Partnerin vom Schlossherrn vertrieben worden waren, suchten sie in Straßburg im Kreise der Straßburger Propheten Zuflucht. Hoffman und andere Mitglieder der Gruppe lehnten jedoch den Ehebruch Freys ab und rieten ihm, zu seiner Frau zurückzukehren. Frey ließ trotzdem nicht von seiner neuen Gefährtin ab, so dass er schließlich von Hoffman und anderen aus dem Kreise der Straßburger Propheten ausgestoßen

\footnotetext{
${ }_{744}$ Deppermann (I979), S. 254.

745 In seinen Verhören taucht diese Bezeichnung für Elisabeth Pfersfelder auf. Ebenfalls verzeichnet sind auch „,eheliche Schwester“, „Eheschwester“, „geistliche Schwester“ etc. TAE II, Nr. 36I, S. IIf; Nr. 362, S. I3f; Nr. 369 , S. 2of; Nr. 388, S. 92 f. \& Nr. 456, S. $208 \mathrm{f}$.

${ }^{746}$ Capito berichtet von einem Brief Claus Freys an Elisabeth Pfersfelder und zitiert daraus, was jener über seine Ehefrau schreibt: „Mein weib ist der alt schlang, der satanas, vnd du das weib, welches somen ir soll den kopff zertretten, (vgl. Gen. 3, I 5) so muß ich nemlich der somen sein [...]." Capito (I 534): Ein wunderbar geschicht und ernstlich warnung Gottes, A6v. In: TAE II, Nr. 564, S. 327.
} 
wurde. Auch von den Bürgern der Stadt wurde die Beziehung zwischen Claus Frey und Elisabeth Pfersfelder argwöhnisch betrachtet. Ihre Anwesenheit in Straßburg wuchs sich zu einem regelrechten Skandal aus, infolgedessen es immer wieder öffentliche Streitigkeiten gab, die erst mit der Verhaftung der beiden zum Erliegen kamen. Als Rache für die ihm zugekommene Behandlung im Kreise der Straßburger Propheten verriet Frey dem Magistrat den Aufenthaltsort Hoffmans und behauptete, dass dieser mit seinen Anhängern die Obrigkeiten nicht anerkenne und ein Aufruhr nicht auszuschließen sei. ${ }^{747}$ Daraufhin wurde Hoffman verhaftet. ${ }^{78}$ Die Anklagen Freys, dass er einen Aufruhr plane, wies Hoffman zwar in einem Verhör am 29. Mai I 533 zurück, „[a]ber es sey nach der h. schrifft gantzer welt ein vffrur vnd rumoren zu besorgen, sey vorhanden “. ${ }^{749}$ Hoffman war der Auffassung, dass dieser Aufruhr durch die Türken ausgeführt werden würde; er rief selbst nicht zu aktivem Handeln in dieser Sache auf. Auch Claus Frey zog seine Anschuldigungen bei einem Verhör am 29. Mai wieder zurück.750 Hoffman blieb trotzdem weiterhin in Haft und Frey wurde infolge des Ehebruchs als einziger Wiedertäufer in Straßburg zum Tode verurteilt und am 22. Mai I 534 ertränkt. ${ }^{75}$ Capito nutzte die Ereignisse, um die Täufer und den hoffmanschen Kreis in ein schlechtes Licht zu rücken, und verfasste einen Bericht, Ein wunderbar geschicht vnd ernstlich warnung Gottes, so sich an eim wiedertäuffer genant Claus Frey zutragen, ${ }^{752}$ der die Geschehnisse und die Anschuldigungen Freys gegenüber Hoffman in einer Weise wiedergab, die Hoffman als Aufrührer

747 Siehe die Verhöre von Elisabeth Pfersfelder und Claus Frey vom I4. Mai, und die Verhöre von Claus Frey vom I9., 20. und 29. Mai I 533 in TAE II, Nr. 36I, S. I 2f; Nr. 362, S. I 3 f. \& Nr. 369, S. 2 of.

${ }^{74^{8}} \mathrm{Zu}$ den Ereignissen und dem Verhältnis zwischen Hoffman und Frey siehe Deppermann (I979), S. 254-256 und Zur Linden (I885), S. 3I 5-3 I7. Siehe auch das Verhör Hoffmans vom 20. Mai I 533 in TAE II, Nr. 364, S. I4f.

749 Protokoll von Hoffmans Verhör am 29. Mai I 533 in TAE II, Nr. 368, S. I 8.

$75^{\circ}$ „Claus Freyen von Winßheim widerumben verhört, gesteet seiner vorigen bekantnus noch wie vor, allein daß er sagt, er hab nie gesagt, daß vil vffrüerer alhie seyen, aber vil seltzsamer widerwertige secten vnd glauben; wo man die sachen nit bey fürkomme, seyen vffruren vnd übels zu besorgen. “ TAE II, Nr. 369, S. 20.

${ }^{75^{1}}$ Capito schreibt in seinem Bericht: „[E]in ersamer rath [hat] am XIX. maij (was am zinstag vor pfingsten) das vrteil geben, das er soll ertrenkt werden [...].“ Am darauffolgenden Freitag, den 22. Mai I 534, wurde er hingerichtet. Capito (I 534): Ein wunderbar geschicht vnd ernstlich warnung Gottes, B3r. In: TAE II, Nr. 564, S. 332 f. Vgl. dazu auch TAE II, Nr. 573, S. 345, Anmerkung I).

752 Vollständiger Titel des Berichts bei Anmerkung 739. 
erscheinen ließ. Höchstwahrscheinlich war diese Schrift der Grund dafür, dass Hoffman zur Feder griff und Eyn sendbrieff an [...] Michel wachter verfasste.

Indem Hoffman sich in dieser Schrift als Autor verschleiert wird der Auslöser, der zugrunde liegende Streit, aus der Sicht des unbeteiligten Caspar Beck dargestellt, aber nicht zum Anlass des Schreibens gemacht. Der inszenierte Anlass ist nämlich, der Bitte Michel Wachters, ihm zu berichten, „wie es stant mit dem diener Gottis und zeugen der ewigen worheit" (A2r) nachzukommen. Demgemäß berichtet Caspar Beck, „daß die lugenhaftigen phariseer zu Jerusalem im noch hals und leben stond, ob sie sein unchuldiges [sic!] plut mochten saufen und sein fleisch fressen durch yr lugenhaftigen schriften und selb erdichte oede zeucknisse" (A2r). Klar erkennbar sind die Positionen des polemischen Antagonismus, der durch das verdeckte Polemisieren aus der Sicht einer Person dargestellt wird, die keine aktive Rolle im Streit selber spielt.

\subsubsection{Die Ver-/Entschlüsselung der Figuren}

Der oben herausgearbeitete eigentliche Anlass für die polemische Schrift Hoffmans wird in Eyn sendbrieff an [...] Michel wachter nicht offenkundig dargelegt, sondern auf der Textebene des gedruckten Sendbriefs nur verschlüsselt angedeutet:

Es hat der eyn plüthundt seynen treck und saurteig wol außgescheumt und auch der andre pluthündt hernoch, jetz kumpt der dritte pluthündt und schreyt grausam nach unschuldigem plut, wie du dann in seinem buechlein hoeren wurst, das ich dir sende mit disem boten. $\left(\mathrm{A}_{2} \mathrm{v}-\mathrm{A}_{3} \mathrm{r}\right)$

Hoffman lässt seinen Briefeschreiber lediglich von ,Bluthunden“ reden und nennt sie nicht beim Namen. Es werden keine konkreten Schriftstücke genannt, sondern es wird beschrieben, dass sie ihren „treck und saurteig wol außscheum[en]“ (A2v) oder „grausam nach unschuldigem plut [schreien]“ (A3r). Ein „buechlein“ (ebd.) wird zwar erwähnt, aber sein Titel bleibt im Unklaren.

Im gesamten Sendbrief sind die einzelnen Figuren, über die geredet wird, durch aufwertende oder abwertende Synonyme verschlüsselt: Auf der einen Seite steht der "diener Gottis und zeugen der ewigen worheyt", auf der anderen „die lugenhaftigen phariseer zu Jerusalem “ (A2r), die „pluthund“ (A4v) und andere Bezeichnungen. Die Verschlüsselung der beiden sich antagonistisch gegenüberstehenden Parteien, die auf der Textebene vorgenommen wird, wird interessanterweise durch einen 
handschriftlichen Zusatz auf der Rückseite der Drucke aufgelöst. Dort hatte jemand offenbar schon in der Druckerei auf sämtliche Exemplare folgenden Text zur Erklärung geschrieben: ${ }^{753}$

Der vnsculdige gefangē zugē

ist Melchior Hofmañ.

Jherusalem ist Straßburg.

Dye pluthund seynt Hedio

Butzer, Capito.

Im buch vber Clauß Kurtzener

hat Capito dye lugen geschreue. 754

Durch diesen handschriftlichen Nachtrag wurden sämtliche indeterminierte Figuren der Textebene entschlüsselt und der bis dahin inszenierte Streit kontextualisiert. Im Nachhinein erfährt die Polemik so erst ihre besondere Schärfe. Die den Streit ausgelöste Schrift, Capitos Bericht über Claus Frey, wird hier zudem eindeutig beschrieben. Unklar bleibt lediglich, auf welche Schriften oder Ereignisse Hoffman bei Bucer und Hedio rekurriert. 755

Diese zusätzlichen Informationen kamen allen Lesern der Schrift zu und lösten zudem beim Rat eine groß angelegte Suche nach dem Urheber und Drucker der Handschrift aus. ${ }^{756}$ Für einen Kenner der Geschehnisse in Straßburg bedurfte es dieser Informationen nicht; da jedoch angedeutet wird, dass die Schrift in weiteren Kreisen als den

753 Kohls (I96I), S. 358.

754 Samt typographischem Layout nach Kohls (I96I), S. 358.Vgl. auch TAE II, Nr. 595a, S. 526. „Clauß Kurtzener“ ist der Kürschner Claus Frey.

755 Bei den Schriften Bucers und Hedios sind sich die Forscher nicht einig. Kohls geht davon aus, dass der erste ,Bluthund' Bucer sei und es sich um seinen zwischen dem I4. Juni und 7. Juli erschienenen Bericht von der Synode (siehe Anmerkung 422) handele. Der zweite ,Bluthund' sei demnach Hedio mit seiner gegen die Sektierer gerichteten Münsterpredigt/Ratspredigt vom I 4. Januar I 534, die am 6. März I 534 im Druck erschien. Kohls (I96I), S. 359 f. In den Täuferakten wird hingegen vermutet, dass alle Schriften aus dem Jahre I 534 stammen. In dem Falle wäre Hedio der erste ,Bluthund' mit seiner Predigt und Bucer der zweite mit seiner Schrift Bericht auß der heiligen geschrift ... der stat und kirchen zu Münster ... geschriben (TAE II, Nr. 5I9, S. 286-29I). Dies würde der Reihenfolge der Aufzählung innerhalb der handschriftlichen Entschlüsselung entsprechen, was aber nicht bedeuten muss, dass die Reihenfolge in dem Hinblick auf die Erscheinungsdaten gewählt wurde. TAE IV, Nr. 595 a, S. 523.

${ }^{756}$ Der Rat ließ vermutlich am 22. oder I 6. August I 534 sämtliche Straßburger Drucker verhören, die alle auf den Drucker Valentin Kobian aus Hagenau verwiesen, den Verfasser der Schrift aber nicht zu nennen vermochten. Protokoll der Verhöre ist zu finden in: TAE II, Nr. 596, S. 37 If \& Nr. 597, S. 372-378. 
Straßburgern vertrieben werden sollte (die Druckanweisungen inkludieren schließlich Übersetzungen in verschiedene Sprachen), war dies ein wichtiger Schlüssel für das Verständnis des Textes. Dass die Auflösung der Verschlüsselung per Handschrift vorgenommen wurde, ist zunächst verwunderlich. Man könnte sie als Ergänzung deuten, die jemand in der Druckerei für relevant hielt, es könnte aber auch als Zusatz des Herausgebers betrachtet werden, der eine eventuelle Zensur durch den Drucker vermeiden wollte. Aufgrund der Tatsache, dass Valentin Kobian - zwar anonym - ein generelles Risiko beim Drucken der Schrift einging, ist es jedoch fraglich, ob eine Zensur durch den Drucker zu fürchten war. Darüber hinaus ist die Handschrift nicht vom Drucker, sondern vermutlich von Cornelius Poldermann, der den Druck der Schrift organisierte. ${ }^{757}$ Als dritte Möglichkeit läge im Kontext des übrigen durchkonstruierten Charakters der Schrift aber auch nahe, dass es sich um eine bewusst eingesetzte Strategie handelt, die Entschlüsselung als Zusatz zu tarnen. Innerhalb der Brieffiktion verbleibt die Polemik indeterminiert und kann insofern als weniger scharf gelten. Die handschriftlichen Zusätze inszenieren dementsprechend Kommentare eines individuellen Lesers zu sein, der seine Interpretation des Textes preisgibt. Eine solche Bearbeitung mit Marginalien und handschriftlichen Kommentaren war im I6. Jahrhundert üblich, so dass die strategische Vortäuschung von Leserkommentaren durchaus glaubhaft war. ${ }^{758}$

Ungeachtet der Intention, die mit ihnen verfolgt wurde, funktionieren die handschriftlichen Zusätze als Katalysator der Polemik: Die Auflösung der Verschlüsselung am Ende der hochgradig polemischen Schrift gibt ihr rückwirkend zusätzliche Schärfe und Aktualität. Sie ist der Zünder für die polemische Detonation.

\subsubsection{Die semantische Klimax des polemischen Antagonismus}

Es ist bereits gezeigt worden, dass die polemische Kommunikationssituation in Eyn sendbrieff an [...] Michel wachter eine besonders

757 Der Druck ist Valentin Kobian nachträglich durch den Vergleich mit anderen seiner unterschriebenen Drucke nachgewiesen worden. Dass die handschriftlichen Kommentare von Cornelius Poldermann stammen, wird aufgrund von seiner Anhängerschaft und früheren Herausgeberschaften vermutet. Siehe dazu: TAE IV, Nr. 595 a (zu S. 37I), S. 526f. Im Verhör am 2I. September I 534 gibt Hoffman neben seiner Autorschaft der Schrift auch die Zusammenarbeit mit Cornelius Poldermann zu, der den Druck organisieren sollte. In TAE II, Nr. 6Io, S. $387 \mathrm{f}$.

${ }^{75^{8}}$ Leider sind keine konkreten Rezeptionszeugnisse vorhanden, die berichten, wie die handschriftlichen Nachträge realiter bewertet wurden. 
aufwendig konstruierte ist: Infolge des verdeckten (pseudonymen) Polemisierens, der Fiktion eines veröffentlichten Privatbriefs und der Verschlüsselungs-Entschlüsselungsstrategie der beiden antagonistischen Positionen wird die ,reale' polemische Situation auf mehrfache Weise verdeckt bzw. als verdeckt simuliert: Der Einsatz des Pseudonyms kann als verdecktes Polemisieren im Sinne der entwickelten Kategorien eingeordnet werden, wohingegen die Fiktion des Privatbriefs und die vorgetäuschte Verschlüsselung der Figuren als Verdeckungsstrategien der polemischen Intention betrachtet werden können. Ihre umgehende Relativierung durch die Veröffentlichung (des Privatbriefs) zum einen und die Auflösung der Verschlüsselung zum anderen sind als ,nachträgliche Verfahren' (zum Teil durch fremde Hand) getarnt, so dass die aufgebauten Suggestionen sich nicht auflösen, sondern ihre Wirkung in dem Spannungsfeld dazwischen entfalten. Das Ergebnis ist extrem scharfe Polemik gegen die Straßburger Reformatoren.

Thematisch ist die kurze Schrift wenig variationsreich, denn es geht lediglich darum, wie die positiv charakterisierte Figur (Hoffman) von insgesamt drei negativ dargestellten Figuren (Hedio, Bucer, Capito) „durch yr lugenhaftigen schriften und selb erdichte oede zeucknisse“ (A2r) denunziert wird. Der Briefeschreiber bezieht von Anfang an eine klare Position und erläutert auf verschiedene Weise, dass die Aussagen über Hoffman in den Schriften der Prediger schlichtweg Lügen, Verdrehungen und Verleumdungen seien. Obgleich die metaphorischen Bilder und Szenarios, die auf unterschiedliche Weise die Verfolgung Hoffmans darstellen, dominieren, können einige Argumente identifiziert werden. Es wird etwa erklärt, dass sich die Prediger bezüglich Hoffmans Person und Handlungen widersprechen: „Der pluthund screybt, er [Hoffman] lig umb mort und aufrůr gefangen. Sihe, wie feyn reympt sich das mit yrem ersten bůch? Do schreyben sie wider sich selber“ (A3v). Das Fazit daraus wird ebenfalls gegeben: „Also muß der gotlose pluetzapf seyn eygen schandt außscheumen und aufdecken“ (ebd.). Es wird argumentiert, dass eine von den Schriften der Reformatoren Hoffmans Offenbarungs-Auslegung verdreht wiedergibt und dass der Vergleich der Schriften miteinander dieses bezeugen würde $\left(\mathrm{A}_{4} \mathrm{r}\right)$. Mit diesen Andeutungen kontextualisiert Hoffman deutlich seine Schrift - für seine Anhänger in Straßburg rasch zu erkennen. Nicht zuletzt kann man die Aussage, dass „im I 533 jar [...] Jesus Christus, das ewig wort und worheit, offentlich verdampt, undertruckt und ermort worden [ist] durch die obgemelten pluthund" (A4v) als Hinweis auf Hoffmans Verhaftung, die Vorladung zur Synode in Straßburg oder 
auch Bucers Bericht der Synode verstehen. Außerdem werden die vermehrten Erlasse gegen die Wiedertäufer angesprochen: Anfangs wurde nur die Bewirtung und Beherbergung von Wiedertäufern verboten, später unter Androhung einer Ausweisung eine Zwangsversöhnung mit der Kirche gefordert, sämtliche Kinder zur Taufe und die Gläubigen zum Schwören des Eids gezwungen. ${ }^{759}$ Hoffman referiert klar auf diese nach und nach eingeführten Mandate:

Wo sie eynen diener und boten Gottis ermercken, do mueß er auß der burger heuser gegeben und anzeigt werden, und do sehen sie dan zů, wye sye yn mit yrem falschen somen und wort besudlen moegen, ja verderben, in grauwel und zů teufel prengen." (A5r)

Insbesondere das Herbergsverbot und der Zwang zur Übernahme einer falschen Lehre - die der Straßburger Kirche - können unmissverständlich wiedererkannt werden. Solche Kontexthinweise sind in Eyn sendbrieff an [...] Michel wachter zwar nur spärlich gesät, aber ein Kenner hätte auch ohne die handschriftliche Entschlüsselung am Ende der Schrift gewusst, wer gemeint war.

Die Polemik in der kurzen Schrift funktioniert allerdings weniger über die kontextuelle Argumentation, als vielmehr über die Darbietung einer Semantik der Extreme. Der polemische Antagonismus in Eyn sendbrieff an [...] Michel wachter wird dominierend durch die Wortwahl und die bildliche Sprache erzeugt. Das verdeckte Polemisieren unterstützt dabei die Möglichkeit eines Direktvergleichs, denn dadurch, dass Caspar Beck als polemisches Subjekt konstruiert wird, befinden sich die beiden Streitparteien, die im Text thematisiert werden (Hoffman und die Straßburger Prediger), im selben Verweisraum - nämlich dem der 3. Person. Es findet demnach kein Wechsel des Verweisraumes (zur I. Person z. B.) statt. Zudem täuscht die Fiktion eines am Streit unbeteiligten polemischen Subjekts eine objektivere Perspektive vor, so dass die Glaubwürdigkeit des Vergleichs zusätzlich erhöht wird.

Wie bereits erläutert, werden die Streitparteien im gesamten Text unter pejorativen bzw. affirmativen Prädikationen verschlüsselt. In der Erzählung des Briefeschreibers werden so weder die Namen noch die beruflichen Rollen der Hauptfiguren genannt, so dass die Prädikationen keine Hinweise auf die dahinter verborgenen Personen geben - wie z. B. die argumentativen Abschnitte. Ihr Zweck liegt lediglich darin, zu beleidigen oder aufzuwerten, was auch durch die Variation der Ersatznamen

759 Vgl. Deppermann (I979), S. 258-267. 
und -bezeichnungen deutlich wird: Die Straßburger Prediger werden einzeln oder in der Gruppe als „des teufels ewige diener“ (A2v), „plůthundt“ (ebd.), ${ }^{760}$ „reyssende[] woelfe[] under dem schofscleydt" $\left(\mathrm{A}_{3} \mathrm{r}\right)$, „mortwolf und mortgeister" (ebd.), ${ }^{76 \mathrm{I}}$ "grauwelgeister und plutzapfer“ (ebd.), „woelf“ (ebd.), „gotlose pluetzapf“ (A3v), „morder Chain“ (A4r) „elendig, mortgyrige lugengeist“ ( $\left.\mathrm{A}_{4} \mathrm{v}\right)$, „pluethund und mortgeister lugenbucher“ (A6r) und „pluetseufer[]“ (ebd.) bezeichnet. Es fällt auf, dass die Bezeichnungen aus hauptsächlich zwei semantischen Bereichen stammen: Zum einen wird das Lügner-Motiv gewählt, zum anderen das Motiv des (blutsaugenden) Mörders in Verkörperung eines Tieres. Das Motiv des Lügners hatte Hoffman auch schon in seinen Streitschriften an Nikolaus von Amsdorf benutzt, das weitaus grausamere und anschaulichere Bild des Bluthundes bzw. blutgierigen Wolfes ist eine Steigerung der bisherigen Polemik Hoffmans. Es taucht erst in seinen späteren Schriften auf und weist auf den sich zuspitzenden Konflikt zwischen Hoffman und den lutherischen und zwinglischen Reformatoren hin. Mit der enormen Dichte der pejorativen Bezeichnungen sticht Eyn sendbrieff an [...] Michel wachter dennoch als besonders scharf polemisierend heraus.

Mit den nominalen Bezeichnungen für die Gegner gehen auch die Tätigkeiten derselben einher: An mehreren Stellen wird erwähnt, dass sie „unchuldiges plut mochten saufen und [...] fleisch fressen“ (A2r). Mehrmals tauchen die Verben ,saufen“ und ,fressen“ auf, die auch schon im Frühneuhochdeutschen eine pejorative Konnotation haben. ${ }^{762}$ Das Trinken bzw. das Dürsten nach „unsculdigem plut“ (A2v) zieht sich durch die gesamte Schrift. ${ }^{763}$ Die vielfache Verwendung dieses Themas wirft die Frage auf, ob das Bluttrinken und die damit verknüpften Prädikationen, wie z. B. „plutzapf“ (A4r), als metaphorische Beschimpfungen fungieren oder ob sie als Schlagwörter zu betrachten sind.

${ }^{760}$ Die Bezeichnung „plůthundt“ taucht (in anderer Schreibung) durchgehend in der Schrift auf, z. B. auf: A2v, A3v, A4r, A4v, A5r, A5v \& A6r.

${ }^{761}$ „mortgister“/,mortgeistern“ auch zu finden bei: A4r, A4v, A6r \& A6v.

${ }^{762}$ „saufen, gierig und unmäszig oder in unschicklicher weise eine flüssigkeit aufnehmen; wann und wo diese bedeutung zuerst aufgekommen, ist nicht näher zu bestimmen. bei LUTHER ist saufen schon durchaus ein starker ausdruck. „SAUFEN“, DWB I4, Sp. I877-I882. Fressen ist zudem bereits ein Ausdruck für Tiere, so dass zusätzlich der Vergleich mit animalischem Verhalten gezogen wird. Vgl. „FRESSEN“, DWB 4 , Sp. I33.

${ }_{763}$ Variationen des Blutdurstes finden sich auch an folgenden Stellen: A2v (2 X), A2v, $\mathrm{A}_{4} \mathrm{a} \& \mathrm{~A} 5 \mathrm{~b}$. 
Im Falle des Schlagwortcharakters kann angenommen werden, dass die Ausdrücke auf die Abendmahlsfrage rekurrieren, die in der Reformation einen wichtigen Teil der Streitigkeiten zwischen sämtlichen Parteien einnahm. Hoffman hatte die Realpräsenz Christi im Abendmahl bestritten und lehnte sowohl die altgläubige Transsubstantiations- als auch die lutherische Konsubstantiationslehre ab. Anfänglich teilte Hoffman die Auffassung von einer geistigen Präsenz Jesu Christi, die durch den Glauben hergestellt wird, mit den zwinglischen Reformatoren in Straßburg. Da Bucer aber seit etwa I530 auf eine Einigung mit Luther hinarbeitete, liegt es im Bereich des Möglichen, dass Hoffman auf Bucers Eingeständnisse gegenüber Luther in der Abendmahlsfrage polemisiert. ${ }^{64}$ Bucer hatte im Zuge seiner Bemühungen, protestantischen Konsens zu erzielen,

die wahre Anwesenheit und Darreichung [des Leibes Christi] in der Abendmahlsfeier [bekannt]. Das Brot schließe [seines Erachtens] den Leib nicht ein, sondern sei kraft Einsetzung das Instrument, mit dem der Leib dargeboten wird. ${ }^{65}$

$\mathrm{Zu}$ dem Entstehungszeitpunkt von Hoffmans Schrift war Bucer also bereits von der Realpräsenz Christi im Abendmahl - wenn auch prinzipiell nicht im, sondern mittels Brot und Wein - überzeugt. Inwiefern Hoffman diese Veränderungen in Bucers Abendmahlsauffassung zugetragen wurden, ist nicht bekannt. Es ist aber durchaus möglich, dass Hoffman darüber im Bilde war, da er mithilfe seiner Gefängniswärter unerlaubterweise regen Kontakt zu seinen Anhängern pflegte. Eine solche Interpretation liegt zudem nahe, da die Ähnlichkeit zu einer Reihe von in der Zeit zu Schlagwörtern avancierten Ausdrücken augenfällig ist. ${ }^{766}$

Zwar wird in Eyn sendbrieff an [...] Michel wachter das Abendmahl nicht an der Textoberfläche thematisiert, Hoffmans Wortgebrauch lehnt

${ }_{764}$ Zwar gab Bucer die zwinglische Grundidee des Abendmahls nicht gänzlich auf, machte Luther aber Zugeständnisse, so dass Zwingli sich selbst verraten fühlte, was er in einem Brief vom 2I. Februar I 53 I an Bucer verdeutlicht. Greschat, Martin (2004): Martin Bucer. A Reformer and his Times. Übersetzt von Stephen E. Buckwalter. Louisville, Kentucky: Westminster John Knox Press, S. 97.

${ }^{765}$ Scheible, Heinz ( 1993 ): „Melanchthon und Bucer“. In: Krieger, Christian \& Marc Lienhard (Hg.): Martin Bucer and sixteenth century Europe. Actes du colloque de Strasbourg, 28-3 I août I992. Bd. I. Leiden: Brill, S. 369-394, hier S. 373.

${ }^{766}$ Lepp (I908), S. 3f. Lepp zählt in diesem Zusammenhang eine Sammlung von allen Parteien genutzter Schlagwörter auf: „Brot-, Fleisch-fresser; Blut-, Weinsäufer; Sacramentsrotter, -schwärmer, -schänder, -dieb, -räuber, -stürmer; Kelcher, Kelchtrinker, Altar-, Messstürmer etc. “ Ebd. 
sich aber deutlich an geläufigen Schlagwortgebrauch an, so dass der Bedeutungsgehalt der bereits etablierten Schlagwörter auf Hoffmans Text zurückwirkt. Die hier angewandte Tiermetaphorik wird so mit der Frage der Realpräsenz Christi im Brot und Wein vermischt. Was bei den Katholiken und den Lutheranern noch geheiligter Akt der Empfängnis Jesu war, wird durch die spiritualistische Auffassung aus dem Kontext der heiligen Zeremonie losgelöst und in den Kontext einer kannibalistischen Handlung versetzt. ${ }^{767}$ In Hoffmans Schrift wird sie noch zusätzlich in den Kontext tierischen Jagdverhaltens gestellt: Die Akteure seien Bluthunde, die nach Beute schreien, und „reyssende[] woelfe[] under dem schofscleydt, [...] die die eynfeldigen und unschuldigen armen schoflein Gottis ermorden [...]“ (A3v). Durch die Tiervergleiche einerseits, die Verben ,fressen' und ,saufen' andererseits wird die Zeremonie des Abendmahls vom heiligen zu einem bestialischen Akt verschoben.

Es bleibt trotz der Gegebenheiten offen, inwiefern Hoffman den Bezug auf das Abendmahl intendierte bzw. den Schlagwortcharakter seiner Polemik mit Absicht anlegte. Auch die Rezeption von Hoffmans Schrift ist in diesem Punkt nicht mehr nachzuvollziehen, so dass schließlich zwei Deutungen möglich sind. Es kann ebenso davon ausgegangen werden, dass Hoffman lediglich die Verwendung metaphorisch beleidigender Sprache intendierte, um auf eine anschauliche Art die Straßburger Prediger und ihre Handlungen zu denunzieren bzw. um zu erreichen, dass seine Schrift dahingehend rezipiert wurde.

Den vollkommenen Gegensatz zu den Straßburger Reformatoren, die als ,Raubtiere', ,Blutsauger', ,Lügner' usw. bezeichnet werden, stellt im Text der „zeuge[] der ewigen worheit“ (A2r), Melchior Hoffman, dar: Er wird zu den „helgen“ (A2v) gerechnet, ist ein „diener Gottis“ (A2r \& $\left.A_{3} v\right)$, „der theure zeug der ewigen worheit“ (A3v), ein „fromer, Gotforchtiger man“ (ebd.) und zählt zu den „unschuldigen“ (A5v). Bei

${ }_{767}$ Hoffman hatte bereits I 530 gegen die lutherische Abendmahlslehre polemisiert: „Aber ich hab sorg dz des Luthers hauff grosse schuld haben / am abgötterischen anbetten des Sacraments die da fürgeben Christū leiblich vnd wesentlich ins brot zůbringen / vom himmel herab wann sy wo̊llen / als die schwatz künstner den Satan in ein glaß [...]“. Hoffman (I 530), Weissagung vsz heiliger götlicher geschrifft, B 3 v. In dieser Schrift legt er auch seine eigene Abendmahlslehre dar: Er argumentiert, dass das Sakrament wie auch der Ehering als ein figürliches Zeichen gegeben wird. Das Sakrament bedeute die Zusage des christlichen Leibes „zů einer eussern befestung / der innerlichē zůsag / welche in das hertz gehơrt. [...] vnd ist das essen Christum / vā sein blůt trincken anders nichts / dan̄ den worten glauben das sein leib für vns am creutz gebrochen ist / vā sein blůt für vnser sund am kreütz vergossen." (B4r) 
der Charakterisierung des Zeugen werden somit hauptsächlich positiv konnotierte Worte gewählt.

Bei einer Gegenüberstellung einzelner Prädikationen wird die hochgradig antithetische Struktur der Semantik deutlich. Besonders fällt der polemische Antagonismus durch die Semantik ins Auge, wenn man versucht, sie in Kategorien aufzuteilen: Stellt man sie in den antonymen Paarungen von Teufel vs. Gott, Gelehrte vs. Einfältige, Jäger vs. Gejagte, Täter vs. Opfer, Lügen vs. Wahrheit etc., wird die semantische Formierung des Antagonismus deutlich (s. Tab. I). Die Wortwahl gibt kein Drittes preis (tertium non datur) und lässt keine Graduierungen zu, denn es handelt sich um sich voneinander entfernende Pole. Hoffman konstatiert in Eyn sendbrieff an [...] Michel wachter den Fakt eines unaufhebbaren Gegensatzes allein durch die Wahl seiner Semantik (siehe Tabelle I).

Mit dieser Konstruktion von Freund- und Feindbildern in antagonistischer Gegenüberstellung zeigt sich Hoffmans Eyn sendbrieff an [...] Michel wachter gänzlich dem Usus der ,rhetorischen Streitkultur' der Reformation verschrieben: Er lässt in seinem Text keine Grauzone oder Neutralität entstehen, keinen Zweifel aufkommen, dass es nicht nur zwei extreme Pole gäbe. Interessanterweise finden sich keine Anhaltspunkte in Eyn sendbrieff an [...] Michel wachter, dass Hoffman nach der Veröffentlichung der Schrift, am I 5. August I 534 bei einem Gefängnisbesuch von Hedio, Bucer und Matthias Zell, Versuche unternommen hatte, eine Einigung mit den Straßburger Predigern zu finden. Er erklärte diesen, „seine und der Prädikanten Positionen seien gar nicht so weit voneinander entfernt “ ${ }^{\text {. }}{ }^{68}$ Die angestrebte Versöhnung scheiterte daran, dass Hoffman von seinen Lehrsätzen, die er auf der Synode verteidigt hatte, nicht abweichen wollte. ${ }^{769}$ Die Entdeckung seiner Autorschaft nur wenige Tage später war für die Straßburger Prediger vermutlich eine weitere Bestätigung der Unversöhnlichkeit.

In Eyn sendbrieff an [...] Michel wachter ist von der Intention einer Einigung oder Versöhnung allerdings nicht die Rede; die Programmatik bildet dort eine klare Abgrenzung von den Standpunkten der Straßburger Prediger. Unter dem Pseudonym war es Hoffman daher sogar möglich, gegen die Prediger zu polemisieren und sie gleichzeitig zur Versöhnung aufzurufen. Hoffman ging insofern zweifach strategisch vor: Mit dem mündlichen Friedensangebot vermeinte er, seine Haft aufzuheben und sein ,reales` Leben zu beeinflussen, während er mit der schriftlichen

${ }^{768}$ Deppermann (I979), S. 307.

${ }_{769}$ Ebd., S. $307 \mathrm{f}$. 


\section{Tabelle 1.}

\begin{tabular}{|c|c|c|}
\hline & $\begin{array}{l}\text { Negative Beschreibungen } \\
\text { (für die Straßburger Prediger) }\end{array}$ & $\begin{array}{l}\text { Positive Beschreibungen } \\
\text { (für Melchior Hoffman } \\
\text { und seine Anhängerschaft) }\end{array}$ \\
\hline $\begin{array}{l}\text { Teufel } \\
\text { vs. } \\
\text { Gott }\end{array}$ & $\begin{array}{l}\text { des teufels ewige diener | } \\
\text { yrem vater dem teufel I } \\
\text { gottlos I vam vater dem } \\
\text { teufel I pund und gelopte } \\
\text { mit der hel und ewigem dot I } \\
\text { [yr] falsche gleysnerische, } \\
\text { mordrische heylickeit }\end{array}$ & $\begin{array}{l}\text { diener Gottis I diener und } \\
\text { boten Gottis I fromer, } \\
\text { Gotforchtiger man I der } \\
\text { helgen plut }\end{array}$ \\
\hline $\begin{array}{l}\text { Schriftgelehrte } \\
\text { vs. } \\
\text { Armgeistige }\end{array}$ & $\begin{array}{l}\text { die lugenhaftigen phariseer I } \\
\text { der deufel mit allen pharisern }\end{array}$ & $\begin{array}{l}\text { die eynfeltigen und un- } \\
\text { schuldigen armen schof- } \\
\text { lein Gottis I kynder Gottes }\end{array}$ \\
\hline $\begin{array}{l}\text { Raubtier } \\
\text { vs. } \\
\text { Beutetier }\end{array}$ & $\begin{array}{l}\text { plůthund I pluthündt I mort- } \\
\text { wolf I plutzapfer I reyssende } \\
\text { woelfe }\end{array}$ & schof I schoflein \\
\hline $\begin{array}{l}\text { Täter } \\
\text { vs. } \\
\text { Opfer }\end{array}$ & $\begin{array}{l}\text { verdruckung und quellung } \\
\text { und plagung I tyranney | } \\
\text { grawel }\end{array}$ & $\begin{array}{l}\text { unschuldig I das unschul- } \\
\text { dige plut I in tyranney } \\
\text { gefangen }\end{array}$ \\
\hline $\begin{array}{l}\text { Lüge } \\
\text { vs. } \\
\text { Wahrheit }\end{array}$ & $\begin{array}{l}\text { lugengeist I lugenhaftig | fal- } \\
\text { sche, gleysnerische heylich- } \\
\text { keit I eythel verwante red I } \\
\text { gewaldige, unverschampte } \\
\text { lügen I lugen I folschen } \\
\text { somen und wort I mit der } \\
\text { falschen, boesen zungen I } \\
\text { mortlügen I lugenbucher I yr } \\
\text { lugenhaftigen schriften und } \\
\text { selb erdichte oede zeucknisse }\end{array}$ & $\begin{array}{l}\text { zeuge der ewigen worheit I } \\
\text { dye ewige worheit und } \\
\text { derselbigen zeugen }\end{array}$ \\
\hline $\begin{array}{l}\text { Gerechtigkeit } \\
\text { vs. } \\
\text { Ungerechtigkeit }\end{array}$ & $\begin{array}{l}\text { ungerechtikeyt I } \\
\text { ungerechticheit }\end{array}$ & gerechtickeit \\
\hline $\begin{array}{l}\text { Negative } \\
\text { vs. } \\
\text { positive Eigen- } \\
\text { schaften }\end{array}$ & $\begin{array}{l}\text { thorheit I schelmerey I yr } \\
\text { torheit, narheit, unsinigkeit }\end{array}$ & ohn mackel befunden \\
\hline
\end{tabular}


Ächtung das Ziel verfolgte, Einfluss auf sein Image - die gesellschaftliche Konstruktion seiner selbst - zu nehmen. Die Folge war eine überdeutliche Polarisierung, die sowohl die Persuasion unparteiischer oder fremdparteiischer Leser erstrebte als auch die Gruppenzugehörigkeit unter Hoffmans Anhängern stärken sollte, während deren Leitfigur im Gefängnis verharrte. 